Florida International University

FIU Digital Commons

3-28-2019

\title{
How Town Engages Gown: Engagement and Collaboration Between Local Governments and Institutions of Higher Education
}

Vivian Gonzalez Cueto

Florida International University, vgonz016@fiu.edu

Follow this and additional works at: https://digitalcommons.fiu.edu/etd

Part of the Public Administration Commons

\section{Recommended Citation}

Cueto, Vivian Gonzalez, "How Town Engages Gown: Engagement and Collaboration Between Local Governments and Institutions of Higher Education" (2019). FIU Electronic Theses and Dissertations. 4023. https://digitalcommons.fiu.edu/etd/4023

This work is brought to you for free and open access by the University Graduate School at FIU Digital Commons. It has been accepted for inclusion in FIU Electronic Theses and Dissertations by an authorized administrator of FIU Digital Commons. For more information, please contact dcc@fiu.edu. 


\title{
FLORIDA INTERNATIONAL UNIVERSITY
}

Miami, Florida

\section{HOW TOWN ENGAGES GOWN: ENGAGEMENT AND COLLABORATION BETWEEN LOCAL GOVERNMENTS AND INSTITUTIONS OF HIGHER EDUCATION}

\author{
A dissertation submitted in partial fulfillment of \\ the requirements for the degree of
}

DOCTOR OF PHILOSOPHY

in

PUBLIC AFFAIRS

by

Vivian González Cueto

2019 
To: Dean John F. Stack, Jr.

Steven J. Green School of International and Public Affairs

This dissertation, written by Vivian González Cueto, and entitled, How Town Engages Gown: Engagement and Collaboration Between Local Governments and Institutions of Higher Education, having been approved in respect to style and intellectual content, is referred to you for judgment.

We have read this dissertation and recommend that it be approved.

Allan Rosenbaum

Howard Frank

Benjamin Baez

Milena I. Neshkova, Major Professor

Date of Defense: March 28, 2019

The dissertation of Vivian González Cueto is approved.

Dean John F. Stack, Jr. Steven J. Green School of International and Public Affairs

Andrés G. Gil Vice President for Research and Economic Development and Dean of the University Graduate School

Florida International University, 2019 
(C) Copyright 2019 by Vivian González Cueto

All rights reserved. 


\section{DEDICATION}

I dedicate this dissertation to my family. To my husband, Victor, no words will ever be able to express how grateful I am for all your love and encouragement during this process. Thank you for always believing in me, supporting my dreams, and being my person. To my daughter, Cecilia, and my son, Elias, let this dissertation serve as a lesson in perseverance and an example that you can achieve great things in your life. To my parents, Gilda and Jose, and my aunt Pamela, thank you for giving me a loving home and a wonderful education. Finally, to my In-Laws, Maggie and Victor, thank you for all your support. This dissertation truly took a village. Thank you to all the members of my tribe. 


\section{ACKNOWLEDGMENTS}

I would like to express my deepest gratitude to my dissertation advisor, Dr. Milena Neshkova. Thank you for both encouraging me and pushing me when I needed it. Thank you for all your patience, wisdom, and support. Your mentorship has been invaluable, and I will forever be grateful to you.

Thank you to my dissertation committee members, Dr. Allan Rosenbaum, Dr. Howard Frank, and Dr. Benjamin Baez. Dr. Rosenbaum, thank you for all your guidance and for broadening my worldview. Dr. Frank, thank you for all your insight during the dissertation process and for giving me an opportunity to work at FIU Metropolitan Center. Dr. Baez, thank you for sharing your expertise in higher education. Your perspective enabled me to integrate the literature of higher education with the theory of public administration.

I would also like to express my gratitude to Emily Gresham. Emily, you are the embodiment of a passionate university administrator working to make the community a better place. Thank you for your mentorship and giving me the opportunity to witness my research in action. To all the wonderful people I had the honor to work with at the Metropolitan Center, thank you for your friendship and teaching me valuable skills that will serve me throughout my career.

I wish to thank the faculty and staff at the Department of Public Policy and Administration for all their help and encouragement. To my fellow colleagues in the PhD program, thank you for creating a wonderful learning environment and for all the friendships, late night study sessions, and willingness to help. I also wish to acknowledge the financial support from the FIU University Graduate School through the Dissertation Year Fellowship. 
Chapter 1: Introduction .................................................................................................................... 1

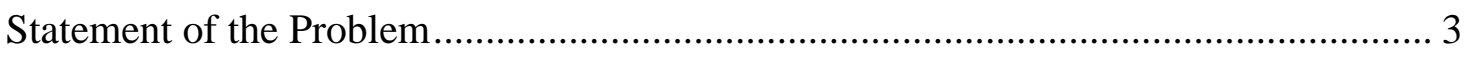

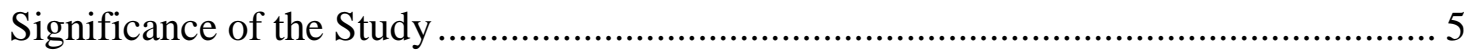

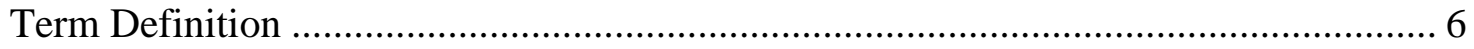

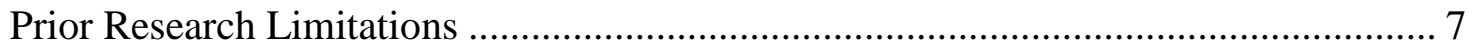

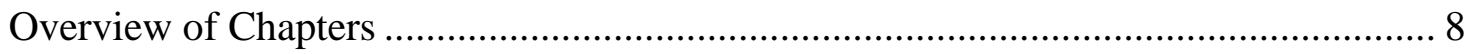

Chapter 2: Literature Review: University Engagement ................................................... 10

Higher Education in Public Administration.......................................................... 10

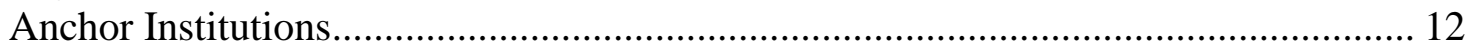

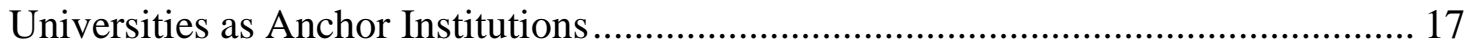

University Engagement: Brief Overview................................................................... 21

Classroom, Laboratory, and Locales ..................................................................... 24

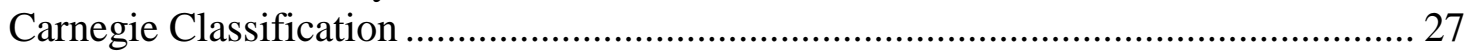

Engaging the Anchor …….................................................................................. 30

Challenges and Opportunities for Local Government/University Engagement ........... 33

Chapter 3: Local Government Collaboration ........................................................................ 37

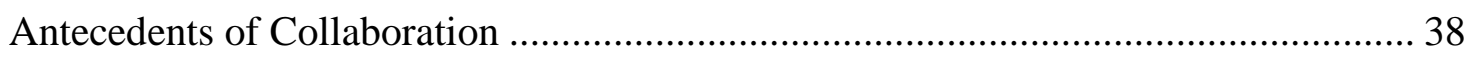

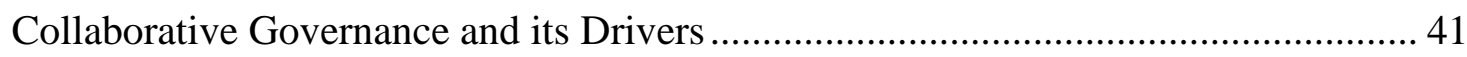

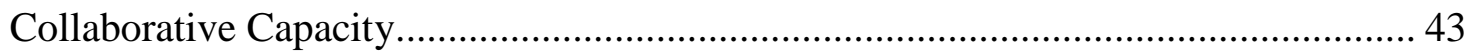

Chapter 4: Conceptual Framework, Research Questions, and Hypotheses .............. 48

Conceptual Model: Collaborative Capacity ................................................................. 48

Conceptual Model: Factors Predicting Engagement and Collaboration....................... 51

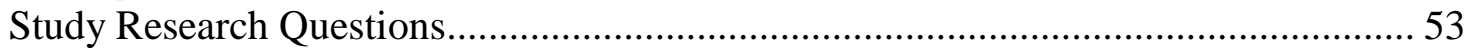

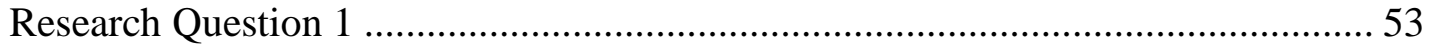

Research Questions 2 and Hypotheses .............................................................. 54

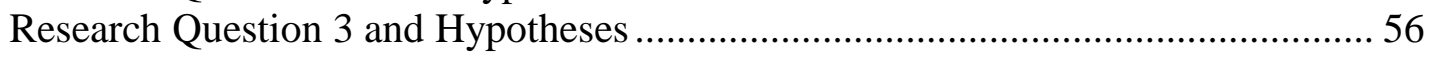

Chapter 5: Data Collection and Sources.............................................................................. 58

Qualitative Data: Semi-Structured Interviews ...................................................... 58

Local Government Officials ............................................................................... 59

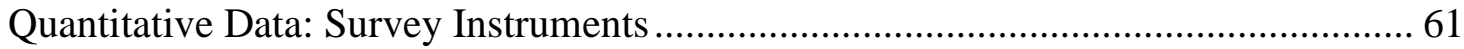

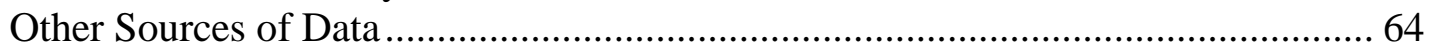

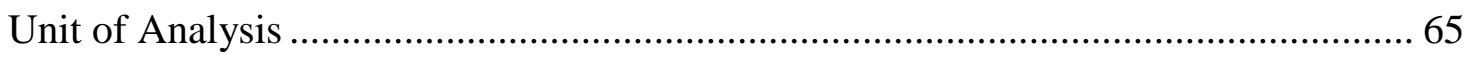

Chapter 6: Perspectives on Engagement ................................................................... 66

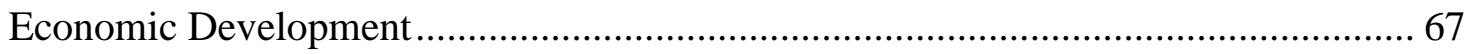

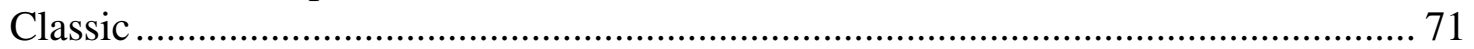

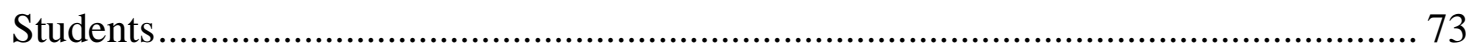

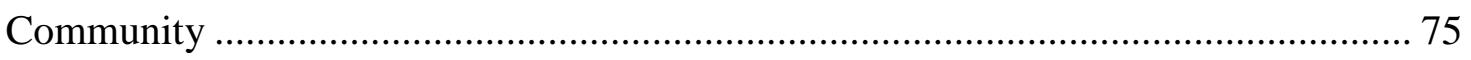




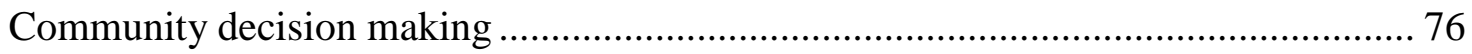

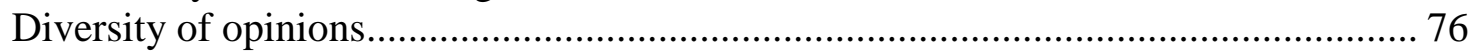

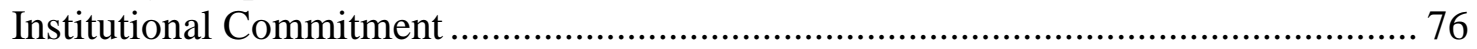

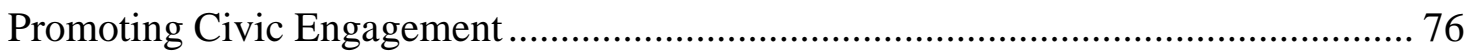

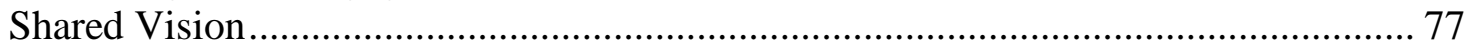

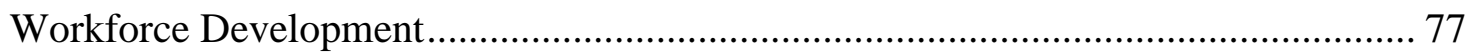

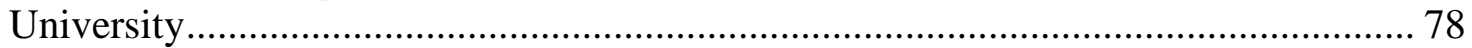

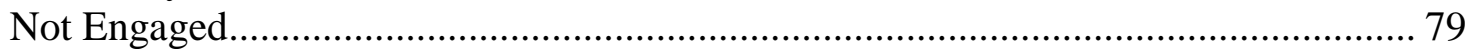

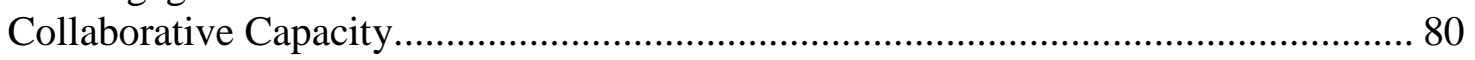

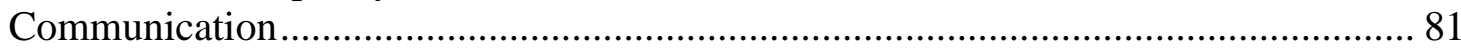

Initiation of Collaboration.............................................................................. 82

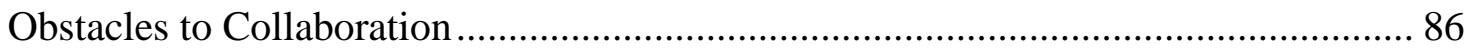

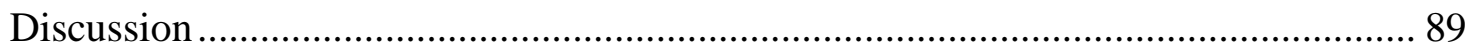

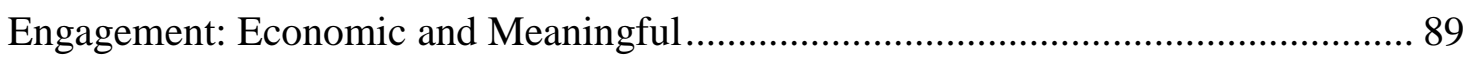

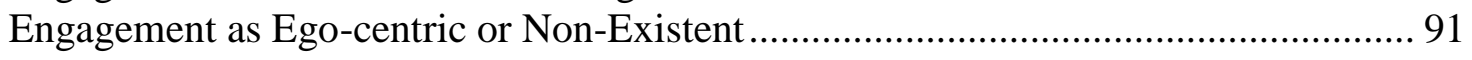

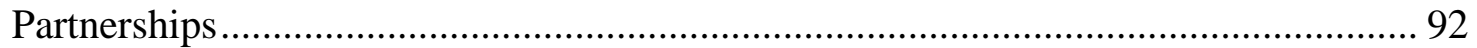

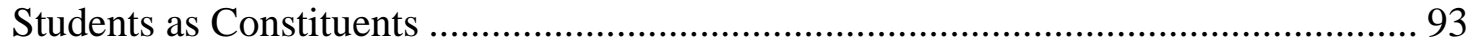

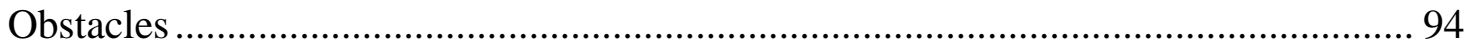

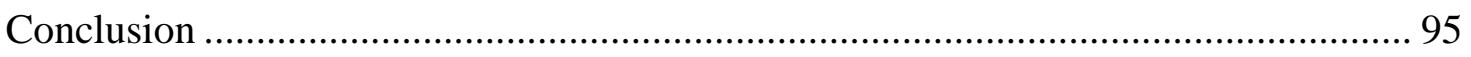

Chapter 7: When Collaboration Becomes Mutually Beneficial: Perceptions from

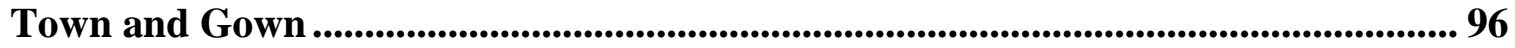

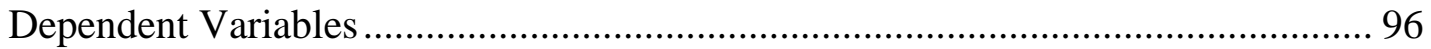

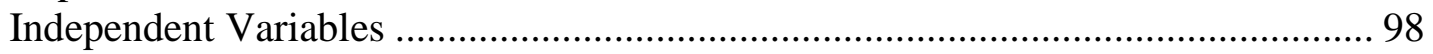

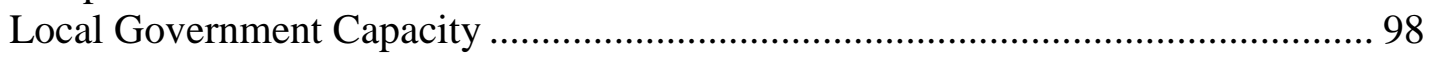

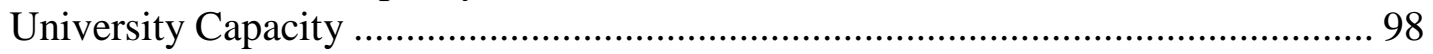

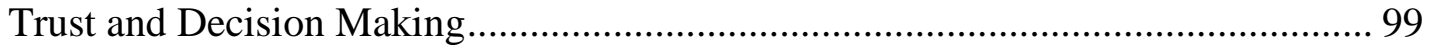

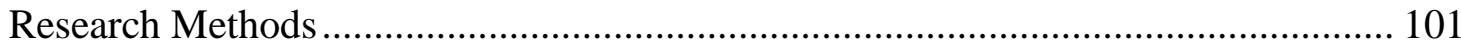

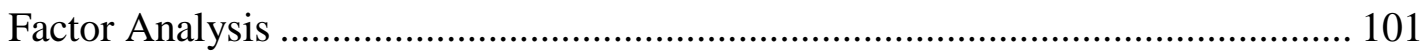

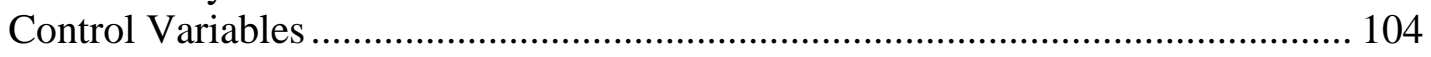

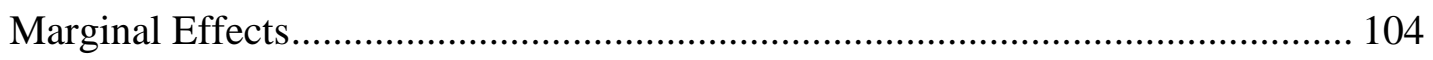

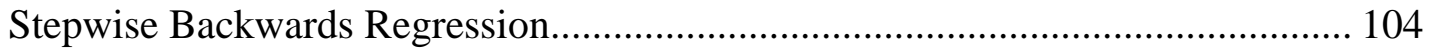

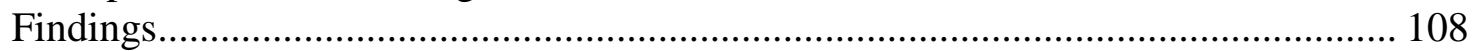

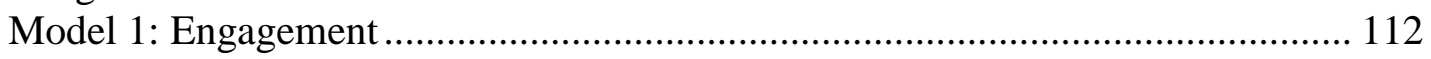

Model 2: Economic Engagement..................................................................... 114

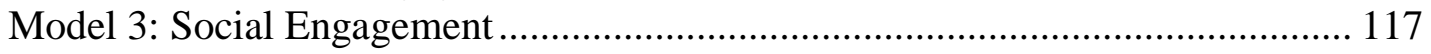

Model 4: Collaboration is a High Priority for the Local Government................... 119

Model 5: Collaboration is a High Priority for the University .............................. 122

Model 6: Mutually Beneficial Collaboration ................................................ 125

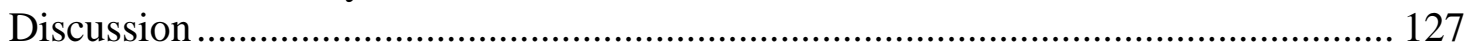

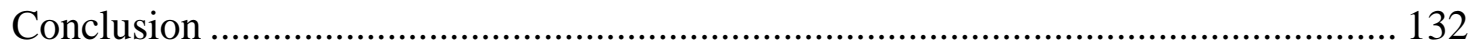

Chapter 8: A Dyadic Analysis of University Engagement Offices and Local Government Officials................................................................................................ 133

Pairing University with a Local Government ................................................... 133 


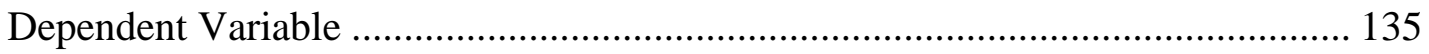

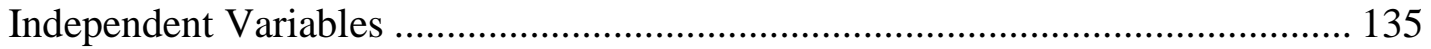

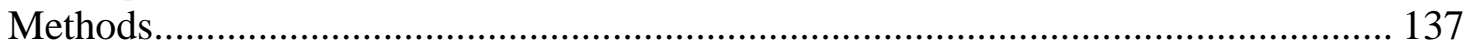

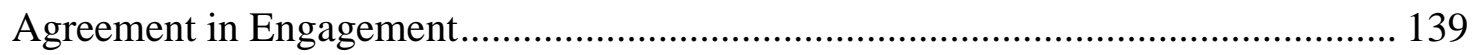

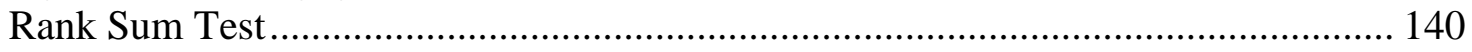

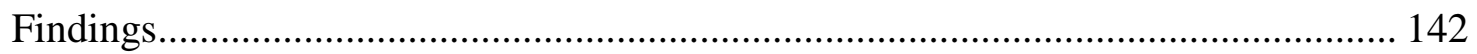

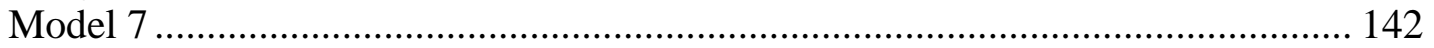

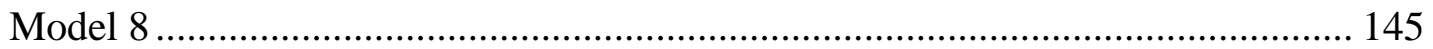

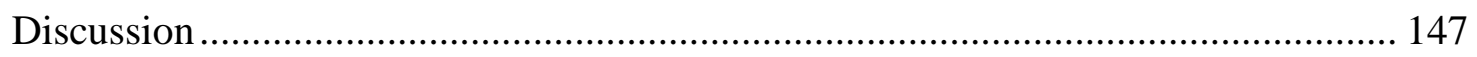

Chapter 9: Policy Recommendations and Conclusion ........................................... 150

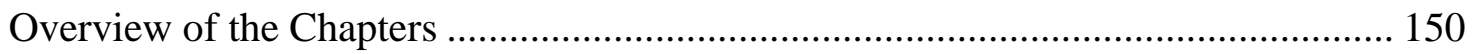

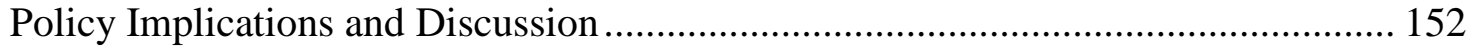

Policy Recommendations for Local Governments ................................................ 158

Policy Recommendations for Universities......................................................... 159

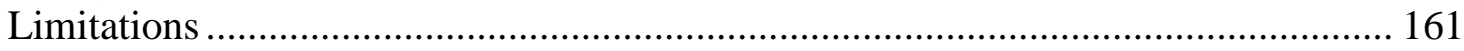

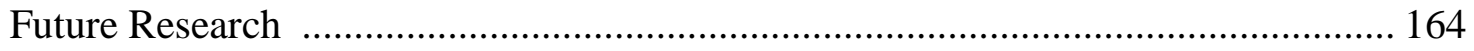

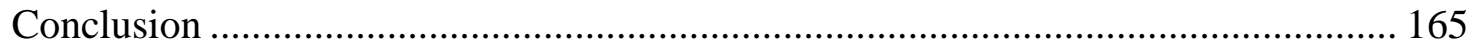

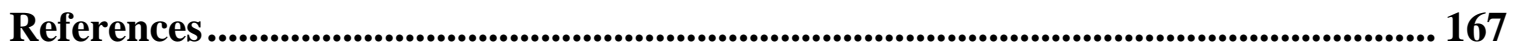

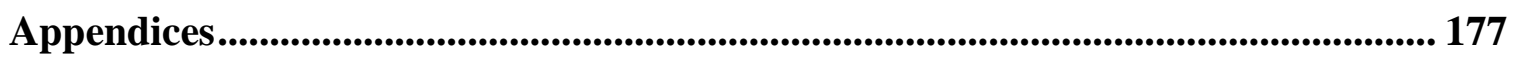

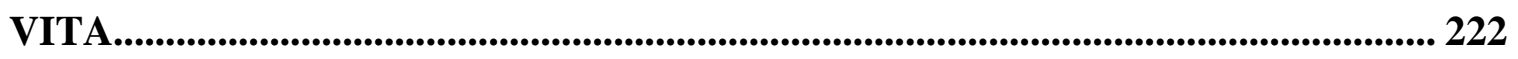




\section{LIST OF TABLES}

TABLE

PAGE

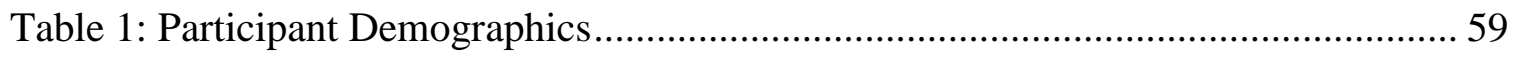

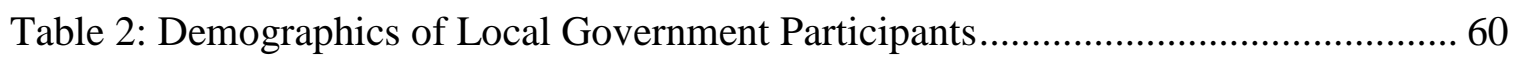

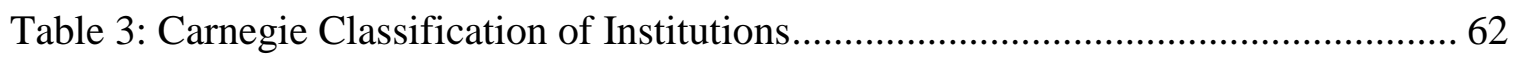

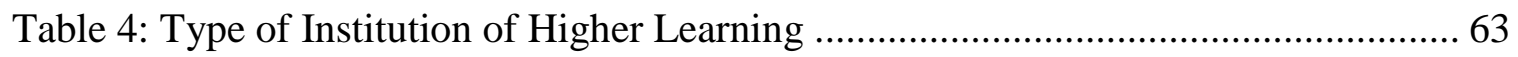

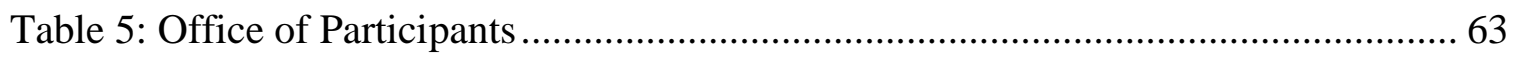

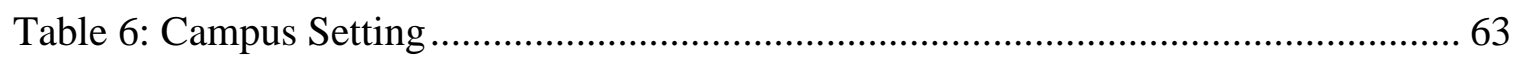

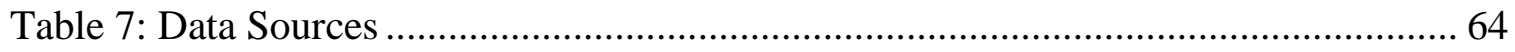

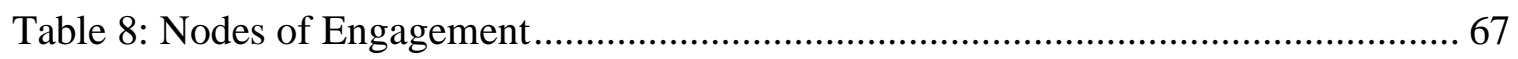

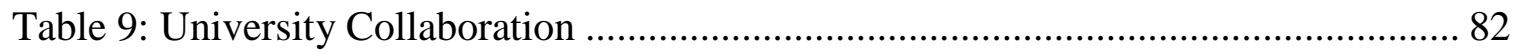

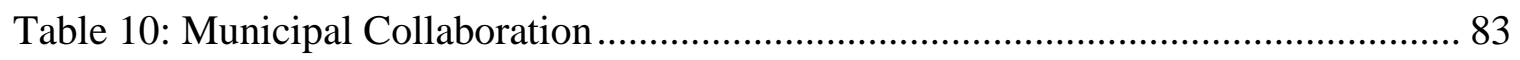

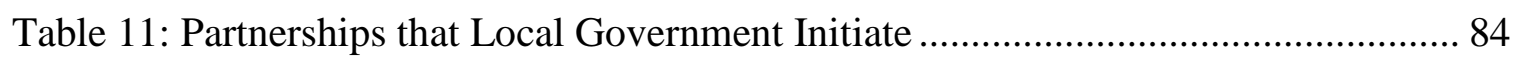

Table 12: Types of Town/Gown Partnership ........................................................ 85

Table 13: Main obstacle to initiating a partnership with the University......................... 87

Table 14: Main obstacle to initiating a partnership with the Local Government ............. 88

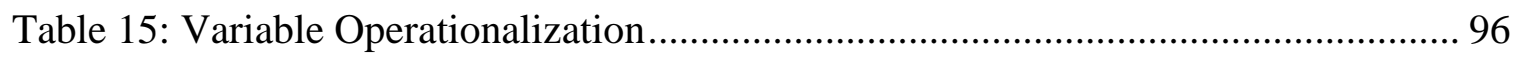

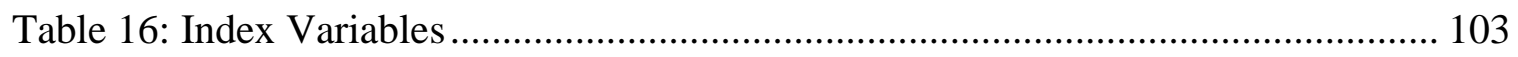

Table 17: Explaining Engagement and Collaboration (No Control Variables) .............. 110

Table 18: Explaining Engagement and Collaboration (With Control Variables)........... 110

Table 19: Variable Operationalization Models 7-8 …........................................... 135

Table 20: Agreement on Levels of Engagement.................................................. 138

Table 21: Levels of Differences in Engagement.................................................. 138 
Table 22: Agreement that Collaborations are Mutually Beneficial ............................. 139

Table 23: Levels of Disagreement that Collaborations are Mutually Beneficial............ 139

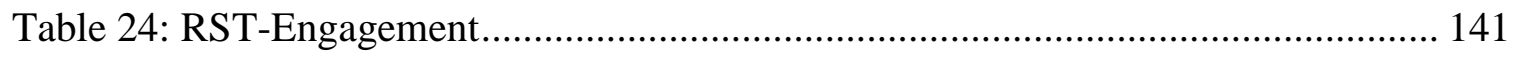

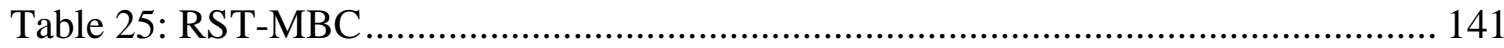

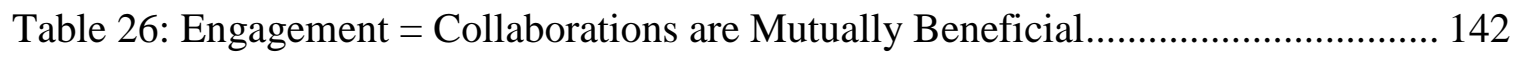

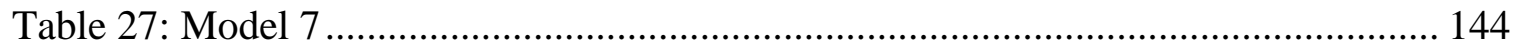

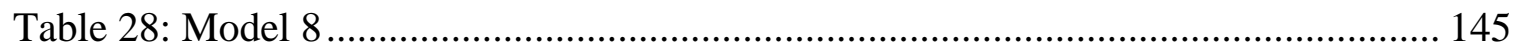




\section{LIST OF FIGURES}

FIGURE

PAGE

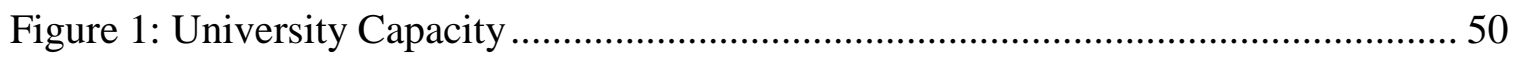

Figure 2: Local Government Capacity............................................................. 50

Figure 3: Engagement and Collaboration Framework .......................................... 51

Figure 4: Factors that affect levels of agreement in engagement and collaboration ........ 53

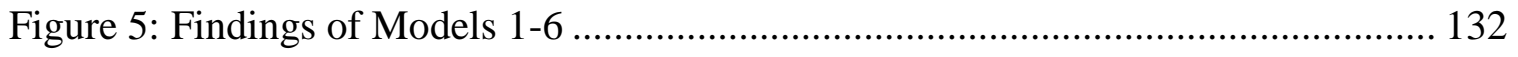

Figure 6: University Representation Models 7-8 ................................................... 134

Figure 7: Local Government Representation Models 7-8....................................... 134

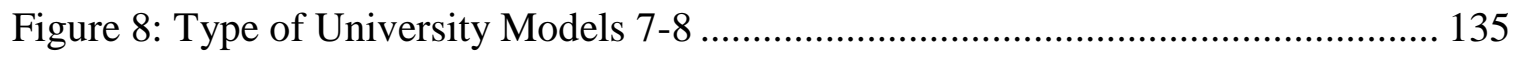




\begin{abstract}
OF THE DISSERTATION
HOW TOWN ENGAGES GOWN:

ENGAGEMENT AND COLLABORATION BETWEEN LOCAL GOVERNMENTS

AND INSTITUTIONS OF HIGHER EDUCATION
\end{abstract}

by

Vivian González Cueto

Florida International University, 2019

Miami, Florida

Professor Milena I. Neshkova, Major Professor

This dissertation analyzes the engagement between universities and their respective municipalities. Although a sizeable amount of research has explored relationships between town and gown, we still lack a clear understanding of why engagement works better between some universities and municipalities but not for others. This dissertation argues that university engagement with local governments, while a necessary and increasingly important part of institutional activities, cannot be effective unless it is done in earnest collaboration with the localities. Short of collaboration, engagement between town and gown only exists as a unilateral relationship, which despite its actual benefits, undermines trust and can cause frustration for both parties. The study contributes to the growing literature advocating a shift away from a paternalistic diffusion of resources from universities toward localities by analyzing a collaborative approach to engagement.

Employing a cross-sectional study of 122 universities and municipalities, this dissertation examines how the collaborative capacity of each of the two parties impacts 
their perceptions of engagement and collaboration. Additionally, using 62 local government-university pairs, the study explores the factors that affect the proclivity of parties to agree on their levels of engagement and consider it mutually beneficial. Finally, semi-structured interviews with university administrators and local government officials sheds light on how the understanding of engagement might differ between the two institutions and explores the factors that can help or hinder the collaboration process.

The quantitative analysis revealed that leadership and trust are positively associated with engagement, while the measure of shared vision was most positively associated with collaboration. Qualitative findings demonstrate that town-gown engagement often carries a different meaning, which is largely dependent on an institutional vantage point. Overall, the findings of this dissertation establish that collaboration is the mechanism through which the independent parties of institutions of higher education and local governments work together to achieve results that they would not otherwise be able to independently achieve on their own. 


\section{Chapter 1: Introduction}

Clark Kerr (1963) mused that the modern university had "some form of contact with nearly every industry, nearly every level of government, nearly every person in its region" (pg.6). Kerr's idea of the multiversity included an "academy [that] influenced and was influenced by trends and forces in the outside world" (Hechinger, 2003). That idea was seen as the herald for a new understanding of how universities interact with issues outside their borders. Ernest Boyer (1996) would later challenge universities to use their resources to the benefit of the cities around them. Answering Boyer's (1996) clarion call for engagement, today almost all universities participate in some type of community engagement. Scholars have taken note of the changes in higher education and recently there has been a surge of literature delving into the community engagement of universities. Additionally, many nonprofit organizations have begun to gather and classify engagement practices and renew the mission of universities as civic leaders (Weerts, 2008). Many of them, including College Compact, the Association of Public and Land Grant Universities, the American Association of State Colleges and Universities, and the American Association of Community Colleges, have programs that facilitate engagement agendas and often seek to bring stakeholders together in order to promote cooperation. In fact, thirty-eight national organizations have formed around the issue of university engagement (Sandmann and Weerts, 2006).

While there are have been a number of scholarly works delving into the relationship between universities and their communities, most studies have framed their research as the university's relationship with the community. Few studies have sought to 
examine the community's relationship with the university. Fewer still have examined the local government's relationship with the university. As a result, the role of the local government in the engagement process has largely been understudied.

One of the reasons the local government's involvement in town and gown relations has been overlooked by the extant literature, and perhaps by the municipalities themselves, is that universities are generally the ones that initiate engagement with the local government (Funkhouser, 2015). It is crucial to understand the link between local governments? and university engagement if the two parties are to enter into a partnership. Partnerships imply two or more actors working toward a common goal. Engagement, therefore, cannot be fully achieved without the local governments as partners. Thus, identifying the strategies used by universities to understand local government needs is necessary to paint the full picture of university engagement.

The term community engagement does not have one (a single?) agreed upon definition that guides how universities engage with their communities. Within universities, community engagement is a term often tossed around that can mean meaning anything from real estate development, incubators of the knowledge economy and/or programs aimed at bringing together university resources with community needs. Traditionally, universities engaged with their communities in a "one-way" approach (Boyer, 1996). That is? Benefits provided by the university, be it economic or academic, were given to communities without input from them and without regard to if the communities needed or wanted them. Communities were simply seen as classrooms, laboratories and locales (Boyer, 1996) but decidedly not as partners. 
Yet, in the 1990s, when state funding started to fall and the public wondered if universities were really there for the public good, it became evident that universities could no longer ignore their communities (Weerts and Hudson, 2009). A "two-way" approach (Boyer, 1996) became the new paradigm. The "two-way" approach implied interacting with community leaders to address the needs of the town (Kellogg Commission, 1999), and shifts away from a paternalistic diffusion of resources toward a collaborative model. Within the new collaborative model, university and community resources are targeted toward a mutually beneficial project.

Aside from the obvious good will engendered, there are tangible benefits afforded to the university that facilitate engagement. For example, in 2006, the Carnegie Foundation for the Advancement of Teaching created a new classification for community-engaged institutions. Additionally, engagement has become a key measure of institutional quality (Higher Education Learning Commission, 2006). As a result, universities garner a certain amount of prestige and institutional self-preservation that is attached to these activities. Conversely, cities too, benefit from universities' prestige. Far from being a zero-sum game, there are quantifiable economic benefits to having an anchor institution within a city's limits.

\section{Statement of the Problem}

There is ample extant literature on the many and varied ways universities engage with their community. Yet, the academic literature around this topic invariably addresses it from the point of view of the university. In that way, not much has changed from the paternalistic diffusion of information. Because anchor universities cannot readily move, municipalities worry less about losing them than they would about losing a Fortune 500 
company. It would seem at first blush that more municipal resources are given to attracting new business and residents than to working in collaboration with universities to achieve similar goals. In fact, a simple Internet search of municipal officers yields many results for Chief Innovation Officer, but no Higher Education Relations Officer (Funkhouser, 2015). That is not to say there is no dedicated liaison between the two entities, simply that there is no uniform way of addressing this issue.

Likewise, the extant literature rarely looks at this two-way street from the direction of the community that determines their own needs. How universities assess those needs are paramount in understanding the extent to which community needs are actually met, if at all. Conversely, it may well be that universities have an internalized mechanism to seek out input, but lack the social capital needed to implement their strategy. Community needs, itself a broad term, might run counter to the desires of the local government, other communities or of the university itself. The issue is to identify the mechanisms at play that can help anchor institutions, community and local government work toward common goals.

What the extant literature so far has failed to capture is the perceptions of local government officials with regard to university engagement. For local government to engage with universities in a meaningful and mutually beneficial manner, it is vital to understand the perceptions of all parties. Local government officials are generally comprised of a mayor, city council members, and a city/town manager. Each position varies in terms of interaction with the university and with the community at large. However, it is clear that these elected and/or appointed members have a clear mission to serve the community they represent. In that role, local government officials have a 
responsibility to seek out collaborative partnerships and work to find common ground with university leaders in terms regards to? of economic and social issues impacting the community. However, the? drivers of engagement and collaboration between local governments and their universities are not well understood.

\section{Significance of the Study}

The significance of this study is twofold. From a theoretical angle, despite the pervasive nature of community engagement within universities, very few studies have sought to understand the holistic framework with which engagement occurs. This study aims to address this gap in the literature, by analyzing under what conditions local governments can be active partners in town-gown engagement instead of simply be recipients of it. It is critical to understand how local governments participate in order to create a real two-way street and mutually beneficial collaboration.

From a practical angle, this study gathers the perspectives of university administrators and local government officials to understand under what conditions are perceived to work well. Indeed, the Carnegie Foundation themselves identified assessing "perceptions of the institution's engagement" as a challenge to the Community Engagement designation (Driscoll, 2008, p. 41). Universities engage their communities for a variety of reasons. Insofar as the practice is an active part of campus life, however, it behooves the university to collaborate in a manner not only seen as mutually beneficial but is in fact mutually beneficial.

Finally, this study aims to examine differences between perceptions of engagement and collaboration between local government officials and university administrators and how often engagement is done in a collaborative manner. 
Understanding the differences and similarities in perceptions of town-gown engagement and collaboration will help both university administrators and municipal officials work together to find common ground. Ultimately, understanding where the two entities agree and disagree can potentially improve engagement outcomes.

\section{Term Definition}

This study analyzes the relationship between universities and municipalities in which they are located and their perceptions of the level of engagement and collaboration. Both engagement and collaboration have the distinction of being ambiguous terms. There are a number of definitions for community engagement, but the definition this study adopts is the one put forth by the Carnegie Foundation. The Carnegie Foundation defines community engagement as "collaboration between institutions of higher education and their larger communities for the mutually beneficial exchange of knowledge and resources in a context of partnership and reciprocity." I chose this particular definition as it acknowledges the variety of ways universities and communities engage with one another. Moreover, the study sample includes? only universities that have been awarded the Carnegie Foundation Community Engagement classification and matches them with the municipalities, in which they are located.

Admittedly, collaboration is found within the definition of engagement. Yet, collaboration in and of itself is an interesting term that merits further attention. Gray (1985) defines collaboration as bringing together "tangible resources, e.g. information, money, labor etc., by two or more stakeholders, to solve a set of problems which neither can solve individually" (p. 912). Although Gray's (1985) work is widely considered a keystone paper for the study of collaboration, three decades after the paper was published 
the definition of collaboration has widened as the term has been applied to a host of unrelated aspects (Mayer and Kenter, 2015). The dictionary defines collaboration as "the action of working with someone to produce or create something" (Merriam-Webster, nd). For the purposes of this study, collaboration within the context of university/local government engagement can be defined as universities and local governments combining their resources to produce mutually beneficial value. Value, itself a loaded term, can be thought of as something that produces benefits to the intended parties. Collaboration can range from specific and localized, from service-learning projects or partnerships toward a given task, such as a grant application. However, they can also be larger in scope, such as a commitment to improving educational access to the surrounding community or the creation of regional innovation clusters that can bolster employment. Whatever the form, it must be done together and not simply an action imposed by one party on the other.

The nuanced view of engagement and collaboration within this study is important because engagement works best when it done as a collaboration. Collaboration requires that two independent parties engage in order to achieve results that they would not otherwise be able to achieve alone.

\section{Prior Research Limitations}

The majority of studies into town-gown relationships are case studies or limited to a small regional context. While there has been a host of studies on local government collaboration, few studies have examined local government collaboration with universities alone, without the input of industry. Even fewer studies have examined local government and university collaboration as a cross-sectional analysis that spans the United States. This dissertation aims to contribute to the extant academic literature by 
examining the perceptions of engagement and collaboration between local governments and universities nationwide, thus adding to the body of literature on both local government collaboration and town-gown engagement.

\section{Overview of Chapters}

This dissertation consists of eight subsequent chapters. The second chapter reviews the extant literature on higher education and depicts the gaps that this dissertation addresses. The third chapter provides a review of prior research on collaboration and collaborative capacity. The fourth chapter presents the research questions and hypotheses guiding the empirical analyses as well as the two conceptual models that form the theoretical framework of this dissertation. The fifth chapter discusses the research design, including sample description and the methodology employed in the subsequent chapters. The sixth chapter of the dissertation depicts the results of the qualitative analysis conducted both within the survey instrument and through interviews with community engagement offices and municipal officials. It imparts various definitions of engagement, types of engagement, and obstacles to engagement through the lens of the university and municipal respondents. The seventh chapter of this dissertation explores the capacity of each party - the local government and the university — to engage and collaborate. The eighth chapter consists of a subset analysis of the sample used for chapter seven. It explores factors that are associated with agreement, both in levels of engagement and with the perception that collaborations are mutually beneficial. Additionally, the chapter examines the difference in perceptions between the university administrators and local officials. The final chapter summarizes the contributions of this dissertation to the body of knowledge on how town-gown 
engagement produces better outcomes if done as a collaborative process, acknowledges the limitations of the presented here empirical analyses, and traces avenues for future inquires. 


\section{Chapter 2: Literature Review: University Engagement}

\section{Higher Education in Public Administration}

It is impossible to separate a modern university from its town. The University of Michigan, for example, is synonymous with Ann Arbor. Yet the collaborative practices of town-gown relations have been overlooked in an effort to conceive of engagement and collaboration in a more globalized and regional context. While widening the focus of town-gown relations is prudent for a host of reasons, it is imprudent do so at the expense of the local municipality.

The study of municipalities is central to the study of public administration. However, institutions of higher education are not always considered within the realm of study for public administration. Indeed, an immeasurable amount of ink has been used in search of the identity of public administration. Uveges and Carter (1983) argue that while public administration has no single definition, it can indeed be found within universities. They argue that modern universities fit all the characteristics of bureaus laid out by Downs (1967) and Keller (1980). That is to say, modern universities are large organizations where top administrative officials are mostly unfamiliar with many of the mid or entry level employees at the university; employ a vast number of individuals for whom the university provides their only source of income; have a system for promotion, retirement and incentives based on employee evaluations; and produce graduates, and increasingly a fair number of widgets, or by-products of patents, technology transfers and university spin-offs. Moreover, within the organization itself, there are various large bureaucratic units, such as student affairs, external relations, and sub-units, such as 
different colleges and departments within colleges. Thus, rendering the public administration of higher education firmly in line with the study of public administration. Moreover, modern universities are inextricably linked to the bureaucracies that surround them and the bureaucracies that fund their pursuits. The interconnectivity of large bureaus itself warrants further inquiry into their collaborative practices and engagement. Indeed, universities themselves often publish reports boasting about the economic impact the respective institution has on the surrounding community. Yet university economic impact reports remain deficient, as they offer a one-sided view of dubiously constructed economic variables measuring direct and indirect employment and business creations (O’Mara, 2012) in an effort to engender public trust and negate what Boyer (1996) called "a nagging feeling that [universities] are no longer at the vital center of the nation's work." Nonetheless, the fact is that universities do contribute vastly to local and regional economies, and are vital to both the economies of local governments and the livability of a given area (Florida, 2002; O'Mara 2012). Thus, understanding the collaborative capacity between local governments, themselves enveloped in bureaucratic structures, and their local university is integrally important and increasingly valuable as both local governments and universities face economic realities that will force them work together.

Many academic papers have detailed the history of universities within the American context (Barzun 1993; Berube 1976; Bok, 2009; O’Mara, 2012; Boyer, 1996). The coined term "town and gown" reflects the differences between members of the community and students in the university, who wore gowns while attending to their studies. This discourse is sufficiently summarized by concluding that local 
municipalities were historically unconcerned with the affairs of the university, and vice versa. Each siloed in their own dominion, any fleeting concern for the other was promptly extinguished by administrators for whom the university was separate and apart from what Josiah Strong (1907) called "the perils of the city."

Such lofty rhetoric was somewhat dampened by ever greater levels of public funding. O’Mara (2012) argues that the way universities grew in the twentieth century was built on increasing levels of public funding. As national and international concerns were coupled with research dollars, researchers frequently sought to capitalize on both financial and institutional incentives to research and publish on issues of national concern. During the mid-twentieth century, universities started concerning themselves with the issues of the State, amid the political and cultural revolutions of the day, and perhaps more importantly, the financial rewards of state and federal money stemming from the newly formed National Science Foundation, G.I. Bill, and an ever-growing student body. Even then, institutions of higher education were thought "capable of participating in the affairs of the state... whose majesty should not be compromised by the affairs of the state" (London, 1992). The affairs of the state notwithstanding, the ever-increasing number of students and funding produced universities that are both "national research centers and statewide teaching institutions" (O’Mara, 2012). Today there is little debate that American universities rely on federal research dollars, federal student aid, and other revenue streams stemming from the state or federal government.

\section{Anchor Institutions}

The term "anchor institutions" has its origins in the urban renewal movements of the 1960s (Goodman, 2013). In the mid-20th Century, the United States underwent 
enormous changes within cities, both in terms of demographics and employment. Those changes often left a void in urban areas that led to unemployment, underfunded schools and crime. To fill that void, institutions, particularly institutions of higher education and hospitals, emerged as anchors in the community (Taylor and Luter, 2013). The term anchor institution was first defined as "institutions that have a significant infrastructure investment in a specific community and are therefore unlikely to move out of that community" (Fulbright-Anderson, Auspos, \& Anderson, 2001, pg. 1). While institutions of higher education and hospitals are most often associated with anchor institutions, the term also captures the functions of large nonprofit organizations, museums, and "other public-spirited institutions that are embedded in a community" (Goodman, 2013, pg. 1672). In that way, anchor institutions represent any institution that has a public mission and possesses "sticky capital" (Dubbs, 2011), as it is difficult for it to move that capital elsewhere. Immobility, then, is generally seen as a hallmark of anchor institutions.

The term anchor institution is also used in United States law and legislation, most notably during the American Recovery and Reinvestment Act of 2009 (ARRA). In ARRA, the United States Government created the Broadband Technology Opportunities Program. That program made grants available to anchor institutions that could provide broadband service to their communities. The term was then expanded by the National Telecommunications and Information Administration to solicit and accept grant applications from "schools, libraries, medical and healthcare providers, public safety entities, community colleges and other institutions of higher education, and other community support organizations and entities” (47 U.S. Code $\S 1305$ - Broadband Technology Opportunities Program). This was the first time the term anchor institution 
was used to differentiate organizations embedded in the community that the federal government could partner with to achieve policy goals.

The economic benefits of anchor institutions are hard to overstate. As demonstrated by the aforementioned example, anchor institutions are used by the United States government as a means to distribute grant funding for local initiatives. Additionally, anchor institutions are usually one of the largest employers in the local community. Anchors institutions are likely to both hire from the local community and use their purchasing power within the community they serve. In this way, anchors use their large purchasing power and need for qualified employees as a way to generally invest in the surrounding community (Dubbs, 2010; Webber et al., 2009; Goodman, 2013). In fact, the role of anchor institutions within the structural economic change of the mid-twentieth century can be seen when examining the change from the manufacturing sector to the education/medical sector. Anchor institutions have become both the catalyst and benefactors of the knowledge economy (Bramwell and Wolf, 2005) as anchor institutions, universities in particular, responded to a changing labor market (Yusef and Evenett, 2003).

Schildt and Rubin (2015) identified seven markers for anchor institutions. As previously discussed, anchor institutions remain put. Their assets are fixed to a particular location. Their investments often cannot be easily liquidated. Moreover, some anchor institutions are bound by their charter, mission, or funders to a particular location and can therefore not readily move to another location. That very fact, given today's increasingly globalized and outsourced economy, provides a source of stability for the surrounding region in terms of jobs and other regional economic drivers. 
Schildt and Rubin (2015) have also defined anchor institution as large and growing. The idea is that in order to have an impact on the local community, the anchor institution needs to be large enough to make that impact. Indeed, some anchor institutions are enormous. Dubb, McKinley, and Howard (2013) found that hospitals and universities within the United States contribute over $\$ 1$ trillion a year to the local and national economy and employ roughly eight percent of the labor force. The local disaggregated data is likewise impressive for any given region within the country. Another defining feature of anchor institutions is that they act to drive regional innovation. Schildt and Rubin (2015) described the idea of regional innovation clusters (Porter, 2001) using universities and hospitals as research hubs that both spin off regional industries and act as business incubators. Porter (2001) believes that integration with regional clusters will be the best way to ensure long-term economic and social prosperity, as this creates a pipeline for jobs and innovation. The inner city with its distinct strategic and cultural advantage can align itself with the primary industries of its location. Those industries can then compete on a national and global scale, making the anchor institution vital to the long-term success of the region.

Among the reasons why anchor institutions are so vital to regions is their stabilizing effect on regional economies (Schildt and Rubin, 2015). Just as regional clusters can create new types of jobs and industries, the anchor institutions themselves create jobs that are publicly funded and, historically at least, less vulnerable to downturns in the American economy. As was seen when large manufacturing plants left cities in the mid-twentieth century, vulnerability within major employers can cause economic strife that can bring down once prosperous communities. As Schildt and 
Rubin (2015) argue, anchor institutions are crucial to the economic well-being of a given area.

What differentiates anchor institutions from other large enterprises is the presence of a social mission (Schildt and Rubin, 2015). According to the National Telecommunications and Information Administration, anchor institutions, namely "schools, libraries, medical and healthcare providers, public safety entities, community colleges and other institutions of higher education, and other community support organizations and entities" (47 U.S. Code $§ 1305$ - Broadband Technology Opportunities Program), all have a public mission. The majority of them have mission statements, strategic plans, and/or funding mandates that require them to serve the local community or some public need within a given geographic region. These missions make them natural partners with community leaders and local governments.

Finally, as defined by Schildt and Rubin (2015), anchor institutions are local leaders. As previously mentioned, their missions make them a natural leadership partner with other leaders in the region, both within government and within the community at large. Presidents of anchor institutions are often well-known members of the community. Indeed, many of the top members of anchor institutions' organizational charts are members of local boards and regularly attend events held by other local organizations. This familiarity with other local leaders, groups, and government officials gives anchor institutions an opportunity for forming collaborations that can advance their missions, and ultimately the well-being of the local community. 


\section{Universities as Anchor Institutions}

Universities are prime examples of anchor institutions (Axelroth and Dubb, 2010; Dubb and Howard, 2012). The place-based nature of universities inherently compels them to invest in the well-being of that area. Brick and mortar universities are essentially fixed to a physical location, where they employ people who live in the community, contract with businesses in the community and promote growth within that community. Although they are generally not considered businesses, universities largely act like a company headquartered in a given area. They produce jobs, innovation, and business involving both students and faculty alike. As early as 1996, universities were spending \$136B on salaries, goods and services within inner cities. In 2009, anchor universities were spending upwards of \$400B in economic activity (Axelroth and Dubbs, 2010). To be sure, that level of resources can take an area struggling with economic problems and infuse it with much needed capital. During the last recession, states clamored to get their share of stimulus money from the federal government. Indeed, many universities were beneficiaries of funds aimed at restarting the economic development. However, having an anchor university in an area, over the long term, is much more beneficial than temporary aid from the government (Perry and Wiewel, 2005).

Looking at universities as anchor institutions, using Schildt and Rubin's (2015) seven markers, it becomes clear why it is contended that universities are the prime example of anchor institutions. Traditional universities are the very definition of institutions that stay put. Their buildings, stadiums, and other brick and mortar assets cannot simply pick up and leave to another location. Their investments, largely land, 
buildings, and the like are also not assets that can be easily liquidated. Though increasingly universities, like other enterprises, have sought to expand their foothold beyond their physical location (e.g., online learning, global programs), their main operations remain largely within their surrounding region (Hodges and Dubb, 2012).

Universities are also large. Public universities may have upwards of fifty thousand students and faculty. Even smaller universities have a large impact in proportion to the size of the surrounding community. Lewisburg, Pennsylvania, for example has roughly five thousand residents. However, Bucknell University, located within Lewisburg's city limits has roughly four thousand students ("Facts about Bucknell," n.d.). When a university, even one that is small when compared to national universities, can almost double the size of the town, it is easy see how colleges and universities can be large players in a given area.

There is perhaps no greater example of regional innovation clusters than Silicon Valley (Hospers, Desrochers, \& Sautet, 2009). The relationship between Silicon Valley and the surrounding universities, particularly Stanford University, has been well documented in the academic literature (Porter, 1998; Porter, 2000; O'Mara, 2015). Universities play a large role in regional innovation, not just in examples such as Silicon Valley or the Research Triangle in North Carolina. The role of universities in research and development has long been recognized in many different areas around the world (Gunasekara, 2006). A sign that universities are taking steps to create innovation throughout their communities is the investment in university-based start-ups. Florida International University, for example, started StartUP FIU in 2016 as a way to help entrepreneurs from both the university and the community. The number of university 
start-ups are hard to come by, but as early as 2012 , there were 3,715 operational university start-ups (Valdivia, 2013). These start-up programs and companies are a great example of how universities bring innovation to their local communities.

Another defining feature of anchor institutions is that they have a stabilizing effect on the local economy. Universities not only spin off companies, but they themselves are a large employer. Indeed, in 2016, 13 states had universities or university-based health systems as the leading employer in the state (Gillet, 2017). It is easy to see why regions value having large universities in their communities. While universities are not immune to economic downturns, and are currently experiencing record levels of decreased funding, enrollment at universities grew during the Great Recession (Fein, 2014). Actually, college attendance has increased during every recession since the 1960s (Brown and Hoxby, 2014). Brown and Hoxby (2014) also found that staff payroll also continued to grow during the recession. In addition, though certainly not in a uniform manner, universities, particularly top universities, were able to secure federal grant funding as a result of recession-era spending bills (Brown and Hoxby, 2014). Being able to weather poor economic times is one of the reasons given by Schildt and Rubin (2015) that anchor institutions are vital to their local economies. Certainly, in that regard, universities are prime examples of anchor institutions. Whether it be private universities, or public land-grant universities, every university has a mission. The original mission of public, land-grant universities was "to teach agriculture, military tactics, and the mechanic arts as well as classical studies so members of the working classes could obtain a liberal, practical education (Morrill Act, 1859). Fenke (1980) states that the mission of the university is "the aspirations, often 
unstated, that society has for institutions of higher education. These aspirations are consensual and represent the most general level of hopes and expectations people in general hold for colleges and universities" (pp. 178-179). Those aspirations are not typically found in for-profit private firms. Indeed, these consensual aspirations are a testament to the social mission that defines anchor institutions and help them engage with the local community, government officials, and industry of a given area.

The final characteristic of an anchor institution is that they are a local leader (Schildt and Rubin, 2015). University presidents are generally well respected, wellknown members of the local community. Many university presidents are also active in national issues. Just recently, a group of college presidents sent letters urging President Donald Trump to protect Deferred Action for Childhood Arrivals (DACA) students from deportation (Fattal, 2017). On the state level, a local newspaper covering a story on the new president of Idaho State University called him "one of the most influential people not just at the university, but throughout the Pocatello/ Chubbuck community" (Beam, 2018). This recognition by the community that university presidents are very influential is echoed around the country and positions universities to better advocate for their mission and the goals that align with the local community.

Aside from the obvious economic impact of the university, anchor universities have an impact on social development. Within the United States, universities have historically been venues for young people to express their voice on broader societal problems. Whether it is the war in Vietnam, war on terror or more recently the Black Lives Matter movement, campuses are a gathering place for the community to express themselves. Additionally, universities create knowledge that can be used within and for 
the community. Education and health partnerships as well as scholarly engagement can help bridge gaps of information and access toward a mutually beneficial relationship.

\section{University Engagement: Brief Overview}

Universities engage for many and varied reasons. Historically, the mission of universities was simply to educate people toward a profession. Yet, universities have been engaging their communities since the 1860s (Mowery, et al, 1999; O’Mara 2005). The Morrill Act of 1862 established the first land-grant universities and instructed them to teach not only the classics, but also more applied subjects like agriculture and manufacturing. As early as the 1950s, the University of Chicago began playing a central role in the urban areas around Hyde Park (Berry et al., 1968). From 1945 to 1990 most American universities adopted the campus model (McGirr et al., 2003), separating themselves from the larger community. More recently, the new wave of engagement has been pioneered by Ernest Boyer (1990), with his clarion call for universities to engage with their communities.

Of engagement, Boyer said "the academy must become a more vigorous partner in the search for answers to our most pressing social, civic, economic and moral problems, and must reaffirm its historic commitment to what I call the scholarship of engagement" (Boyer, 1996). Boyer argued that universities had lost their mission and their standing among the public. Further, he contended that universities were "in danger of being a private benefit, not a public good" (Boyer, 1996). To combat this, Boyer proposed that universities become more attuned to the important social and civic issues of the day, not only by conducting practical research, but also by engaging the communities around them. Many more scholars and commissions echoed Boyer's 
sentiment as he introduced the term engagement as a catch-all phrase for the work universities ought to be doing in the community (Roper and Hirth, 2005; Kellogg Commission, 1999). Most recently, the Association of Public and Land Grant Universities (APLU) listed the "centrality of engagement" (Fitzgerald, et al, 2012) as a major focus and initiative. For APLU and its members, community engagement is understanding the fact that "not all knowledge and expertise resides in the academy, and that both expertise and great learning opportunities in teaching and scholarship also reside in non-academic settings" ("Centrality of Engagement”, 2018).

The call to become more engaged with the community was also about setting an agenda that moves beyond the walls of the university. The organizational structure of universities is complex. Faculty often have a decentralized organizational structure, but community engagement offices work in a vertical organizational structure lead by the university president. On account of that fact, community engagement offices have been thought of as a tool to further the university president's agenda. These offices might only engage in topics or areas that have a specific political gain to the university.

Engagement offices themselves often do not have a handle on the engagement practices within their own universities. Community engagement projects are most often done by faculty members as part of student learning or their own research. Few mechanisms exist within universities to collect that engagement data, however, that task falls on the community engagement offices. The engagement offices collect the data in order to use it for university awards, funding proposals, or in reports to the Board of Trustees or other similar organizations. 
Public institutions in particular seek to use this information to the credit of the university. For example, the Florida Board of Governors (FBOG) 2025 Strategic plan states "Board of Governors expects that all state universities will achieve the Carnegie Foundation national "community engagement" classification by 2025 " (The State University System of Florida 2025 System Strategic Plan, p. 15) In effect, the FBOG has mandated that each public university in Florida collect engagement data and create a narrative around their engagement. This task falls on community engagement offices as a directive from the university president, who must deliver per the goals of the new FBOG. This dynamic is not simply an issue in Florida. Around the country universities are placing enormous resources in demonstrating their community engagement, both as a means to attain the Carnegie Classification and as a signal that universities serve the community.

The political pressure placed on university presidents and by extension to the community engagement offices has little to do with the actual work of engaging and collaboration with the local government or community groups. Although it is an important dynamic, this dissertation seeks to understand the factors that promote and hinder engagement between local governments and universities. Local governments are often not privy to the inner dynamics of universities, whether it be a struggle between faculty and administration, or a governing body of a particular university. Therefore, to the local government, any engagement from the university is attributed to the university as a whole. Likewise, when faculty or engagement offices choose to devote university resources for a collaboration, any external pressure to be "engaged" gives way to the goals and metrics of the particular partnership. To that end, this dissertation focuses 
more on the typology of engagement and the organizational factors and behaviors that impact the levels of engagement.

\section{Classroom, Laboratory, and Locales}

The typology of engagement that universities have historically used in their neighborhoods are classrooms, laboratories and locales (Moore, 2014). That is to say, they have used the surrounding community as a place to do research, teach students and as a physical location to recruit and attract students and employees. The same is true for engagement. Engagement can be seen through the lens of classroom, laboratory, or locale.

Engagement as classroom is best thought of as service learning. Service learning is a class taken for credit in which students participate in a service activity to meet the needs of the community (Bringle et al., 1996). The purpose of service learning is both to teach students and help the community. Ultimately, the goals are such that students can garner an appreciation for the issues facing residents off campus. In that way, they can become more active citizens when they graduate from college. The literature lauds service learning as a wonderful example of two-way engagement. It is not difficult to understand why. Students are learning, and problems are being addressed. Yet, the literature says little in the way of how localities select these assignments, whether they do it in conjunction with the university or how issues can properly be addressed within the time limits of a semester or an academic year. Surely, service learning has a role. To diminish service learning would be an unfortunate way to read this critique. Specifically, this dissertation seeks to explore the ways communities' organizational structures help 
students and universities benefit from service learning while addressing the real concerns for the residents in question.

Universities engage with cities through research. When Boyer (1996) called for greater engagement of universities with their communities, he suggested that universities research applied problems facing the counties in which they operate. In particular, he felt that universities could do more research on K-12 education and various problems facing the urban core. Indeed, many universities today study practical issues important to their surrounding communities. Research on how to address inequality, social justice, and crime proliferate the academy. Not only do universities see this as an avenue through which they can contribute to the broader public interest, but also as an opportunity to help students conduct research and learn. In that way, engagement as a laboratory can be viewed as a two-way street, with both parties gaining something in the process.

What remains unclear - and where there is a gap in the literature - is how research problems get selected and by whom. Research problems impacting the community ought to be arrived at in mutual way. Yet, to what extent universities are acting in a paternalistic manner, a collaborative manner or a mixture of both? The extant literature is also scarce on the organizational mechanisms that promote a collaborative research agenda.

Universities engage in their locales as a form of economic development. Yet, engagement in locale can also be seen as a way of improving their campus by extension. Understanding that walling off their campuses would not inoculate them from the impacts of the surrounding communities, universities began to recognize that a holistic approach is needed when working within the community. The best thing the university 
could do to help the institution was to help the surrounding area and community. Improving the neighborhood, they reasoned, would help attract and retain quality students and faculty. "Success depended upon mitigation in all areas, as ignoring any area could potentially undermine all other areas" (Smart, 2008). Although some of the mitigation can be looked at in terms of gentrification, it is within a community's best interest to keep and encourage universities to grow. Nevertheless, from the university's point of view, the financial reasons for becoming a powerful actor within the community are crystal clear.

Community engagement can often become a mechanism used by universities in their pursuit of prestige. As Toutkoushian (2010) contends, universities today trade in prestige and reputation to attract those students and, perhaps more importantly, research dollars. Today, many funding agencies require "broader impacts" that help mitigate a societal problem. Prestige seeking has incentivized universities to look for illustrious faculty in order to garner better ratings and more research funding. In order to attract prestigious faculty and more motivated students, all universities strive to create amenities in and around the university, and a greater number of academic programs and student activities. Additionally, universities seek to attract students by providing them with "real world" experiences through community led student learning, effectively turning the neighborhood into a classroom.

Prestige seeking, and university development are not necessarily congruent with the surrounding area. The community around a university is not always ideal. Many universities are surrounded by low income and blighted neighborhoods. Still others are surrounded with rural communities who lack the infrastructure to welcome a large 
institution. Regardless of the particular circumstances, universities that tend to improve their neighborhoods to attract students do so in a manner that do not displace and disrupt the lives of the town's residents. Although prestige seeking has a negative connotation, the engagement that flows out from it can have very real and positive impacts on the local community. While those may not be the most altruistic reasons, in the end, wealthier students and more research dollars have the potential to benefit the area surrounding the university.

\section{Carnegie Classification}

As universities started to engage their communities, there arose a mechanism for recognizing universities that excelled at the process. The Carnegie Foundation's Classification for Community Engagement, which began in 2005, is a classification for which a university can apply. It is important to note, that institutions seek out this classification purely on a voluntary basis and do so as a means to gain recognition for behavior they believe demonstrates their ongoing commitment to the community. To attain the status under the Carnegie classification, a university needs to collect and submit data, both qualitative and quantitative, on the scope and nature of their community engagement activities. The application seeks information about the institutions' mission, strategic plan, and other guiding documents. The process often requires an institutional self-assessment of community engagement activities. This undertaking is not a quick process, generally taking upwards of a year to complete and is considered both by the Carnegie Foundation and institutions of higher education as a substantial investment of time and personnel resources. Participating universities gain 
the classification for the whole institution; the classification cannot be given to a college or particular school within the institution.

The Carnegie Foundation is quick to point out that the classification is not an award. The classification is a recognition of a community engaged institution, grounded on "evidence-based documentation of institutional practice." A National Advisory Panel reviews the applications and decides if the applicant institutions merit the recognition. The panel is comprised of nationally and internationally renowned scholars of community engagement. Classification is not a one-time occurrence; it must be renewed every five years.

The National Advisory Panel rates institutions of higher education based on the Carnegie Foundation's definition of community engagement. As previously mentioned, that definition portrays engagement as a collaboration between institutions of higher education and their larger communities. Interestingly, community is defined as including the local community, as well as the regional, state, national, and global community. Community, therefore, is a broad term that can really encompass any locality around the globe. Yet, most applications focus on mutually beneficial collaborations and partnerships within a university's region.

The Carnegie Classification states that the purpose of community engagement is for collaboration with both the public and private sector. These collaborations should be mutually beneficial partnerships that "enrich scholarship, research, and creative activity; enhance curriculum, teaching and learning; prepare educated, engaged citizens; strengthen democratic values and civic responsibility; address critical societal issues; 
and contribute to the public good." That is a fairly large mandate, but one that clearly delineates working with the community, broadly defined, on economic and social issues.

While the Carnegie Classification is not a perfect system, it is nonetheless indicative of a university that has given community engagement serious institutional attention. A given university has put in the time and effort to demonstrate their engagement. The process of classification requires that the universities collect data about their community engagement activities and requires sufficient activities as to merit the classification. What is not immediately obvious from the classification is whether these engagement practices and activities amount to real collaboration between the universities and those they are engaging. Moreover, the classification does not necessarily suggest a collaborative relationship with the local government.

\section{Engagement}

In terms of town-gown relations, "engagement is an umbrella that features good practice in teaching, research, and service that is community based" (Fitzgerald, et al, 2012, p. 7). And ultimately, it is the mechanism from which collaboration can occur. For the university, engagement starts with student engagement. Student engagement are "activities that are empirically linked to desired outcomes of college and what institutions do to induce students to participate in these activities" (Kuh, 2009, p. 683). It is often thought as a tool to prevent student from dropping out of college and successfully completing their degrees (Mosher and MacGowan 1985; Christenson et al., 2012). This view of engagement largely impacts the university's perceptions of institutional engagement. Indeed, there are a number of ways student engagement blends into the way institutions view their engagement practices. 


\section{Engaging the Anchor}

Boucher, Conway, and Van der Meer (2003) identified different themes when regions interact with universities. These themes include universities and the governance of regions; student migratory flows and local labor market dynamics; the role of universities in information society initiatives; management of universities; the social shaping of knowledge workers; universities and regional culture; the role of universities in regional innovation strategies; universities and sustainable regional development. Although the Boucher et al. study (2003) is focused on the regions in the European Union, I believe those themes can also be identified within U.S. cities.

As local governments understand the economic and social potential, they tend to engage more. Amin and Thrift (1994) found that "institutional thickness" or how universities use their resources toward a collaborative goal positively impacts a region's economy. Further, the more "institutional actors" work with one another, the more likely they are to help one another as "economic entities" (Thanki, 1999). To the community and local government, a university becomes an economic entity when it plays a significant role as an economic contributor. Economic contributors are defined as significant employers, buyers and vendors of goods and services, and as an entity that attract new residents to the area, namely students (Thanki, 1999; Bleaney et al., 1992; Armstrong et al., 1997).

As cities participate more and more in the knowledge economy, the commodification of knowledge and innovation clusters becomes a major draw for engagement (Charles et al., 1995; Oakley, 1995; Brett et al., 1991). Social networks and capital have also shown to form connections that lead to innovation, scholarship and 
policy actions and initiatives (Goddard et al., 1994; Keane et al., 1999; Boucher, et al., 2003; Campayo et al., 2000; Van der Meer et al., 2000a). Tsipouri et al. (2000a) found that the most significant factor for regional engagement is informal connections by departments in both the university and municipality.

To be sure, there are a number of benefits that governments derive from having universities nearby. These benefits are often thought of as the basis of engagement. For example, federal grants obtained by the university can increase the economic development of a community and thus improve relations between the local government and university. Similarly, there are many university interactions with the local community that can yield benefits such as when the university works with the local government or community to incubate businesses or when student led service-learning projects help both teach students and generate a benefit for the community. Likewise, on an institutional level, the collaborative work of university faculty and centers with officials from a variety of jurisdictions on both simple and wicked problems that benefit from university expertise in turn benefit the community. Benefits from funding from the National Institutes of Health (NIH) and the National Science Foundation (NSF) as well as state and local governments can also help create strong community engagement practices. In fact, many universities also speak of the concept of economic engagement. That is, engagement that involves the use of human capital, research skills and funding applied towards the stewardship of their place (Association of Public and Land Grant Universities (APLU), 2015). Economic engagement is essentially community engagement with an economic focus. 
Among the ways that economic engagement has been quantified is by the amount of state and federal funding that stems from research projects. The research skills and funding aspects of economic engagement are an interesting consideration when taking into account the rhetoric around the amount of impact university-based research has on the local economy. Valero and Reenen's (2016) retrospective study of university based economic development in 78 countries over the span of 60 years found that while GDP rose in places with universities, it was ultimately innovation and talent that thrived in those areas. The University System of Ohio Board of Regents (2012) conceptualized this process of innovation as a commercialization ecosystem. The ecosystem is an intersection of Research (University), public policy (Government), and expertise (Industry). In turn, both APLU and Ohio’s Board of Regents have called for the collection of metrics pertaining to this ecosystem.

\section{Town-Gown Relations}

To be sure, there have been numerous studies on town-gown relationships. The vast majority of these studies have been conducted as case studies or within small defined geographic regions (Addie \& Olds, 2015; Wiewel and Perry, 2015a; Gavazzi \& Fox 2015; Arefi \& Al-Douri, 2016). These studies have examined a host of different issues, such as crime (Wynn, 2017; Griffiths \& Best, 2016), e-government (Levy, A. 2015; Clark et al, 2015), the environment (Daneri et al, 2015; Matthews \& Smith, 2015; Mosier, S. 2015; Niewolny et al, 2016), spatial development (Srouri, 2005; Lui, 2017), neighborhood revitalization (Mapes, et al, 2017; Perry \& Wiewel, 2015; Wiewel \& Perry, 2015b ; Ehlenz, 2017), studentification (Moos, et al, 2018; Carter, 2017; Powell, 2016), professional development (Borrero and Reed, 2016), power relations (Wise, 
2017), and student engagement (Clarke \& DeGreeve, 2016; Shelton, 2016; Ford, 2016).

Studies have even examined how the town-gown relationship can be viewed through the lens of marriage (Troost, 2016; Vernon, 2017). Indeed, the topic of town-gown relationships has been explored in a myriad of ways. Each of these inquiries have identified many examples of how universities and communities engage each other.

\section{Challenges and Opportunities for Local Government/University Engagement}

The opportunities universities represent for local governments are coupled with corollary problems and contrasting views on proper town-gown relations. These include simple matters such as poor behavior by college students, as well as more complicated ones like studentification (Hubbard, 2009), or student led gentrification, which often displaces longtime residents, without leaving the area improved. Rather, it simply changes the residents of the neighborhood. This process engenders resentment from the local community, not only from the community members it displaces, but also as a result of changes brought by the type of businesses that are often attracted to a neighborhood as a result of studentification. Those businesses tend to be different from the local businesses that were found in the area before the process of studentification. In fact, studentification is almost always accompanied by businesses geared to students such as box stores, bars, banks, bookstores and any number shops focused on the needs and interests of students (Bromley, 2006).

Crime rates around college campuses have been found to be relatively low compared to other areas (Zhang, et al, 2006). However, perceptions of crime around a given campus, particularly urban campuses were found to negatively affect student perceptions of the campus' adjacent neighborhoods (Hignite, et al, 2018). Likewise, 
student behavior on campus is largely dependent on perceptions regarding the safety and potential dangerousness of adjacent neighborhoods. Students practice avoidance techniques (Garafalo, 1977), including taking more online courses and taking additional precautions when on campus. Hignite, Marshall and Naumann's 2018 study found that in an urban inner-city campus, $28 \%$ of their sample avoided the area around campus in general, $62 \%$ of respondents avoided the area at night, and $7 \%$ of them avoided the university entirely at night. Unsurprisingly, the fear of crime was predictive of taking such actions.

If a student perceives the neighborhood to be dangerous, it stands to reason that engagement might also suffer. As further described in Chapter 4, this may result from how universities conceive of engagement, namely as student centric. For example, should students not want to "engage" or take part in experiential student-learning within the community the university is in, the levels of engagement might well decrease.

Similarly, the local government's perception of a university might also be clouded by crime. Arrests on campus, even if the arrest itself was done by campus police, use up local resources through the judiciary system. Although there are not many studies that specifically look at the local government's perceptions of crimes committed by college students, one can posit that there is likely an inverse relationship between crime and perceptions of engagement.

Another point of contention between local governments and universities is the issue of taxation. Local governments have the ability to tax, and the impetus to do so in order to afford to pay for needs of their communities. Police officers, emergency vehicles, garbage pickup, and public infrastructure, such as roads, are all provided for by 
tax dollars. However, institutions of higher education are generally tax-exempt because they fall under section 501(c)(3) of the Internal Revenue Service code that provides tax exemption to non-profit organizations on the basis of their educational mission. This tax exemption limits the revenue local governments can generate. Some have called for reviewing the policies that protect universities as tax exempt entities, yet currently institutions of higher education do not pay taxes.

On account of a university's nonprofit status, there are some municipalities that request Payment In Lieu of Taxes (PILOTs). PILOTs are voluntary agreements between municipalities and non-profit organizations which involve payment for the very services that traditional taxes pay for. In 2017, the city of Boston received 65\% of the PILOTs requested, with 14 of the 19 universities in Boston paying less than what was asked of them (Krantz, 2017). The City of Philadelphia is likewise attempting to establish PILOTs for its many institutions of higher learning but is facing resistance from many of the city's universities (Fernandez, 2016). This creates tension between the local government and the university. Many universities would argue that PILOTs are unnecessary as they often contribute to their own needs and in fact the needs of the community. This difference of opinion often creates tensions between the local government and the university.

Making matters more difficult is the issue of transient student residents. These residents mostly have little, if any negative interactions with their neighbors. However, there is a small number of college students that create problems for the neighborhood. Contentious behavior by students frequently involves under aged drinking, loud parties, and parking violations (Bromley, 2006). However, student discipline off campus often 
falls beyond the scope of institutional responsibility. Nevertheless, negative sentiments about students from neighbors is often transferred to the institution.

These negative sentiments are a problem for both the institution and for the community. Rankings such as "best party schools" do little to assuage parents' concerns about a particular college. Likewise, community residents worry that their proximity to such schools lowers property values. Institutions of higher education do well to maintain a respectable image, because a less than desirable image for an institution can "attract only the desperate, the mal-intentioned and the foolhardy" (Bromley, 2006, pg. 8) to the institution as well as the surrounding city. Overall, despite these aforementioned areas of contention and tension, municipalities largely enjoy the many positive spoils of having an institution of considerable repute within their jurisdiction.

One example of a positive yet contentious relationship between universities and local governments exists in the context of the "creative class" (Florida, 2002). This is particularly true of municipalities looking to spur economic recoveries in light of dwindling population and shuttered businesses. From the perspective of municipalities, it is argued that universities serve to attract bright minds and new businesses. In turn, these new constituencies will attract additional entities that will help develop the area and make the municipality a more desirable place to live. In turn, housing developments and new businesses increase the tax base and create vitality in the community. In summary, there is little doubt that municipalities have a vested interest in engaging with universities to achieve communal success. 


\section{Chapter 3: Local Government Collaboration}

There have been a number of studies on local government collaboration with industry (Abbas et al, 2018), nonprofit organizations (Cheng, 2018), and inter-local collaboration (Shen and Feiock, 2017). These studies have analyzed various topics of

collaboration with the local governments, largely through case studies (Vogt et al, 2017), qualitative interviews (Hendriks et al, 2015), and quantitative methods. Among them are public service delivery (Tomkinson, 2017; Pérez-López et al, 2015), food policy (Gupta et al, 2018; McCartan \& Palermo, 2017), sustainability (Swann, 2017; Kiron et al, 2015), K-12 education (Hadfield \& Ainscow, 2018; Starr, 2015), and disaster management (Sitas et al, 2016; Iimoto et al, 2015). Studies have also examined how local governments work with both industry and universities in what is referred to as the Triple Helix Model (Rodrigues and Melo, 2013; Etzkowitz, 2003). The theoretical aspects of local government collaboration have also been of seminal importance to scholars for some time (Gray and Wood, 1991; Feiock, 2007; Feiock, 2008; Feiock, 2014; Warm, 2011; Agranoff and McGuire, 2003; Brinkerhoff, 2002; Hall, 2009; Gargen, 1981). The extant literature on local government collaboration has considered this topic through a variety of lenses.

Bingham and O'Leary (2006) found that collaboration, while widely practiced, is a concept with multiple meanings that lacks a collective definition. Warm (2011) identified several factors that encourage local governments to collaborate, namely financial, competitive, and practical considerations. Financial considerations spur collaboration for a number of reasons, not least of which is the challenge of fiscal 
constraints brought about by ever decreasing levels of state support (Hanson, 2018). Those financial considerations have moved local governments towards partnerships across key sectors of society (Cigler, 2018). Despite the fact that neither finances or collaboration are certain, financial consideration elicits collaboration in an effort to promote efficiency and innovation. The practical considerations for collaboration are as numerous as the issues facing municipalities on a daily basis. From wicked problems to traffic problems, municipalities are simply not able to face all problems alone. In fact, nearly every municipality within the United States has a formalized agreement with another entity (Warm, 2011). Collaboration has proven useful to municipalities as a form of citizen engagement, K-12 education, and various wicked problems such as climate change and chronic poverty. Yet once again, it is important to note that Bingham and O'Leary (2006) pointed out that collaboration, while widely practiced, is in fact a concept with multiple meanings that lacks a collective definition.

\section{Antecedents of Collaboration}

Gray and Wood (1991) described collaboration as an area of study with three distinct elements: antecedents of collaboration, the process of collaboration itself, and the outcomes of the process of collaboration. This dissertation primarily focuses on the antecedents of collaboration. These antecedents are the aspects of collaboration that need to be present for collaboration to take place and flourish in the early part of a partnership. The starting point for collaboration begins with a need or problem shared by stakeholders with a level of autonomy and shared norms and rules, Gray and Wood (1991). Further, they posit that collaboration must have intentionality. That is, the intention to solve a given problem, not merely pay it lip service. Intentionality gives 
organizational leaders the impetus to seek out and work on collaborative efforts to address a given topic or issue.

Mayer and Kenter (2015) updated Gray and Wood's (1991) conceptual model of collaboration and added some key elements. Their research added element such as shared decision making, shared vision, trust, and leadership. Shared decision making, also referred to as consensus decision making is a process that includes having previously agreed terms regarding the outcome and the process of collaboration. Shared decision making is a process that mitigates risks and creates a vested interest in all parties involved. Shared vision is conceptualized as a shared understanding of the partnership that extends beyond one project; it requires a shared vision of what the collaboration can bring to the stakeholders. It also creates a vested interest within the participants. Ansell \& Gash (2007) posit that shared vision is a measure of the success of any collaboration. Conversely, one can think of shared decision making as an antecedent of shared vision. Once the two parties can work out their terms and the process, a vision can start to form which all parties can rally around.

Trust is another crucial factor when conceptualizing collaboration. Trust "is often cited as one of the most vital components necessary to build and sustain collaboration" (Mayer and Kanter, 2007, p. 57). Indeed, many scholars have attempted to conceptualize trust with regard to collaboration. McNamera (2012) posited that collaboration between two organizations, even if there is a power imbalance, can work provided they trust that their work is achieving a common end. Mayer, et al (1995) conceptualized that trust is a factor of tolerance for risk. Lasker et al. (2001) found that trust is related to shared 
responsibility and social capital. Their study ultimately concluded that without trust, the likelihood that a collaboration's efforts will succeed sharply decrease.

Interestingly, Ansell and Gash (2007) found that strong levels of trust between a subset of stakeholders could ultimately backfire as those stakeholders choose to achieve the project on their own. Trust, in that regard, is only valuable to the degree that the parties involved believe themselves to be interrelated. Further, Ansell (2003) found that trust and interdependence could also produce cliques that are not prone to collaborative partnerships with groups perceived as outsiders. Overall, however, the process of developing trust among stakeholders is still a worthwhile endeavor for strong collaborative efforts.

Leadership is a well-recognized aspect of collaboration. Interestingly, leadership within collaboration is fluid, as it can be transferred from one person to another and it can involve both formal and informal processes (Bryson et al., 2006). Bryson et al. (2006) also concluded that leadership is essential for getting the collaboration off the ground, organizing the collaboration, and initiating the process. Strong leadership is also vital in solving early conflicts and in agenda setting (Ansell \& Gash, 2007; Mayer and Kanter, 2008). Of note, Denhardt \& Campbell (2006), found leadership to be the bridge between the particular goal of a given partnership and the macro-level significance of a project to a participant's parent organization or group. Finally, Mayer and Kanter (2008) concluded that "effective leadership is perhaps the most critical element of a collaborative being able to achieve its goals" (pg. 53). Leadership that is both interested in collaboration and can effectively convene partnerships is vital for the conceptualization of collaboration between two organizations or parties. 
Collaborative leadership within the public sector can sometimes be challenging. Public sector leaders derive their authority from a hierarchical structure (Getha-Taylor \& Morse, 2013). The fluid nature of collaborative leadership can be disorienting to persons and organizations that are not accustomed to a vertical power structure. Several scholars have found a generational shift to leadership and power structures, with younger community or organizational leaders finding collaborative efforts and vertical power structures more efficient than their older peers (Agranoff \& McGuire, 2003; Esteve, et al., 2014). Ultimately, having a growth mindset (Dweck, 2006) around leadership and power structures is necessary, particularly early on in the process, when partnerships are more likely to fail due to lack of cohesion, vision, and trust (Mayer and Kanter, 2008).

\section{Collaborative Governance and its Drivers}

The antecedents of collaboration are foundational in collaborative governance. Indeed, while collaboration as a theory or practice can be applied to a host of different activities, collaborative governance is geared toward the public sector. Like governance itself, collaborative governance has no set definition and its use in the extant literature is inconsistent (Emerson, et. al., 2012) However, Ansell and Gash (2007) posit that collaborative governance is uniting "public and private stakeholders together in collective forums with public agencies to engage in consensus-oriented decision making" (p. 543). Their definition of collaborative governance entails several criteria. For it to be collaborative governance, either the public agency or organization initiate a formal meeting, and it includes a non-state actor. The participants of the meeting have a voice in the decision-making process and decisions are made by consensus, or consensus leaning (Connick and Innes, 2003). The main criteria, however, is that the focus of the meeting is 
the advancement of a public policy or management problem. Collaborative governance is ultimately a way for public agencies to create a process to work with public and private stakeholders towards the public good.

Emerson, Nabatchi, and Balogh (2012) created a framework from which to study collaborative governance. Their framework builds on the work of scholars, notably Ansell and Gash (2011) and Bryson, Crosby and Stone (2006), but broadens the reach of collaborative governance to include non-governmental actors, as well as multi-partner governance (Agrawal and Lemos, 2007). Emerson, Nabatchi, and Balogh (2012) propose a framework for collaborative governance that recognizes four drivers of collaborative governance: leadership, consequential incentives, interdependence, and uncertainty.

Leadership is a familiar concept in the literature pertaining to both municipal governments and institutions of higher education. Similar to other scholars, (Gray and Wood, 1991; Agranoff \& McGuire, 2003; Ansell \& Gash, 2007; Mayer and Kanter, 2008, Getha-Taylor \& Morse, 2013; Esteve, et al., 2014) the framework requires effective leadership as a driver of collaborative governance to encompass a commitment to solve problems, a willingness to listen to a variety of opinions without partiality and be trusted by the other party. Emerson, Nabatchi, and Balogh (2012) list leadership as the "first essential driver" of collaborative governance.

Consequential incentives are drivers that warrant action from both parties to attain an important incentive, such as a grant application or economic development project. Interdependence refers to two or more groups that require the aid of the other to achieve a particular goal which is too big to solve alone. Interdependent groups cannot effectively solve a problem without the assistance of the other party. Uncertainty is the final driver of 
Emerson, Nabatchi, and Balogh (2012)'s collaborative governance framework.

Uncertainty can force two parties to work together in order to mitigate risk or manage a large societal problem with no immediate solution. This framework is a great starting point for producing positive outcomes, however, the parties involved must be able to collaborate before these drivers can initiate a long lasting and fruitful collaboration.

\section{Collaborative Capacity}

For a municipality to engage a university, they need to have the ability to collaborate. That is, they need to have collaborative capacity (Foster-Fishman, et al., 2001). Goodman et al. (1998) conceptualize collaborative capacity as the potential that communities have to solve a given problem. There are many dimensions to collaborative capacity. Gray (1989) posits that collaborative capacity has five general characteristics, including stakeholder interdependence, partnerships that handle their differences constructively, decisions that are made jointly, responsibility is shared and all parties understand that collaborations are an "emergent process," where the growth or contraction of the endeavors can take place. To measure the general success of these characteristics, a three-step process was derived to model collaborative capacity (Gray, 1989; McCann, 1983); the first step is problem setting, which is followed by direction setting and concluding with third step of implementation.

Other scholars, most notably Roussos and Fawcett (2000), have stipulated that there is no single best way to develop collaborative capacity. A number of scholars have attempted to develop additional frameworks to model the ways in which communities' partner with each other and organizations, most often in the healthcare field. An overview by Foster-Fishman et al. (2001) suggests that collaborative capacity requires 
capacity at each level of partnership; that is to say, with members, relationships, organizational structures, and programs. In terms of this study, we find that the addition of a local government capacity is paramount to collaborative capacity of town-gown relationships.

Community capacity, sometimes referred to in the extant literature as member capacity, denotes a skill that community members bring to a partnership. A study by Goodman et al. (1998) found that community capacity ought to include proactive leadership, participation, resources, skills and social networks. Applied to the context of community engagement, this implies that a community must first have capable leadership that is willing to work with universities. Insofar that it is true that universities initiate engagement more than communities, it can be speculated that a lack of community leadership can help explain that phenomena. However, leadership itself is not sufficient for community capacity, rather the community or its appointed representatives must participate in the endeavor. Those that participate must be able to bring skills, resources and/or social networks to the partnership. Universities have their own skills, resources and networks, but rely on the community coalition for structural support and participation. Although this dissertation does not go as far as to explore the relationship between the local government, university and the community, it is nonetheless important to note the aspects of community capacity, notably leadership, which are vital to engagement and collaboration.

Community capacity is an important point within the context of collaborative capacity, but one that does not necessarily apply to an examination of a dichotomous relationship, such as the one between the local government and the university. However, 
aspects of community capacity are still important to the analysis within this context. Proactive leadership, resources, and skills, for example, are crucial to the success of the collaboration for either party.

Similar to community capacity, organizational capacity refers to what the organization can bring to a partnership. Wandersman, Goodman, and Butterfoss (1997) found that organizational capacity is necessary to connect members toward solving a goal and without it, the vision was not clear. Organizational capacity necessitates a strong leader and administration. Further, it requires formalized procedures, dedicated resources, quality assurance, and excellent communication both internally and externally (Foster-Fishman et al., 2001). Moreover, organizational capacity must bring with it a clear vision for the organization and for the partnership (Roussos and Fawcett, 2000). With regards to this study, university capacity first requires buy-in and leadership from the administration. Moreover, it requires formalized procedures. Universities have an advantage of being able to dedicate resources to the execution and evaluation of a project, but without strong leadership, a clear vision cannot be formulated. The fact that universities are more often than not the ones that initiate engagement, suggests that it is incumbent upon them to have a clear vision of the partnership.

Local government capacity is similar to both community and organizational capacity, but at the local government level. According to Wallis et al. (2002), local government capacity has four dimensions: institutional, technical, administrative and political. Institutional capacity permits local governments to set policies and laws to govern. It enables them to "set the rules of the game" (Grindle, 1996). While local governments' technical capacity empowers them to set a clear economic policy and their 
administrative capacity allows for the bookkeeping and paperwork necessary for economic activities. Political capacity refers to the extent to which local governments can mediate conflict in order to reach a common goal (Grindle, 1996).

In terms of university engagement, economic policies brought forth by local governments can facilitate or perhaps necessitate community engagement. Institutional capacity often sets the rules for development or expansion of both communities and universities, and it often sets up restrictions and policies for interacting with citizens, particularly minors. When conflict arises, the political capacity can help mediate between community leaders and university administration.

Relational capacity is similar to social capital, but it relies not only on relationships, but also on a shared vision. In order to have a collaborative capacity, the partnership must have internal and external relationships that will help create cohesion throughout and meld together diverse opinions into one that can be championed. Diversity is prized in relational capacity for its ability to bring many perspectives to the table, and thus help create a collective vision. Ultimately relational capacity will help keep community members interested in the partnership and prevent it from falling apart as time goes on (Chavis, 1995). In terms of university-community partnerships, relational capacity is vital. Universities and local governments can work together to identify strong community leaders and organizations that can help bring partnerships to fruition that will not dissipate if conflicts arise within the group.

Finally, programmatic capacity relates to the ability to implement a project and assures that it has a "real, meaningful impact within the community" (Wallis et al, 2002). Programmatic capacity applies to both the university and the community. It 
requires shared resources, initiative and mobilization. Here again, a clear mission is crucial for the success of a partnership because it is important to know exactly where resources are being spent (Barton et al., 1997).

Drawing from this body of literature, the subsequent chapter will detail the conceptual framework that informed the empirical analysis. The conceptual model is, by and large, based on literature on collaboration and collaborative capacity, yet it also offers some novel insights. 


\section{Chapter 4: Conceptual Framework, Research Questions, and Hypotheses}

This chapter introduces the conceptual framework that informs the research questions and hypotheses of this study. The three research questions of this dissertation and the hypotheses guiding the empirical analyses follow below.

\section{Conceptual Model: Collaborative Capacity}

This dissertation draws on the collaborative capacity framework and selects seven aspects that together form the collaborative capacity of municipalities and local governments. While the analysis of the variables will be detailed in other chapters, the gist of the framework is as follows. Local government capacity refers to a municipality's time, monetary resources, and its technical capacity. Another consideration of local government capacity is its willingness to include the university as an economic stakeholder and a stakeholder in local social issues, such as unemployment or education. Moreover, local government capacity is a function of having leadership that wants to collaborate with the university. Such leadership would be considered proactive in university/municipal engagement. Lastly, the local government's capacity includes their willingness to value a diversity of opinions. A diversity of opinions is included in the capacity of local government because it demonstrates willingness to entertain differing points of view that may lead to a shared vision after all viewpoints are debated.

The university capacity is similar in that it considers the university's time, monetary resources and technical capacity. From the extant literature and findings from this study, it became evident that a main factor in working with the local government was having formalized procedures for creating partnerships with university. University 
capacity also involves having proactive leadership willing to engage with the local government and valuing a diversity of opinions.

The last element that comprises the framework is Trust and Decision making. Trust is perhaps the most important element for collaborative capacity. Trust in this study is the credibility and reliability of the other party. It is manifested in a given party's reliably to deliver on previously agreed terms and solve conflicts that arise during a particular collaboration or more generally as town-gown relations ebb and flow There are aspects of trust that are unique to town-gown engagement.

One last element must be present for collaborative governance, namely good government. Fredrickson (2015) describes good government plainly: it is honest, democratic and competent. For collaboration between local governments and universities to work, good government is foundational. If good government is in fact honest, democratic and competent, collaboration must then include trust, diversity of opinions, and capacity to collaborate. And yet those qualities within government do not alone guarantee success in collaboration. Given that collaboration and engagement are thought of as two-way streets (Boyer, 1992), universities must also be trustworthy, value diverse opinions, and have the capacity to collaborate.

The conceptual framework of local government capacity is presented in Figure 1. Likewise, the framework for university capacity is presented in Figure 2. Figure 3 presents the combined conceptual framework that will guide research question 2. Aside from university and local government capacity, the framework notes the importance of Shared Vision and Trust. Together those elements are conceptualized to result in collaboration that is mutually beneficial to both parties. 


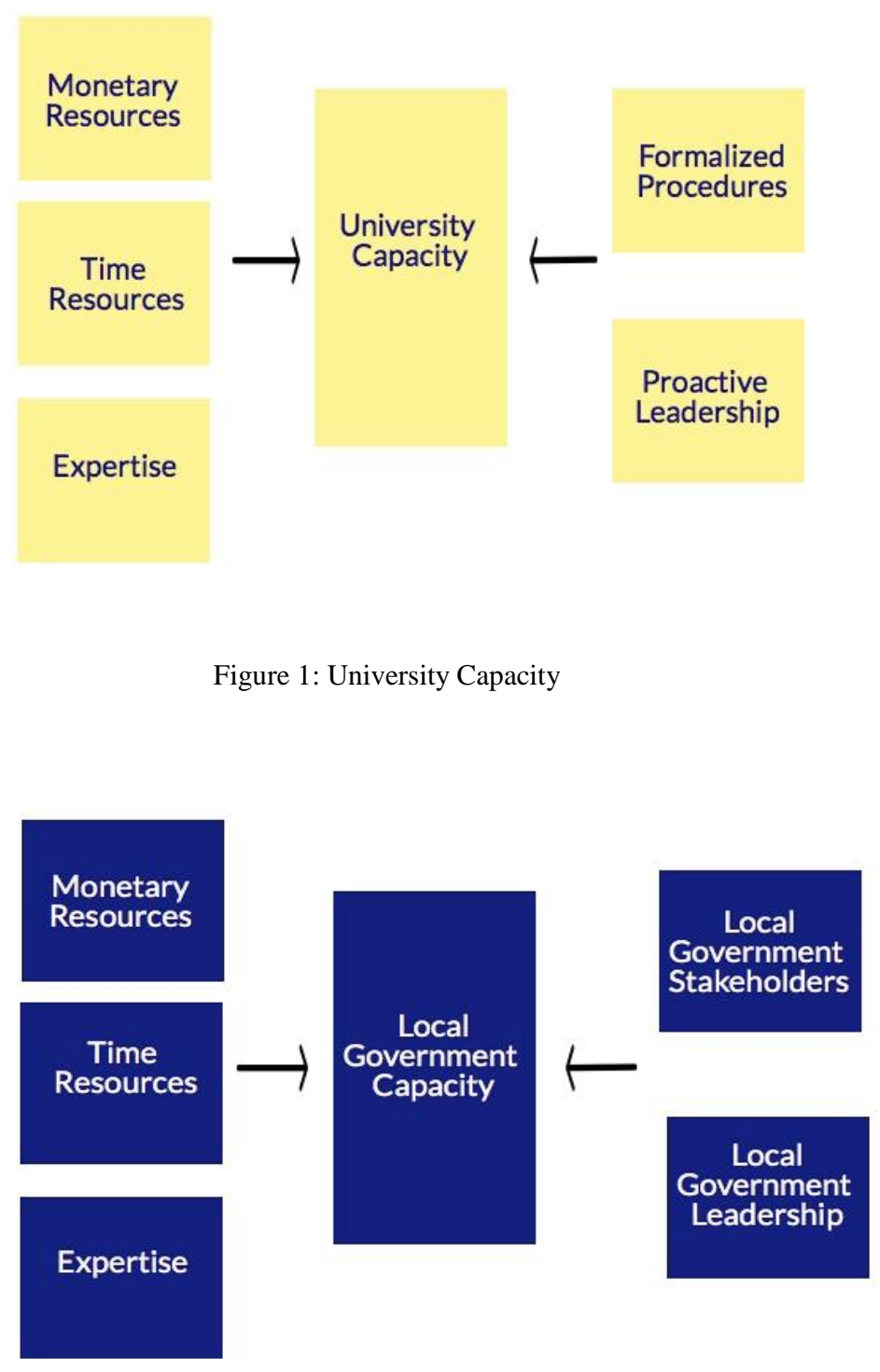

Figure 2: Local Government Capacity 


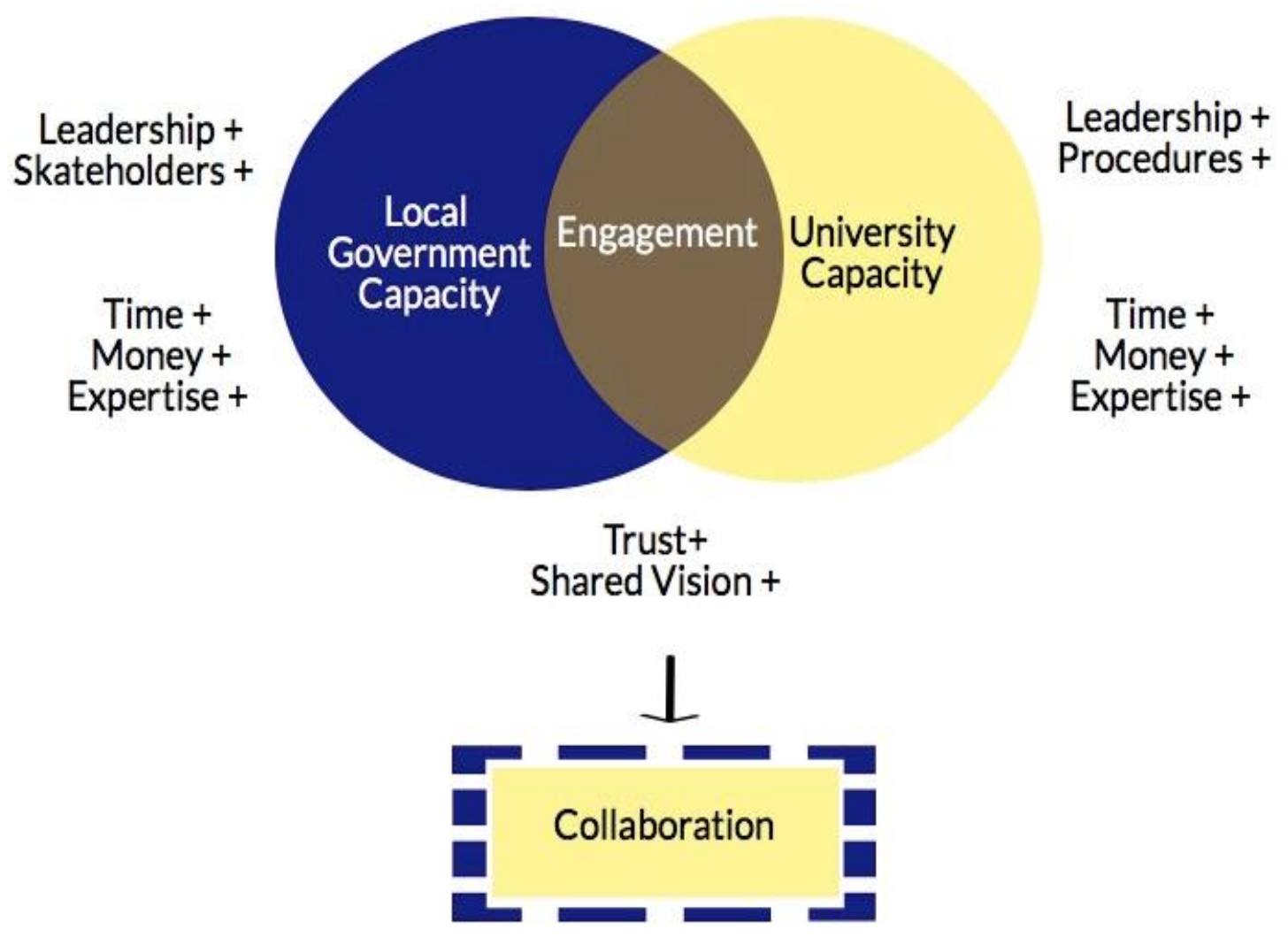

Figure 3: Engagement and Collaboration Framework

\section{Conceptual Model: Factors Predicting Engagement and Collaboration}

The extant literature suggests that crime (Hignite, et al, 2018) strains town-gown relations, while the presence of grant funding affects them positively. Little information is available, however, on other characteristics such as type of institution, as well as neighborhood and student demographics. Yet, it stands to reason that more students are positively associated with engagement, simply by virtue of numbers. Prior research notes that student engagement is of utmost importance to universities, and the more students, the more chances to engage (Bringle and Hatcher, 2002). Same is true for "traditional students," or full-time students. An additional element was added to traditional students: 
attending college in-state. In fact, in the fall of 2016, within public universities, a full $83 \%$ of first-time college students attended a university in the state in which they resided (College Board, nd). Likewise, a larger town provides more needs and opportunities to engage with the local university.

Prior research offers little on the characteristics of neighborhoods that affect town-gown collaboration. Studentification, a phenomenon that has displaced residents and brought about "excessive noise" (Mosey, 2017) tends to be viewed negatively by older populations and those with higher incomes. On the other hand, students who do not feel safe around their campus, do not engage the local area. As crime and poverty rates are interconnected, here too it is posited that they would have a negative association agreement in levels of engagement and collaboration. As the extant literature on engagement and collaboration is often conflated, it is hard to tease out which characteristics impact engagement and/or collaboration, and for this study the same inferences made about engagement apply to collaboration. Figure 4 below details the conceptual model and the expected relationship of each variable to engagement and collaboration. 


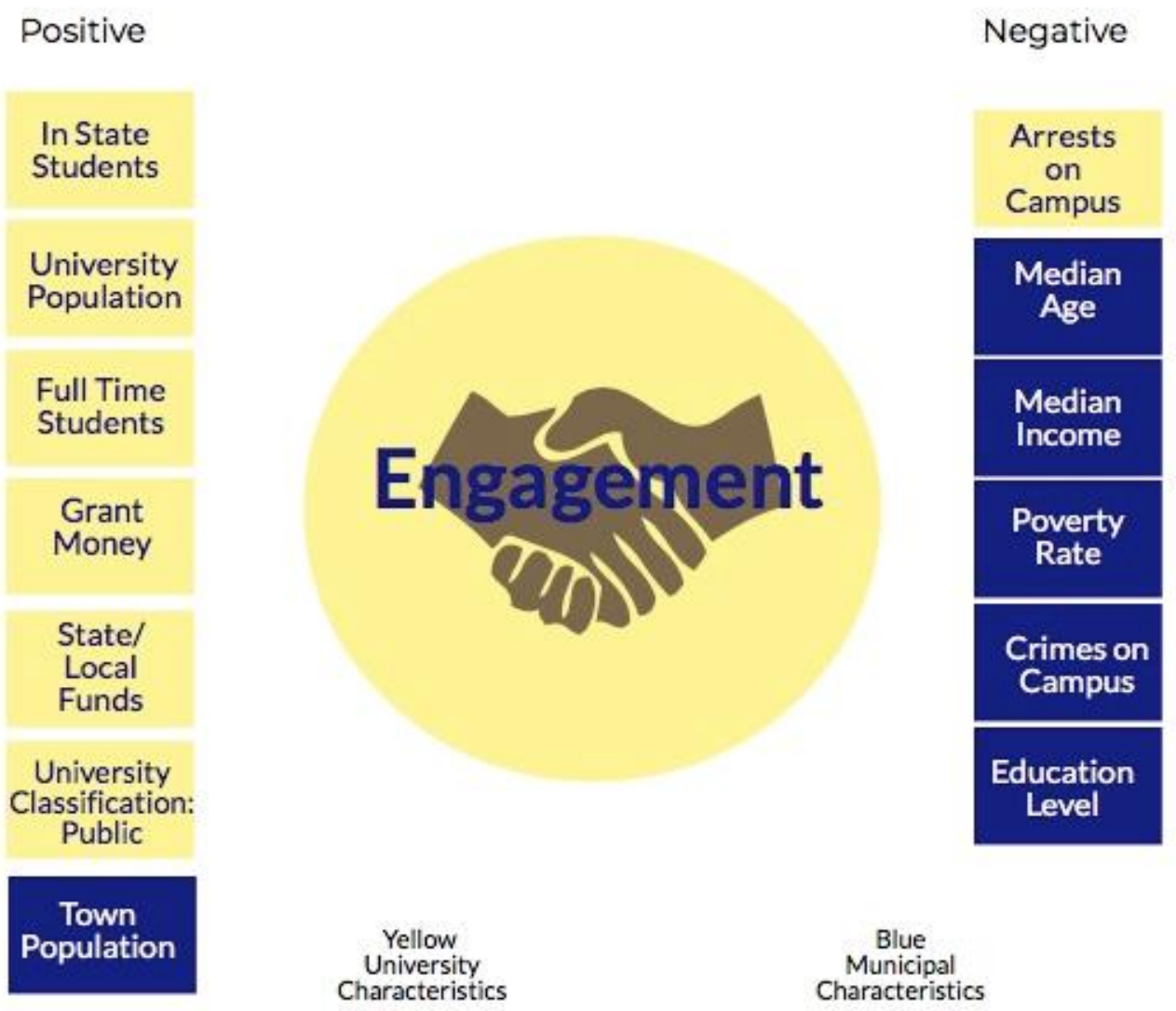

Figure 4: Factors that affect levels of agreement in engagement and collaboration

\section{Study Research Questions}

\section{$\underline{\text { Research Question } 1}$}

The first research question is exploratory in nature. The purpose is to investigate how universities and municipalities understand engagement and the factors that facilitate it. In effect, these are two interrelated questions:

Research Question 1a: How does engagement as a concept and in practice vary among universities and municipalities?

Research Question 1b: What are the main factors that enable or hinder engagement? 
The aim is to explore if there are differences and similarities in the way practitioners conceptualize local government and university engagement. Research question $1 \mathrm{~b}$ explores the factors that helped and hindered the process. Lastly, the study aims to analyze the importance of various types of engagements - that is economic development, and student learning — are to local government officials and university administrators. These questions were investigated through qualitative research methods. As such, no hypotheses were formulated for this research question.

\section{$\underline{\text { Research Questions } 2 \text { and Hypotheses }}$}

Research Question 2: How does the collaborative capacity of the university and the local government affect the level of engagement? Does the effect vary depending on the type of engagement?

For this study, organizational capacity is imbued on university and local government capacity as vital to collaborative capacity of town-gown relationships. Organizational capacity is an amalgamation of organizational factors, such as time and money, as well as organizational behaviors, such as trust and leadership. Local government capacity, therefore, is a combination of time, technical expertise and monetary resources. In addition, local government capacity includes strong leadership and viewing the university as a stakeholder, or interdependent with the university (Balough and Nabatchi, 2015a). Figure 1 is a visual representation of local government capacity and takes into account the aforementioned variables. Likewise, university capacity is a combination of time, technical skills and monetary resources in addition to leadership and formalized procedures (Foster-Fishman et al., 2001). Figure 2 is a visual representation of local government capacity. 
The hypothesis was formulated based on the framework of collaborative capacity, or "the conditions needed for coalitions to promote effective collaboration" (FosterFishman, et al., 2001, p.243). It is not necessary for all factors to be present, however, scholars have noted that some variation of these factors is required for collaborative capacity. As engagement can be economic and/or social, the research question and therefore the hypothesis applies to the three forms of engagement. That is, engagement as defined by the Carnegie Foundation, economic engagement, and social engagement. As a result, the following is the expectation about collaborative capacity and engagement.

Hypothesis 1: The higher collaborative capacity of university and local government, the higher the level of engagement.

Local government and/or university capacity are vital for engagement. That is for both or either party to engage the other, and for collaboration to be a priority. For example, a university might conduct a research project in a given community, which may be viewed as engagement by university, but the community might not have been invested in the project. The local government or university's capacity to engage the other party does not guarantee reciprocity from the party they are trying to engage. Indeed, it is possible for either party to claim that they are engaged, when in reality it was a one-sided engagement. For collaboration to take place, it must be a priority for both parties. As a result, the following expectation was formulated about collaborative capacity and collaboration as a priority.

Hypothesis 2: The higher collaborative capacity of university and local government, the more likely collaboration is considered a priority. 
This dissertation draws a distinction between engagement and collaboration, and local government and university capacity must be coupled with shared vision (Ansell \& Gash, 2007), and trust (Mayer and Kanter, 2008) for organizations to have collaborative capacity. That is, for true collaboration, both parties must be able to engage with one another, formulate a shared vision, and trust one another to deliver on that vision. As a result, the following hypothesis was formulated:

Hypothesis 3: The higher collaborative capacity of university and local government, the more likely collaboration is perceived as mutually beneficial.

Research Question 3 and Hypotheses

The third research question seeks to understand if particular characteristics found in either the university or the local government are positively or negatively associated with agreement in perceptions of engagement and/or collaboration. Lastly, this dissertation distinguishes between engagement and collaboration. Yet, while the concepts differ in practice, they are intertwined. It is posited that engagement is best conducted as a collaboration, and as such would most certainly impact agreement in the levels of engagement. Similarly, agreement in levels of engagement are also associated with agreement that collaborations are mutually beneficial. In that way, the two concepts are interwoven, if to varying degrees. To that end, the following research questions and hypotheses were formulated:

Research Question 3a: Under what circumstances are universities and local governments more likely to match their level of engagement?

Hypothesis 4a: More traditional students, public institutions of higher education, larger grants, and greater town population increase the likelihood for a match in the level of engagement of university and local government. 
Hypothesis 4b: High crime, poverty, and median age decrease the likelihood for a match in the level of engagement of university and local government.

Hypothesis 4c: The more university and local government perceive collaboration as mutually beneficial, the higher the likelihood for a match in the level of engagement of university and local government.

Research Question 3b: Under what circumstances are universities and local governments more likely to consider collaboration mutually beneficial?

Hypothesis 5a: More traditional students, public institutions of higher education, larger grants, and town population increase the likelihood that university and local government will consider collaboration mutually beneficial.

Hypothesis 5b: Higher levels of crime, poverty, and median age decrease the likelihood that university and local government will consider collaboration mutually beneficial.

Hypothesis 5c: The more university and local government agree on their levels of engagement, the higher the likelihood for a match in mutually beneficial collaboration. 


\section{Chapter 5: Data Collection and Sources}

This chapter introduces the various types of data collected to test the hypotheses and answer the dissertation's research questions. The first research question is answered using qualitative data, while the rest are answered using quantitative data.

\section{Qualitative Data: Semi-Structured Interviews}

To answer the first research question, qualitative data were first collected from community engagement offices within universities in the Summer of 2016. The interviewees were provided with a written statement detailing the study, the anonymity of the participant, and the contact information of both myself and my advisor. The semistructured interviews were conducted in person. To inform the pilot survey, the first round of interviews was conducted on campuses around South Florida. Since community engagement is not confined to the Engagement Office, snowball interview techniques were used to garner names of other university officials that could be contacted. To that end, interviews were conducted with department heads, deans, personnel from the provosts' office, and personnel from economic engagement offices.

After reaching saturation for the initial survey instrument with 17 interviews in South Florida, the interviews were broadened nation-wide. During the summers of 2017 and 2018, I attended the Association of Public and Land Grant Institutions' annual summer meeting. Those meetings provided opportunities to meet and interview representatives from community engagement offices nationwide. Interviews were also conducted with university engagement officials around the San Francisco Bay Area. Lastly, interviews were conducted with community engagement officials in a small rural town in Texas. The interviews in Texas were conducted over the phone. Not all 
participants allowed recording of interviews. During such interviews, I took copious notes and analyzed the data that same day for clarity. The interviews that were recorded were transcribed and analyzed using NVIVO 13. Table 1 details the demographics of all participants by gender, position, and region.

Table 1: Participant Demographics

\begin{tabular}{ll}
\hline Gender & Freq. \\
Total Persons & $\mathbf{2 6}$ \\
Female & 11 \\
Male & 15 \\
\hline Universities Represented & $\mathbf{1 2}$ \\
Public Universities & 7 \\
Private Universities & 3 \\
Region & 3 \\
South & \\
Southwest & 2 \\
West & 2 \\
Mid Atlantic & 2 \\
Midwest & 1 \\
\hline Florida & 17 \\
California & 2 \\
Texas & 1 \\
Other & 6 \\
\hline Community Engagement Office & 12 \\
Other University Post (e.g., Dept. Chairs, Professors) & 14 \\
\hline
\end{tabular}

\section{Local Government Officials}

Semi-structured interviews were also conducted with city council members, mayors, and city managers from around the country. The interviews were all conducted over the phone. During the interviews, participants were emailed a consent form detailing the study, the anonymity of the participant, and the contact information of both myself and my advisor. I also used these interviews to construct the pilot survey. Again, not all participants allowed me to record them. During such interviews, I also took copious notes and analyzed the data that same day for clarity. The interviews that were 
recorded were transcribed and analyzed using NVIVO 13. Table 2 details the demographics of all participants by gender, position, and region.

Table 2: Demographics of Local Government Participants

\begin{tabular}{ll}
\hline Total Persons & 13 \\
Female & 6 \\
Male & 7 \\
\hline Municipalities Represented & 9 \\
Large Municipalities & 4 \\
Small Municipalities & 6 \\
South & 4 \\
Southwest & 1 \\
Mid Atlantic & 2 \\
\hline Florida & 3 \\
California & 2 \\
Texas & 1 \\
Other & 7 \\
\hline City Council Member & 7 \\
Mayor & 4 \\
City Manager & 2 \\
\hline
\end{tabular}

As Table 1 and 2 show, the sample included 12 universities and 9 municipalities. While most universities and municipalities were only interviewed once, there were 2 universities and 3 municipalities where multiple people were interviewed. The largest percent of interviews on the university side came from public universities. That is consistent with the sample of the quantitative chapters. Private universities accounted for $30 \%$ of the interviews. Small municipalities, or municipalities that have less than 100,000 persons living within the town borders, accounted for $60 \%$ of the sample. It should be noted that some of the smaller municipalities, while technically considered "small" and assigned as such, exist within a larger metropolitan area. The interviews were geographically distributed except for the notable absence of the northeast. The 
interviews had slightly more males than females, but the overall sample was fairly balanced by gender.

\section{Quantitative Data: Survey Instruments}

The qualitative data collection consisted of two phases. Phase 1, which was in effect a pilot survey took place in the Winter of 2017-2018. Fifty universities and their corresponding municipalities were invited to participate. Surveys were sent to a university representative at the community engagement office. In the rare case that the university did not have an engagement office, the survey was sent to the university's Office of the Provost, as that was the office identified as responsible for community engagement when the university had no standalone office. It was also sent to the municipal leaders; the mayor, city council and city manager (if applicable). Of the 50 pairs, at least one member responded in 48 cases. In 16 of the cases there was just one respondent, 12 cases had 2 respondents, 9 cases had three respondents, and 11 cases had four or more respondents. Of the cases with four or more respondents, two provided seven respondents each.

Phase 2 took place in the Spring of 2018. One hundred universities and their corresponding municipalities were invited to participate. Of the 100 pairs, at least one member responded in 88 cases. 20 cases had one respondent, 26 cases had 2 respondents, 15 cases had three respondents, and 25 cases had four or more respondents.

Of those cases, seven had five respondents, five provided six respondents each and two provided seven respondents each.

Table 3 shows the types of campus settings as designed by the Integrated Postsecondary Education Data System (IPEDS). There were various reasons why the 
particular sample was selected. First, the universities included were all designated by the Carnegie Foundation as "Community Engaged." This is an important note, because it serves to highlight these concepts at work under the best of circumstances. That is, when the university itself purports to be engaged. The second advantage to using the Carnegie list is that there is a good mixture of both public and private colleges and universities, as well as a variety of types of research institutions. Tables $3,4,5$, and 6 show the frequency of the Carnegie Research Classification, the types of colleges and university, and the offices of the respondents, and campus setting, respectively.

Survey data were collected using Qualtrics. Individual links were provided by pair and emailed to respondents. Each pair was given a unique identifier. Adhering to confidentiality, any identifying information was deleted, and the files were kept in a password protected computer. The questionnaire contained a total of 55 questions. The responses were converted to numerical values, 1-4, with 1 corresponding to Strongly disagree and 4 corresponding to Strongly agree.

Table 3: Carnegie Classification of Institutions

\begin{tabular}{llll}
\hline Carnegie Classification & Freq. & Percent & Total \\
\hline Associate's Colleges: High Transfer-High & 4 & 1.17 & 1.17 \\
Baccalaureate Colleges: Arts \& Sciences & 41 & 12.02 & 13.20 \\
Baccalaureate Colleges: Diverse Fields & 4 & 1.17 & 14.37 \\
Doctoral Universities: Higher Research & 69 & 20.23 & 34.60 \\
Doctoral Universities: Highest Research & 86 & 25.22 & 59.82 \\
Doctoral Universities: Moderate Research & 36 & 10.56 & 70.38 \\
Master's Colleges \& Universities: Large & 73 & 21.41 & 91.79 \\
Master's Colleges \& Universities: Medium & 20 & 5.87 & 97.65 \\
Master's Colleges \& Universities: Small & 8 & 2.35 & 100.00 \\
\hline Total & $\mathbf{3 4 1}$ & & $\mathbf{1 0 0 . 0 0}$
\end{tabular}


Table 4: Type of Institution of Higher Learning

\begin{tabular}{llll}
\hline & Freq. & Percent & Cum. \\
\hline Private 4 Year & 118 & 34.60 & 34.60 \\
Public 2 Year & 4 & 1.17 & 35.78 \\
Public 4 Year & 219 & 64.22 & 100.00 \\
\hline Total & $\mathbf{3 4 1}$ & $\mathbf{1 0 0 . 0 0}$ & $\mathbf{1 0 0 . 0 0}$
\end{tabular}

Table 5: Office of Participants

\begin{tabular}{llll}
\hline & Freq. & Percent & Cum. \\
\hline City Council Member & 123 & 36.28 & 36.28 \\
City Manager & 23 & 6.78 & 43.07 \\
Mayor & 25 & 7.37 & 50.44 \\
City Official (undefined) & 50 & 14.75 & 65.19 \\
University Administrator & 118 & 6.78 & 100.00 \\
\hline Total & $\mathbf{3 3 9}$ & $\mathbf{1 0 0 . 0 0}$ &
\end{tabular}

Table 6: Campus Setting

\begin{tabular}{llll}
\hline & Freq. & Percent & Cum. \\
\hline City: Large & 65 & 19.06 & 19.06 \\
City: Midsize & 52 & 15.25 & 34.31 \\
City: Small & 75 & 21.99 & 56.30 \\
Rural: Fringe & 1 & 0.29 & 56.60 \\
Rural: Remote & 3 & 0.88 & 57.48 \\
Suburb: Large & 71 & 20.82 & 78.30 \\
Suburb: Midsize & 22 & 6.45 & 84.75 \\
Suburb: Small & 6 & 1.76 & 86.51 \\
Town: Distant & 27 & 7.92 & 94.43 \\
Town: Fringe & 12 & 3.52 & 97.95 \\
Town: Remote & 7 & 2.05 & 100.00 \\
\hline Total & $\mathbf{3 4 1}$ & $\mathbf{1 0 0 . 0 0}$ &
\end{tabular}




\section{Other Sources of Data}

Table 7 describes the data sources. For this dissertation, there are three data sources: the survey data, data from the Integrated Postsecondary Education Data System (IPEDS), and data from the United States Census. For all universities, IPEDS data provided demographic, enrollment, and financial information. IPEDS also helped to standardize the size of the municipality where the university resides. Further, IPEDs provided information that standardized the classification of the university, as defined by the Carnegie Foundation. For all municipalities, Census data was derived using the American Community Survey (ACS) 2016 5-year estimate, which was the last year available. The information derived from the ACS came from S0601, Selected Characteristics of the Total and Native Populations in The United States and DP03, Selected Economic Characteristics.

Table 7: Data Sources

\begin{tabular}{|c|c|}
\hline Survey Data & $\begin{array}{l}\text { Survey sent out to } 150 \text { university engagement offices and } \\
\text { the city council, mayor, and city manager (when } \\
\text { applicable) of the town in which the university resides. }\end{array}$ \\
\hline $\begin{array}{l}\text { Integrated } \\
\text { Postsecondary } \\
\text { Education Data System } \\
\text { (IPEDS) }\end{array}$ & $\begin{array}{l}\text { Student Population, } \% \text { White, } \% \text { Black, } \% \text { Asian, } \% \text { Hispanic, } \\
\% \text { of students that are full time, } \% \text { of students that are } \\
\text { under } 24, \% \text { of Students that are from the state, arrests on } \\
\text { campus, crime on campus, grant funding from local/state } \\
\text { government, Carnegie classification, town classification }\end{array}$ \\
\hline Census Data & $\begin{array}{l}\text { Total Population, \%white, \%black, \%asian, \%hispanic, } \\
\text { median age, unemployment rate, poverty rate, median } \\
\text { household income, \% of population that have above a } \\
\text { bachelor's degree. }\end{array}$ \\
\hline
\end{tabular}


The data collected for this study was gathered using electronic methods for dispersing the survey. Qualtrics was used for both phase 1 and phase 2 to create 150 independent links. Each link corresponded to a survey that was tailored to each specific university/municipal pair. Links were emailed to the publicly available emails of community engagement offices, city councils, mayors, and city managers. Not all emails were publicly available. In such cases, efforts were made to call the municipality or university to obtain the email address. If the email address for a particular person was not given, they were omitted from the sample. The emails were sent three times over the span of a month starting in January 2018 for phase 1 and March 2018 in Phase 2.

\section{Unit of Analysis}

The unit of analysis for both the qualitative and quantitative method is the official, either of the university or the municipality. This study examines perceptions of engagement, and as such it necessarily examines the individual perspective on activities conducted at the organizational level. 


\section{Chapter 6: Perspectives on Engagement}

This chapter addresses the first research question, which seeks to examine the variation in understanding of engagement as a concept and practice vary among university and municipality officials. Additionally, it explores the main factors that enable or hinder engagement and how they differ for universities and municipalities.

Both university administrators and municipal leaders were asked to define engagement within the context of a university. The analysis showed that there were 8 nodes pertaining to engagement. Definitions pertaining to the node of community were the most numerous, comprising $26 \%$ of the sample. Of note, $12 \%$ or 24 respondents did not have a definition for engagement as much as an understanding that it was not happening. The smallest category of the group was "unsure," representing uncertainty about how universities and municipalities engage. The nodes were constructed using 175 survey respondents and 29 interviews. Table 8 displays the nodes of engagement.

The interviews and open-ended questions from the survey were analyzed using a “hybrid approach" (Fereday \& Muir-Cochrane 2006). The hybrid approach combines both deductive and inductive coding. Deductive coding allows the researcher to code according to pre-existing literature, while inductive coding allows the research to develop new nodes from the data. In this particular case, the nodes Classic, Economic Development, and Students were taken from the Classroom, Laboratory, and Locale framework detailed in previous chapters. The other nodes-Not Engaged, Workforce Development, Community, Unsure, and University—-were derived from the data. Keeping with statements of confidentiality, participants are identified by their specific office, gender, and geographic location. Not all respondents provided demographic 
information, in such cases respondents are identified by their role as a local government official or university administrator.

Table 8: Nodes of Engagement

\begin{tabular}{lll}
\hline & Freq. & Percent \\
\hline Economic Development & 38 & 19 \\
Classic & 42 & 21 \\
Students & 18 & 09 \\
Not Engaged & 24 & 12 \\
Workforce Development & 12 & 06 \\
Community & 54 & 26 \\
Unsure & 4 & 02 \\
University & 12 & 06 \\
\hline Total & 204 &
\end{tabular}

\section{Economic Development}

As previously discussed, economic development is an important aspect of collaboration between municipalities and universities. Economic development was reported, too, in the definition of engagement. As expected, when asked to define economic development, university administrators and municipal officials had diverging viewpoints. University officials were more apt to link economic development to university-related expansion and providing local business with student-customers. In contrast, yet not surprisingly, the municipality was more likely to view the economic development through the lens of town needs.

For municipalities and communities, universities have been thought of as a way to attract educated people, companies, and ultimately create a vibrant community. Richard Florida's term "Creative Class" is a prime example of this type of thinking regarding economic development. Florida (2002) posited that universities can help communities attract more professionals. Ultimately, however, the "only indicator that 
matters is the strength of a city's creative economy, measured by the number of businesses and employees, and by the wealth they produce" (Montgomery, 2005, p.339). This is exactly the sentiment expressed by a majority of municipal officials. The question of town-gown engagement really boiled down to how the university and municipality could work together to attract and create businesses, keep students in the town and as part of the local workforce, and create an environment that promotes the town as a desirable place to live and work.

Examples of economic development include:

"Engagement can be defined as helping to bring in other employers to improve wages and create affordable housing. " Local Government Official

"Working together to make the downtown and student neighborhoods world class and appealing." Mayor, Male, Northeast

The interviews also yielded interesting aspects of economic partnerships. Of interest is both the realization that the university is an enormous contributor to the local economy, and that their contribution is much more than money.

"If [the university] left our town, it would be like steel leaving Pittsburgh. It would be devastating." City Council Member, male, Mid-Atlantic city

Time and again, respondents discussed the idea of indirect contributions from the university. Engagement, in that vein, was conceived of as a way to create a place where people want to live and work. Moreover, the university was a place that attracted visitors and helped generate income for local business. The quote below best describes this idea. It is from a municipal leader from a small town in the Southwest. Her town is small, but within a 2 to 3-hour drive from a major city. She said that within her state, her town was synonymous with the university's sports team. This point was underscored by the 
visitors to her town. Whenever she would invite people to come to her town for meetings, they would want to wait until the sport team was playing. That team attracted visitors, filled hotel rooms, and gave the town an identity. This sentiment was echoed throughout the interviews with municipal leaders. They saw the university as an economic asset, even if the university itself was not directly contributing financial resources. In turn, many municipal leaders reported working with the universities when they had events, promoting university expansion, and being generally willing to assist however they could. Engagement, within this context, can then be defined as a mutually beneficial exchange that financially contributes to the well-being of both the town and the university.

"Engagement with the university is economic, but is the relationship with the university mainly economic? No. There are many factors. Many things are intangible. They bring a culturally diverse community... it's not just the money; it's all the other things that the university brings to the town. They bring an attitude of vitality. And sports. The sports are probably the most important thing [laughing]." Mayor, female, Southwest

During the analysis of this theme, there were various other threads that became apparent. These were considered secondary themes, but nonetheless important. The following are subcategories that are associated with economic development theme: local business patronage, taxes, economic decision-making, services provided and participation in events.

Examples of local business patronage:

"[The university should] permit meal cards of students to be used in local restaurants, encouraging students and faculty to patronize [municipal] businesses. " City Council Member, Male, Northeast

"Involving [the university] in local activities to include partnerships with nonprofits, business, etc." City Council Member, Female, Southwest 
Examples of taxes:

"[The university should] permit the [municipality] to collect the amusement tax it's entitled to from campus entertainment events and sports activities open to and promoted to the public on ticket admissions sold to non-students. They need to contribute economically to [the municipality] " City Council Member, Male, Northeast

"Engagement includes financial contributions to [municipality] and community events" City Council Member, Male, Northeast

"It would be helpful if they pay taxes for the services they used." Local Government Official

Examples of economic decision-making:

"[The municipality should] bring the University, the City, businesses, nonprofits and the larger community into the decision-making process." University Administrator, Male, Midwest

"Consideration for the town in University planning and development, including economic development" City Council Member, Female, Northeast

"Willingness to work with the City collaboratively to solve problems and pursue opportunities” Mayor, Male, South

Examples of economic collaboration process:

"Regular collaborative meetings with key staff; generation of projects to implement economic strategies. " City Manager, Male, West

"Active participation by university staff and leaders in community events, decision making, and initiatives. "University Administrator, Female, Southwest

"Engagement means being actually being engaged and working together on all possible projects financially and capital projects" City Council Member, Female, Midwest

"Engagement is working together of economic development and cultural assets of the community" Mayor, Female, Midwest

Examples of services provided: 
"Improving the quality of life for residents and business through services and programs dedicated to community development and the promotion of healthy communities, people, and environments." University Administrator, Female, South

Examples of participation in events:

"The University is an active participant in community events both financially and in physical presence at events. " City Council Member, Male, West

[The University and Municipality] work together in promoting public relations, city events and activities. Also, they should provide financial participation" Local Government Official

\section{Classic}

"Classic," or the Carnegie definition of engagement, namely "Collaboration between institutions of higher education and their larger communities for the mutually beneficial exchange of knowledge and resources in a context of partnership and reciprocity" (Carnegie Foundation, 2005) was a popular node, mentioned by $21 \%$ of survey respondents and interviewees.

This definition of engagement was widely favored by university officials, that is neither unexpected nor out of step with how engagement is generally conceived of by university administrators. After all, the sample of universities includes only those designed by the Carnegie Foundation as "community engaged." Thus, it stands to reason that university engagement offices are amply aware of the definition. Moreover, the definition was given at the onset of the survey to ensure a uniformity of meaning across respondents. All that notwithstanding, there were some interesting findings regarding the definition of engagement. 
The nodes were coded as "classic" if it emphasized working together for mutually beneficial partnerships. Within that view, engagement can be defined as mutually or reciprocally beneficial partnerships. Examples of classic responses include:

"Engagement between the university and members outside the university for mutually beneficial, reciprocal, and asset-based partnerships. " University Administrator

"Reciprocal and sustained partnerships that simultaneously meet community needs, enhance academic work, and develop leaders who are empowered to enact social and environmental change." City Council Member, Female, Northeast

"We strive to connect university resources with community priorities and initiatives, resulting in more engaged faculty and students; greater prosperity for local residents, businesses, and organizations; and improved quality of life for all." University Administrator

There were again secondary themes found during the analysis. Although they are secondary themes, they helped to confirm some measurements used in the survey explored in other chapters. The following are subcategories that are associated with the "classic" theme within the sample: meaningful, shared vision, and stakeholders.

Meaningful:

"Engagement that creates meaningful connections that are mutually beneficial for both the university and the community." University Administrator, Female, South

"Active participation in community events and projects that will have direct and indirect benefits to the health of the community and University." University Administrator, Female, Midwest

"Collaborative efforts - not tied to specific classes or student projects - but meaningfully improve the local social, economic, environmental conditions." City Council Member, Female, West 
Shared Vision:

"Shared vision with clear objectives that are mutually beneficial" City Council Member, Female, Midwest

"City/University leaders working together in a transparent environment" City Manager, Male, Midwest

"Shared \& Collaborative communications, programming and practical services \& resources" City Manager, Female, West

Stakeholders:

"Community engagement is a collaborative process where stakeholders from the community and the university define an issue to be address and work to implement a solution." University Administrator, Male, Midwest

"Working collaboratively with community partners on mutually-beneficial projects” University Administrator, Male, Midwest

"Identifying and implementing plans to develop shared value or resolved shared conflicts." Mayor, Male, Northwest

"Partnerships for the sake of mutual benefit based on shared resources, trust, and reciprocity." University Administrator, Male, South

The interviews also yielded interesting aspects of the classic definition of community engagement. Even though attitudes about university vary, the sentiment of working together remained. Among the interesting findings is the willingness to work together, if not perhaps the knowledge of how to do so.

“We want to work with the city. We do. I think sometimes we don't know how, or on what, but whatever we do we try very hard to loop them in and work side by side with them." University Official, Female, South.

\section{Students}

The last of the deductive coding was the category "students." The students theme generated $9 \%$ of responses in the sample. Again, not surprisingly, university officials 
were the most predominately featured within this node. This node is interesting in that it expresses a lot of the similar aspects of both classic and economic development, but it does so with students as the primary benefactor and/or contributor. It acts almost as a counterpoint to municipal economic development, revealing the fundamental aspects of engagement that resonate with universities.

"We define community engagement broadly - through service learning, community based work-study, internships, research opportunities and so on." University Administrator, Female, Northeast

"Community engagement is a type of public engagement, one with partnerships and students at its core. In community-engaged work, community partners are equal players, and projects are created, developed and carried out collaboratively with students from the start." University Administrator, Male, Northeast

"Engagement provides for the undertaking of academic pursuits, in a mutually beneficial way, within and with the individuals that make up our community populations" University Administrator, Female, West

"Community engagement supports and assists students in developing and fostering meaningful connections to the University Community and [the municipal] community through experiential-learning opportunities." University Administrator, Female, Southwest

The analysis of this theme revealed two threads. One that held the student as the primary benefactor of engagement, and the other dealt with the pedagogy of engagement. These were considered secondary themes; however, they help to better understand how engagement is conceptualized, particularly within the university.

\section{Pedagogy:}

"Partnership for learning, for collaboration, for impact. reciprocity, ethical action, and respect for multiple perspectives and forms of knowledge" University Administrator 
"Giving students experiential learning and civic engagement” University Administrator, Female, MidAtlantic

"Proving [students with] real world experiences while benefiting the external community that allows for service learning, volunteerism, community-based research, social activism, civic activism, and research application" University Administrator, Female, Northeast

“[The university's] main stakeholder is our students. How we engage needs to begin and end with them. There are ways to create win-win situations and we try to find those and work with it." University Administrator, Female, West

\section{Community}

The qualitative analysis also yielded other nodes than the ones expected from the literature. The first of these nodes is "community." Community was coded for responses that impacted the community first. The community being that of the municipality, and not necessarily the student body. Aspects of community can be found within economic development, classic, and students; however, these findings pertain to the community first and foremost. The primary examples of the community as an engagement node and as the best representation of a definition of engagement based on community are:

"Working with residents around the campus to help mutually benefit neighbors and the college dedicating time and resources to help address community issues and concerns" City Council Member, Male, South

"Finding ways for the university and local government to work on projects that affect the community" City Council Member, Male, Midwest

"Engagement is working together in effort to integrate the university into the community” Mayor, Male, Northeast

During the analysis of this theme, there were several threads. These secondary themes were Community Decision Making, Diversity of Opinions, Institutional Commitment, Civic Engagement and Shared Vision. These themes help situate this analysis within the larger context of community engagement. 
Community decision making

"Community members involved in university decisions and attending campus events. University Administrator, Female, Midwest

"Working with the town on off campus student behavior." City Council Member, Female, Northeast

"Working with the community to address student behavior and university expansion." Local Government Official

Diversity of opinions

“The university would welcome community opinions" University Administrator

"Understanding and asking for the desired needs and expectations of people who reside near the university. " City Council Member, Female, Northwest

"Actively seeking out opinions from a variety of sources and then making sure that the university's action actually is built on response to those community questions, concerns, not preconceived ideas." City Council Member, Female, Mid-Atlantic

Institutional Commitment

"Applying expertise to solve community problems." City Council Member, Male, South

"Using [the university's] expertise and students to help overcome the great need for and use of a growing Food Panty; overcoming poverty; "University Administrator

"There are many types of community engagement from individual professors involved in local project contributing expertise." University Administrator

Promoting Civic Engagement

"Community engagement is the development of active citizen habits among students." University Administrator, Female, Northwest

"Volunteerism throughout the city, not just on campus" City Council Member, Female, Northwest 
Shared Vision

"Engagement is working alongside partners in the community to achieve a shared goal” University Administrator, Female, South

"Shared vision... shared goals... we ALL are COMMUNITY” City Council Member, Male, South

"Engagement means viewing each other as partners in solving our key challenges of our community like affordability and mobility, for instance." Local Government Official, Female, South

One of the most informative responses on this issue pertains to a new development that a university was building at the edge of their campus. Because the building was at the edge of campus, the city was not asked for permits or input.

However, around two-thousand students were going to be housed in that building and the municipality was responsible for the externalities generated by those students. The community was particularly concerned about increased traffic.

“It's like they don't think sometimes. We can't afford to make bigger roads because they wanted to more housing. That's 2000 more cars on the road in that area! Our town has 3-5 million dollars in planned, unfunded projects. We don't have funds for the projects we plan, much less the ones we don't. As the university continues to grow, it's the community that is pushed out. It's the community that's losing. " City Council Member, Female, Southwest

\section{Workforce Development}

Workforce development did not get as much fanfare as other aspects of engagement, but it was at the forefront of the minds of many interviewees and is an important aspect of collaboration between municipalities and universities. The survey results yielded a theme around Interns. That seemed to be how engagement was 
conceived of when addressing workforce development. Below are two examples of how interns manifested in the definition of engagement:

“Engagement happens by providing interns.” Local Government Official

"Shared human resources and expertise, including interns." Local Government Official

However, work force development was front and center for interviewees.

Particularly in smaller municipalities, the university was seen as a place that trained the local workforce and provided enough reasons for them to stay in the area after they had graduated.

"We really do rely on the university for employees. Just here in City Hall, almost all of us got our degrees from [university]. We're proud of that, and to be honest I'm not sure we could attract the caliber of employee that we do if the university wasn't there. We've created a pipeline, at the hospital, schools, to get them in while their students and retain them when they graduate." City Council Member, Male, Southwest

\section{University}

Universities tend to think of community engagement in terms of students and the classic definition. It was interesting to note, however, that there was a strand of respondents that answered the question of engagement in a university-centric way. That is, as a benefit to the university first. Engagement that benefitted student life or university rankings.

"Strong community engagement benefits the University" University Administrator, Female, South 
"We do not have an official definition, but Civic Engagement refers to curricular and co-curricular activities." University Administrator, Female, MidAtlantic

\section{Not Engaged}

While much of this section deals with various definitions of engagement, there was one thread of the engagement that was surprising. As shown in Table $8,12 \%$ of respondents define engagement as nonexistent with the local government. It seems interesting that none of the interviews I conducted yielded this thread, but when asked on a survey, the sentiment that the local government and the university were not aligned really came into focus. Other chapters will discuss the mismatch in perception of engagement from a quantitative angle, but below are some responses along that theme.

Engaged, just not with the local government:

"Much of our community engagement is with private partners and regional nonprofits rather than with local government." University Administrator, Female, Northwest

"Engagement is poor to non-existent. The town doesn't seem to know what is going on here." University Administrator, Male, South

"We also can work together to enhance what the university wants to do in ways that bolster what the city wants to do. Problem is we are not partners." City Council Member, Female, South

Not engaged with the university:

"Parking is a big issue the university seems to ignore around the perimeter of campus." City Council Member

"It would be a step forward if we talked at all." City Council Member, Male, Southwest

"There is very little between Town/Gown engagement, it is habitually conflicted." City Council Member, Male, Northeast

"University is more engaged with [a nearby larger city] rather than the Town." City Manager, Male, Northeast 


\section{Collaborative Capacity}

Lastly, it was important to see the extent to which aspects of collaborative capacity play a part in town-gown relationships. For example, many of the municipal leaders insisted that while they routinely set policies and laws that can impact the university, they did not do "spot legislation." That is, they do not make laws on account of what the university wants. It did not seem from the interviews that law-making was an important aspect of town/gown relations.

"We take them into account, sure, but we make the laws. Recently we passed a party ordinance and many students were upset. But we need to do what is right for all the residents." City Council, Female, West

For college towns, in particular, there seemed to be a consensus that both the university and the local government had the technical and administrative capacity to get work done. For college towns, however, the dependence on the university colors the partnership. The partnerships described seemed to be for the benefit of the university and its students. The benefit to the town, however, was more of a positive externality rather than a concerted effort to attract businesses.

"We needed money for [local project]. It helped [the university] too, but it was something the town needed. We went to the university and together we went to the governor and got them to give us $\$ 8 M$ for the project." City Council, Male, Southwest

"The university is a partner for our town. They bought the post office, so our town could have one. We didn't have a post office before. They brought us a Barnes and 
Noble and a movie theater. Our town wouldn't be the same if they left. We'd lose a lot." City Council Member, Female, MidAtlantic Town

\section{Communication}

One of the interesting findings was the divide between university administrators and local government officials regarding communication. On the one hand, many university administrators will say that they do not need meetings to get things done. They get as much done in the faculty club or out in a social setting as they do in a meeting. On the other hand, without exception, the city officials spoke about the need for formalized procedures to work together. They said they needed to understand whom they should approach if they needed something from the university. More than that, it was a question of institutional memory and institutionalized roles. Many mayors felt that once a person, on either side left, it took months or longer to figure out whom would take on the role that was left vacant.

"I've made more deals in the faculty club and on the golf course than I have ever have in meetings or through email. People today don't realize how useless emails are for hatching an idea or cementing the details. " University Official, Male, South

"I don't understand why [the university] doesn't institutionalize the folks who have a say in town-gown issues. It drives me crazy. Things are kind of just done at an ad hoc basis. I mean, I'm complaining, but I will retire in two years and with me so will the institutional memory of working with [the university]. When I leave, I don't know if the relationship will be the same. We need to put town-gown in the job description, so it is the same position that handles it no matter who is in it." City Manager, Male, South 


\section{Initiation of Collaboration}

Another aim of this chapter is to explore the types of collaborations, opportunities and obstacles to town and gown partnerships. To achieve these aims, questions were asked in the survey pertaining to types of collaboration either the university and the local government would initiate. Additionally, participants were queried about the types of partnerships in which universities and municipalities engage. Lastly, the survey asked participants to select the main obstacles to forming a partnership with the university and the main obstacles to forming a partnership with the local government.

Table 9: University Collaboration

\begin{tabular}{llllll}
\hline $\begin{array}{l}\text { Collaboration } \\
\text { University is Most } \\
\text { likely to Initiate: }\end{array}$ & Freq. & Percent & $\begin{array}{l}\text { Collaboration } \\
\text { University is Least } \\
\text { likely to Initiate: }\end{array}$ & Freq. & Percent \\
\hline $\begin{array}{l}\text { Economic } \\
\text { Development }\end{array}$ & 53 & 21.63 & $\begin{array}{l}\text { Economic } \\
\text { Development }\end{array}$ & 127 & 54.27 \\
$\begin{array}{l}\text { Other } \\
\text { Research }\end{array}$ & 24 & 9.80 & Other & 19 & 8.12 \\
Student Learning & 23 & 9.39 & Research & 67 & 28.63 \\
\hline Total & 145 & 59.18 & Student Learning & 21 & 8.97 \\
\hline & 245 & & Total & 234 &
\end{tabular}

Table 9 shows collaborations that universities are most and least likely to initiate. Unsurprisingly, student learning was the kind of collaboration that universities were most likely to engage with municipalities on. Almost $60 \%$ of those that responded believe that student learning was the most important collaboration to the university. This finding really comes through when thinking about the definitions of engagement. Student learning was at the forefront of engagement practices because, after all, students are the main stakeholder of the university. As university's main stakeholders, students 
are of primary concern to universities, it naturally follows that collaborations would also include students. Research is widely considered a strength that the university has in its wheelhouse, but it was not among the commonly chosen options for collaboration.

Table 10: Municipal Collaboration

\begin{tabular}{|c|c|c|c|c|c|}
\hline $\begin{array}{l}\text { Collaboration } \\
\text { Municipality is Most } \\
\text { likely to Initiate: }\end{array}$ & Freq. & Percent & $\begin{array}{l}\text { Collaboration } \\
\text { Municipality is Least } \\
\text { likely to Initiate: }\end{array}$ & Freq. & Percent \\
\hline $\begin{array}{l}\text { Economic } \\
\text { Development }\end{array}$ & 142 & 58.68 & Economic Development & 32 & 13.79 \\
\hline Other & 10 & 4.13 & Other & 7 & 3.02 \\
\hline Research & 21 & 8.68 & Research & 123 & 53.02 \\
\hline Student Learning & 69 & 28.51 & Student Learning & 70 & 30.17 \\
\hline Total & 242 & & Total & 232 & \\
\hline
\end{tabular}

Table 10 again predictably observes that economic development is far and away the most likely type of collaboration in which the local government engages. Economic development accounted for $59 \%$ of responses. This also follows the pattern gleaned from the definition of engagement that tended to skew towards economic development, particularly among municipal officials. It is interesting to note that student learning was the second most common answer. This suggests that even on a macro level there is some overlap in priorities between the university and the local government in terms of collaboration.

Table 11 displays the types of partnerships local governments are most likely to initiate. It demonstrates potential points of collaboration with the university. As expected, K-12 education received $29 \%$ of the responses. It is noteworthy that $21 \%$ of respondents chose that the university was a gathering place for city events, giving credence to the notion that universities are a central part of the town's identity. Although 
none of the interviews described healthcare as a primary function of the university, $12 \%$ of respondents chose public health as the partnership that local governments were most likely to initiate. As more universities expand into academic medical centers, this will increasingly become an area of town/gown collaboration.

Table 11: Partnerships that Local Government Initiate

\begin{tabular}{lll}
\hline $\begin{array}{l}\text { Partnerships local government } \\
\text { most likely to initiate? }\end{array}$ & Freq. & Percent
\end{tabular}

\begin{tabular}{lll}
\hline Climate Change & 16 & 6.78 \\
$\begin{array}{l}\text { Continuing education for city } \\
\text { employees }\end{array}$ & 18 & 7.63 \\
Gathering place for city events & 50 & 21.19 \\
Income Inequality & 12 & 5.08 \\
K-12 Education & 68 & 28.81 \\
Other & 43 & 18.22 \\
Public Health & 29 & 12.29 \\
\hline Total & 236 & 100.00
\end{tabular}

Interestingly, the answers that garnered the least responses pertained to wicked problems. Wicked problems are problems that cannot be solved easily or by one entity. Income inequality and climate change are precisely the types of issues that researchers and government officials could work on for their mutual good, but together both answers generated a little more than $11 \%$ of all responses. It might be that these issues are simply not currently a priority for either party. Either way, as both issues continue to dominate political and social discussions, there seems to be an area of growth as it pertains to these issues. 
Table 12: Types of Town/Gown Partnership

\begin{tabular}{llll} 
Mean & Mean & Mean & \\
Score by & Score by & Score by \\
UA & CCM & Mayors & Overall \\
\hline
\end{tabular}

The local government uses University resources (e.g., researchers, students) to tackle issues related to climate change $\begin{array}{llll}2.95 & 2.50 & \mathbf{2 . 1 3} & 2.48\end{array}$ The local government uses University resources (e.g., researchers, students) to address issues related to income inequality (e.g., housing issues) 2.33

2.75

The local government uses University resources (e.g., researchers, students) to address issues related to public health (e.g., screening programs, student-run clinics)

$\begin{array}{llll}3.14 & 2.83 & 3.13 & 2.85\end{array}$

The local government uses University resources (e.g., researchers, students) to address issues related to public education? The local government uses the University space as a gathering place for city events The local government uses University programs for continuing education for city employees

The local government actively works with the University to help students with housing issues (e.g., affordable student housing, homelessness)

The local government actively works with the University to help students facing struggling with food insecurity

$\begin{array}{llll}3.10 & 2.67 & 3.13 & 2.74\end{array}$

$\begin{array}{llll}2.57 & 3.16 & 2.38 & 2.44\end{array}$

Students are treated as constituents by the local government

$\begin{array}{llll}\mathbf{2 . 1 4} & 1.83 & \mathbf{2 . 1 3} & 2.22 \\ 2.29 & 2.17 & 2.63 & 2.23 \\ & & & \\ 2.33 & \mathbf{1 . 6 7} & 2.38 & \mathbf{2 . 0 7} \\ 2.67 & \mathbf{3 . 1 7} & \mathbf{3 . 2 5} & \mathbf{2 . 8 8}\end{array}$

Table 12 shows the mean scores of different types of collaborations by municipal official and university administrator. The overall score takes everyone into account, including city managers and those who did not choose to identify their office. 
For the university administrators, the highest mean score corresponded to using university resources to address issues related to public health (3.14). As with Table 11, this finding supports the notion that public health is fertile ground for local government and university collaboration. City officials overall (2.88), and City Council members in particular (3.17), strongly believed that students are treated as constituents by the local government. Ironically, the lowest reported score by city council members (1.83) and overall (1.07) was that the local government actively works with the university to help students struggling with food insecurity (1.83). That dissonance is startling considering that food insecurity is a problem facing $36 \%$ of student surveyed in a recent study (Goldrick-Rab et al, 2018). As a pressing issue for college students, there is ample opportunity for local governments and universities to work together to help students struggling to eat.

\section{Obstacles to Collaboration}

This section details the obstacles to partnerships between the university and the local government. As Table 13 shows, there are unexpected obstacles to initiation a partnership with the university. The majority of respondents cited unclear objectives to collaboration (23\%). While the literature does support the notion that clear objectives are necessary for collaboration, it is astounding that roughly a quarter of respondents did believe they had clear shared goals with the other party. Unclear objectives were followed closely by university bureaucracy $(21 \%)$ as a main obstacle to initiating a partnership with the university. This was a surprising finding considering how important formalized procedures seemed to be for local government officials. Furthermore, as was evident with the interview data, communication also seemed to play a role. Poor 
communication, unclear contact persons within the local government, and unclear contact persons within the university together accounted for $20.4 \%$ of the responses. This finding goes hand in hand with the notion that there are unclear objectives to working together. It is difficult to ascertain a clear goal within a partnership, if one is unclear with whom the partnership is being forged.

Table 13: Main obstacle to initiating a partnership with the University

\begin{tabular}{|c|c|c|}
\hline & Freq. & Percent \\
\hline $\begin{array}{l}\text { Lack of interest by } \\
\text { university }\end{array}$ & 17 & 7.56 \\
\hline $\begin{array}{l}\text { Lack of interest by local } \\
\text { government }\end{array}$ & 11 & 4.89 \\
\hline $\begin{array}{l}\text { Local government } \\
\text { bureaucracy }\end{array}$ & 2 & 0.89 \\
\hline Other & 39 & 17.33 \\
\hline Poor Communication & 22 & 9.78 \\
\hline $\begin{array}{l}\text { Poor experience in past } \\
\text { collaborations }\end{array}$ & 9 & 4.00 \\
\hline $\begin{array}{l}\text { Unclear objectives of } \\
\text { collaborations }\end{array}$ & 52 & 23.11 \\
\hline $\begin{array}{l}\text { Unclear university contact } \\
\text { person }\end{array}$ & 10 & 4.44 \\
\hline Unclear municipal contact & 15 & 6.22 \\
\hline University bureaucracy & 48 & 21.33 \\
\hline
\end{tabular}

In a similar vein, Table 14 shows the obstacles to initiating a partnership with the local government. In line with the findings in Table 13, the majority of respondents cited that it was unclear how local government would collaborate with the university $(26 \%)$. Of note, while the survey respondents did seem to believe that the local government was interested in partnering with the university, $16 \%$ of them cited lack of interest from the 
university. These findings show that a little less than half of respondents either could not conceive of how to partner with the university or thought the university had no interest in doing so. Considering that sample of universities within the study, this is a surprising finding. The assumption was made that these universities were interested in engaging and being engaged by the community, yet it would seem not their local government. Nevertheless, it does indicate a clear window of growth between the two parties.

Also, of note, university bureaucracy was once again listed as main obstacle to initiating partnerships with the local government (12.5\%). Communication continued to be a smaller, yet noteworthy obstacle in town and gown partnerships. Both these findings are consistent with interviews that expressed uncertainty about whom to contact regarding particular questions.

Table 14: Main obstacle to initiating a partnership with the Local Government

\begin{tabular}{lrr} 
& Freq. & Percent \\
\hline Lack of interest by University & 34 & 16.35 \\
$\begin{array}{l}\text { Lack of interest by local } \\
\text { government }\end{array}$ & 3 & 1.44 \\
Local Government bureaucracy & 6 & 2.88 \\
Other & 37 & 17.79 \\
$\begin{array}{l}\text { Poor Communication } \\
\text { Poor experience in past }\end{array}$ & 25 & 12.02 \\
collaborations & 9 & 4.33 \\
Unclear on how local & & $\mathbf{2 6 . 4 4}$ \\
government would collaborate & 55 & \\
with University & & 6.25 \\
Unclear who is University Contact & 13 & 12.50 \\
University bureaucracy & 26 & 100.00 \\
\hline Total & &
\end{tabular}




\section{Discussion}

It is clear from the findings that engagement can mean many things, ranging from economic development to student research. The qualitative research did yield some results that can contribute to the extant literature of town and gown relations. Namely, the variety of ways engagement is conceptualized. The many definitions of engagement can, in future research, help inform and create a typology of town/gown engagement.

\section{Engagement: Economic and Meaningful}

Engagement as an economic development strategy is widely discussed in the academic literature (O’Mara, 2012; Burning el al, 2006; Martin and Smith, 2005) and in the findings. While there are different ways of achieving economic development, there were a number of responses targeting the lack of taxes paid by the university. This finding suggests that ideas such as PILOTS might be worth exploring within these university-municipality pairs. Regardless of how that might go over at the university, it may open the door to other aspects discussed, such as providing services to the community, and facilitating student purchases at shops owned by local vendors.

Whatever the outcome of those initiatives, it is important to note the trend that would most likely lead to positive outcomes, economic collaboration. For example, Amazon recently put out a bid for their second headquarters. The criteria for choosing a given location included the ability to attract and retain talent. Colleges played a large role in the whittling down of the locations (Kerr, 2018). Indeed, many municipalities that bid on the headquarters touted the talent and research capacities of their universities. The process is illustrative of working together towards the good of both the university 
and municipalities. Landing an Amazon headquarters would benefit students, as it would give them employment options, and it would benefit the municipality as it would increase tax revenue. Working together to have a common vision with regard to economic development helps drive business, attract students and faculty, and creates a vibrant community where no party feels that the other is pushing them out (Addie et al., 2011).

Aside from economic development, the Carnegie Foundations' definition of engagement was also widely used. It was particularly interesting to find meaningful as a sub-node to engagement. Earlier iterations of the survey instrument tried to measure meaningfulness in engagement, but the feedback from the respondents was that measuring whether something was mutually beneficial and meaningful amounted to the same thing, and the added length dissuaded participants from taking the survey. Engagement can be meaningful, in that it is symbolic, or it can be meaningful in that it has a direct and lasting impact on the local community. Either way, for engagement to be perceived as meaningful it needs to substantively matter, it cannot simply be lip service.

For engagement to have meaningful impact, it must include the other themes described under classic, stakeholders and shared vision. Part of the interesting findings was a recognition that the local government should be a main stakeholder for the university, and vice versa. It seems fairly obvious, but it is something that is clearly either not currently happening or is happening artificiality. This is particularly evident given the obstacles to collaboration. If the local government and university do not consider themselves stakeholders, it is easy to understand how so many respondents could not see a clear vision towards a partnership. It is only by having meaningful conversations that a 
shared vision can be created. Thus, the Carnegie Foundation's definition of engagement might well be altered to include stakeholder participation to create a shared vision.

\section{Engagement as Ego-centric or Non-Existent}

Two nodes of engagement were ego-centric, that is, primarily focused on either the university or the community. It is understandable how this might occur. Engagement ought to serve those engaged. It is possible that the ego-centric responses were merely reflecting the fact that in order to engage their party must also benefit. This view is particularly noteworthy when coupled with the combined $8 \%$ of respondents that expressed having a poor prior collaboration. In terms of the community-focused engagement, it was striking to note the sense of intrusion. Particularly in the interviews, there was an impression that the town was being pushed out on account of the university. Moreover, the university was not doing enough to help the community with problems that the university's students created, such as parking. There was also a sense that the universities were not being good neighbors, and that resentment might well be what fueled the community-centric responses.

The other node denoted that engagement simply did not exist. This is unexpected because as previously noted, the group of universities selected in the study is "community-engaged." One can think of a variety of reasons to possibly explain this finding. First, a dozen or so universities in this study experienced a change in leadership at the community engagement office. Two universities had merged the offices since they filed the application for engagement. While attempting to locate contact information for a director of community engagement, I spoke with a university administrator that said he was unaware about the designation because it had been a project under the last person to 
hold his position. While choosing this list was advisable to understand how this process works under the best circumstances, the findings revealed that even among this list of universities engagement was by and large lip service.

\section{Partnerships}

The survey results regarding partnerships show that local governments tended to favor initiating partnerships in K-12 education. This is consistent with the extant literature confirming the existence of strong relationships between K-12 educational systems and universities, particularly around Science, Technology, and Engineering and Mathematics (Willams and Lee, 2017; Billig, 2000). While such partnerships are not new, there are a number of complex ways universities and local governments engage with in regard to education. For example, the University of Texas just announced earlier this year that five of its campuses would form a partnership with their local school districts. The idea is to help schools falling behind on state standards. The president of the University of Texas San Antonio emphasized "further collaboration between his university and local school districts" (Foster-Frau, 2018). Given the resources at universities that could benefit K-12 education, it is easy to see why municipalities chose K-12 education as the most common type of partnership.

Another partnership often initiated by the local government is with the university as a gathering place for city events. There has been an uptick in literature on so-called “third places" (Das 2008; Lambiri et al. 2007; Kearney, 2006; Oldenburg, 1989). As a term, third place refers to a gathering place that foster community outside of one's work or home (Jeffres et al, 2009). Universities are increasing becoming beacons for cultural and public life (Gumprecht, 2007), as they serve as venues for events and attractions. 


\section{Students as Constituents}

Both university administrators and local government leaders struggle with the question whether students should be treated as constituents. Are they a mutual stakeholder? Insofar as students are regarded as constituents, local governments ought to also work in their best interest. Much of the academic literature tends to dichotomize municipal and university residents as the "townies" and the students (Aden et al., 2010). But in fact, many college students tend to stay very close to home when they attend university. $57.4 \%$ of college freshman attend a university that is less than 50 miles from where they currently live (Eagan et al., 2014). Socio-economic barriers and family and cultural dynamics also tend to keep college students nearby (Somers et al., 2006). Therefore, the idea that students are not vested in their communities is outdated.

The survey data reinforce the idea that students, with their issues and concerns, are in fact taken into consideration by the local government. However, an interesting twist in the data shows that their issues and concerns may not be as salient. The lowest scoring mean answer for specific types of engagement concerns food insecurity, a topic salient to many students today. Nationwide, collegiate food insecurity is more widespread that it is for the general population (Broton et al., 2014). Sara Goldrick-Rab et al. (2017) estimated that between $20-50 \%$ of college students are food insure, particularly in California where the number in community colleges hoovers around 50\%. While perhaps this issue has not yet reached the local government, it remains real for college students and one that universities and local governments could partner to improve. 


\section{Obstacles}

The most jarring finding is that $23 \%$ of respondents believed that the main obstacle for local governments to partner with universities is the lack of clarity on how local government could collaborate with a university. In addition, $26 \%$ of those who responded said it was the same obstacle to collaborating with the university. Around onefourth of those asked could not think of a way that their local government would collaborate with their local universities. Another 7-16\% cited a lack of interest by the university. One can argue that the silo nature of both universities and local government precludes them from thinking outside their day-to-day activities that may not involve the other. It could also be that there is a lack of shared vision between universities and local governments that make collaborations less likely. It is unclear because each perceive the other to want something that do not align with their goals. As the next chapter will demonstrate, however, it seems more likely that there is a lack of local government leadership with regard to collaboration with the university, and/or there is a lack of trust the university will engage with the local government for a mutually beneficial goal.

One surprising obstacle was university bureaucracy. Respondents rated university bureaucracy as a main obstacle in both partnering with the local government and partnering the with university (21\% and $12 \%$, respectively). While anyone who works at or attends a university can readily attest to the bureaucracy of higher education, it was nonetheless an unexpected finding. Local governments, themselves known for high levels of bureaucracy, seem to find the red tape at universities to be rate limiting step. Future research should delve into the aspects of university bureaucracy that hinder collaboration. 


\section{Conclusion}

This chapter aimed to explore the various definitions of engagement. Additionally, it explored the types of collaborations and partnerships between the local government and university, the obstacles to those partnerships. Helping to find nodes that define engagement can go a long way towards creating a shared vision and a shared understanding. It was particularly helpful to understand the economic development, classic, and student dimensions of engagement, while finding other less pronounced nodes, such as workforce development. Large issues that every community faces such as health and education seem to be established areas of collaboration; however, there seems to be a dearth of collaboration around issues such as climate change and poverty.

Finally, the obstacles to engagement and collaboration show significant room for improved relations by educating both parties how collaborations could work to benefit both the municipality and the university. 


\section{Chapter 7: When Collaboration Becomes Mutually Beneficial: Perceptions from Town and Gown}

This chapter addresses the second research question, how collaborative capacity affects various types of engagement. It also addresses the third research question, what organizational factors and behaviors impact perceptions that collaboration are mutually beneficial. These questions explore the effect of local government and university capacity, trust, and shared vision on university and municipal engagement and collaboration. All variables used in the models and their respective operationalization are described below in Table 15.

Table 15: Variable Operationalization

\section{Dependent Variables}

$\begin{array}{lll}\text { Engagement } & \begin{array}{l}\text { According to the Carnegie } \\ \text { Foundation: Community } \\ \text { engagement describes } \\ \text { collaboration between } \\ \text { institutions of higher } \\ \text { education and their larger } \\ \text { communities (local, } \\ \text { regional/state, national, } \\ \text { global) for the mutually } \\ \text { beneficial exchange of } \\ \text { knowledge and resources } \\ \text { in a context of partnership } \\ \text { and reciprocity. } \\ \text { (from 1- Strongly } \\ \text { Based on that definition, } \\ \text { how engaged are } \\ \text { [municipality] and } \\ \text { [University] }\end{array} \\ \end{array}$




\begin{tabular}{|c|c|c|}
\hline Economic Engagement & $\begin{array}{l}\text { How engaged are } \\
\text { [municipality] and } \\
\text { [University] in addressing } \\
\text { economic challenges }\end{array}$ & $\begin{array}{l}\text { Survey Data, Ordinal } \\
\text { Categorical variable } \\
\text { based on a Likert scale } \\
\text { (from 1-Strongly } \\
\text { disagree to } 4 \text { - Strongly } \\
\text { agree) }\end{array}$ \\
\hline Social Engagement & $\begin{array}{l}\text { How engaged are } \\
\text { [municipality] and } \\
\text { [University] addressing the } \\
\text { social challenges of your } \\
\text { community? }\end{array}$ & $\begin{array}{l}\text { Survey Data, Ordinal } \\
\text { Categorical variable } \\
\text { based on a Likert scale } \\
\text { (from 1- Strongly } \\
\text { disagree to } 4 \text { - Strongly } \\
\text { agree) }\end{array}$ \\
\hline $\begin{array}{l}\text { Collaboration is a high } \\
\text { Priority for the Local } \\
\text { Government }\end{array}$ & $\begin{array}{l}\text { Overall, Local } \\
\text { Government/University } \\
\text { Collaboration is a high } \\
\text { priority for the local } \\
\text { government }\end{array}$ & $\begin{array}{l}\text { Survey Data, Ordinal } \\
\text { Categorical variable } \\
\text { based on a Likert scale } \\
\text { (1 Strongly disagree-4 } \\
\text { Strongly agree) }\end{array}$ \\
\hline $\begin{array}{l}\text { Collaboration is a high } \\
\text { Priority for the University }\end{array}$ & $\begin{array}{l}\text { Overall, Local } \\
\text { Government/University } \\
\text { Collaboration is a high } \\
\text { priority for the university }\end{array}$ & $\begin{array}{l}\text { Survey Data, Ordinal } \\
\text { Categorical variable } \\
\text { based on a Likert scale } \\
\text { (1 Strongly disagree-4 } \\
\text { Strongly agree) }\end{array}$ \\
\hline $\begin{array}{l}\text { Collaborations are } \\
\text { mutually beneficial }\end{array}$ & $\begin{array}{l}\text { Collaborations between the } \\
\text { local government and } \\
\text { university are generally } \\
\text { mutually beneficial }\end{array}$ & $\begin{array}{l}\text { Survey Data, Ordinal } \\
\text { Categorical variable } \\
\text { based on a Likert scale } \\
\text { (1 Strongly disagree-4 } \\
\text { Strongly agree) }\end{array}$ \\
\hline
\end{tabular}




\section{Local Government Capacity}

LGTech

LGLawsUni

LGUniEconStakeholder

LGUniSocStakeholder

LGStrongLeadership

LGLeadershipColl

University Capacity
The local government has the technical expertise to form mutually beneficial partnerships with the University.

The local government sets policies and laws that can positively impact the University.

The local government includes the university as a vital stakeholder when creating and implementing policies to achieve broad economic goals.

The local government includes the university as a vital stakeholder when creating and implementing policies that address social challenges (e.g., noise ordinances, gun violence, climate change).

The local government has effective leadership in regard to municipal/university collaborations.

The local government leadership actively seeks to collaborate.
Survey Data, Ordinal Categorical variable based on a Likert scale (1 Strongly disagree-4 Strongly agree)

Survey Data, Ordinal Categorical variable based on a Likert scale (1

Strongly disagree-4 Strongly agree)

Survey Data, Ordinal Categorical variable based on a Likert scale (1

Strongly disagree-4 Strongly agree)

Survey Data, Ordinal Categorical variable based on a Likert scale (1 Strongly disagree-4 Strongly agree)

Survey Data, Ordinal Categorical variable based on a Likert scale (1

Strongly disagree-4 Strongly agree)

Survey Data, Ordinal Categorical variable based on a Likert scale (1 Strongly disagree-4 Strongly agree) 
unitech

UniMoney

UniTime

UniLeadership

uniformP

Trust and Decision Making

Trust

LGTUnitoDeliver
The University has the technical expertise to form mutually beneficial partnerships with the local government.

The University has the monetary resources to form mutually beneficial partnerships with the local government.

The University has the time resources to form mutually beneficial partnerships with the local government.

The University has effective leadership in regard to municipal/university collaborations.

The University has formalized procedures to engage the local government

The local government and the university have a relationship built on trust

The local government can trust the university to deliver on previously agreed upon terms
Survey Data, Ordinal Categorical variable based on a Likert scale (1

Strongly disagree-4 Strongly agree)

Survey Data, Ordinal Categorical variable based on a Likert scale (1

Strongly disagree-4 Strongly agree)

Survey Data, Ordinal Categorical variable based on a Likert scale (1

Strongly disagree-4 Strongly agree)

Survey Data, Ordinal Categorical variable based on a Likert scale (1

Strongly disagree-4

Strongly agree)

Survey Data, Ordinal Categorical variable based on a Likert scale (1 Strongly disagree-4 Strongly agree)

Survey Data, Ordinal Categorical variable based on a Likert scale (1

Strongly disagree-4 Strongly agree) Survey Data, Ordinal Categorical variable based on a Likert scale (1 Strongly disagree-4 Strongly agree) 


\begin{tabular}{|c|c|c|}
\hline LGTUnitoSolconflicts & $\begin{array}{l}\text { The local government can } \\
\text { trust the university leaders to } \\
\text { solve any conflicts that might } \\
\text { arise as part of a } \\
\text { collaboration }\end{array}$ & $\begin{array}{l}\text { Survey Data, } \\
\text { Ordinal Categorical } \\
\text { variable based on a } \\
\text { Likert scale (1 } \\
\text { Strongly disagree-4 } \\
\text { Strongly agree) }\end{array}$ \\
\hline Sharedecisions & $\begin{array}{l}\text { During collaborations, the } \\
\text { local government and } \\
\text { university share decision- } \\
\text { making power }\end{array}$ & $\begin{array}{l}\text { Survey Data, } \\
\text { Ordinal Categorical } \\
\text { variable based on a } \\
\text { Likert scale (1 } \\
\text { Strongly disagree-4 } \\
\text { Strongly agree) }\end{array}$ \\
\hline LGvaluesaDiv & $\begin{array}{l}\text { During collaborations, the } \\
\text { local government values a } \\
\text { diversity of opinions }\end{array}$ & $\begin{array}{l}\text { Survey Data, } \\
\text { Ordinal Categorical } \\
\text { variable based on a } \\
\text { Likert scale (1 } \\
\text { Strongly disagree-4 } \\
\text { Strongly agree) }\end{array}$ \\
\hline Clearproggoals & $\begin{array}{l}\text { During collaborations } \\
\text { between the local } \\
\text { government and university } \\
\text { there are clear programmatic } \\
\text { objectives }\end{array}$ & $\begin{array}{l}\text { Survey Data, } \\
\text { Ordinal Categorical } \\
\text { variable based on a } \\
\text { Likert scale (1 } \\
\text { Strongly disagree-4 } \\
\text { Strongly agree) }\end{array}$ \\
\hline UniTLGtosolconflicts & $\begin{array}{l}\text { During collaborations, the } \\
\text { university can trust the local } \\
\text { government to resolve any } \\
\text { conflicts that might arise }\end{array}$ & $\begin{array}{l}\text { Survey Data, } \\
\text { Ordinal Categorical } \\
\text { variable based on a } \\
\text { Likert scale (1 } \\
\text { Strongly disagree-4 } \\
\text { Strongly agree) }\end{array}$ \\
\hline UniTLGtoDeliver & $\begin{array}{l}\text { During collaborations, the } \\
\text { university can trust the local } \\
\text { government to deliver on } \\
\text { previously agreed terms }\end{array}$ & $\begin{array}{l}\text { Survey Data, } \\
\text { Ordinal Categorical } \\
\text { variable based on a } \\
\text { Likert scale (1 } \\
\text { Strongly disagree-4 } \\
\text { Strongly agree) }\end{array}$ \\
\hline UnivaluesDivOpin & $\begin{array}{l}\text { During collaborations, the } \\
\text { university values a diversity } \\
\text { of opinions }\end{array}$ & $\begin{array}{l}\text { Survey Data, } \\
\text { Ordinal Categorical } \\
\text { variable based on a } \\
\text { Likert scale (1 } \\
\text { Strongly disagree-4 } \\
\text { Strongly agree) }\end{array}$ \\
\hline
\end{tabular}




$\begin{array}{lll}\text { SharedSocVision } & \begin{array}{l}\text { In terms of social policy, the } \\ \text { local government and the } \\ \text { university have a shared } \\ \text { vision of what is in the } \\ \text { community's best interest }\end{array} & \begin{array}{l}\text { Survey Data, } \\ \text { Ordinal Categorical } \\ \text { variable based on a } \\ \text { Likert scale (1 } \\ \text { Strongly disagree-4 } \\ \text { Strongly agree) }\end{array} \\ \begin{array}{ll}\text { In terms of economic policy, } \\ \text { the local government and the } \\ \text { SharedEconVision }\end{array} & \begin{array}{l}\text { Survey Data, } \\ \text { Ordinal Categorical } \\ \text { vision of what is in the } \\ \text { community's best interest }\end{array} & \begin{array}{l}\text { Likert scale (1 } \\ \text { Strongly disagree-4 } \\ \text { Strongly agree) }\end{array} \\ & & \end{array}$

\section{Research Methods}

$\underline{\text { Factor Analysis }}$

Index variables were used in the analysis. In order to properly construct index variables, a factor analysis was conducted on each of the domains pertaining to collaborative capacity: local government capacity, university capacity, and trust and shared vision. To measure sampling adequacy, the command factortest was employed in Stata 15 to obtain the Kaiser-Meyer-Olkin Measure of Sampling Adequacy. After assuring that the sample met an appropriate level of adequacy, a factor test was done using the command, factor. Table 16 lists the variables used to construct each index variables, as well as the Cronbach alpha coefficient from the factor analysis. Appendix 1 details the complete factor analysis for each index variable.

Local government capacity was measured by eight variables. The Kaiser-MeyerOlkin Measure of Sampling Adequacy was 0.82. The factor test yielded three distinct factors. The variables Local Government Time (LGTime), Local Government Money (LGMoney), and Local Government Technical Capacity (LGTech) had a Cronbach alpha coefficient of 0.79. Accordingly, an index variable called Local Government Capacity (LGCap) was created to represent these three variables. Similarly, the variables of Local 
Government Strong Leadership (LGStrongLeadership) and Local Government wants to Collaborate (LGLeadershipwantsColl) had a Cronbach alpha coefficient of 0.80. From those two variables, an index variable pertaining to local government leadership (LocgovLeadership) was created. The variables that examine whether the local considers the university an economic stakeholder (LGUniEconStakeholder) or a social policy stakeholder (LGUniSocialStakeholder) had a Cronbach Alpha's coefficient of 0.75. From those variables, an index variable, LocCapStakeholder was created.

University capacity was measured by five variables. The Kaiser-Meyer-Olkin Measure of Sampling Adequacy was 0.77 . The factor test yielded one distinct factor. The variables university technical capacity (Unitech), university monetary resources (UniMoney), university time resources (UniTime), university has strong leadership (UniLeadership) and university has formalized procedures for local government/university collaboration (uniformalizedP) were used to create the index variable, Universitycapacity. The university capacity index variable had a Cronbach Alpha coefficient of 0.78 .

The final index variables created pertained to trust and shared vision. The KaiserMeyer-Olkin Measure of Sampling Adequacy coefficient was 0.87. The factor test yielded three distinct factors. The variables that measured university leadership (UniLeadership), university valuing a difference of opinion Univaluesadiversityofopinion), the local government trusts the university to deliver on previously agreed goals (LGTUnitoDeliver) and solve issues (LGTUnitoSolveIssues) and finally that the relationship was built on trust (trust) yield a Cronbach Alpha coefficient of 0.88. From those variables, an index variable was created called LGTrustsUni. The 
second factor, UniTrustsLG, was constructed by variables that measure if the university trusts the local government to deliver on previously agreed goals (UniTLGtoDeliver) and solve conflicts (UniTLGtosolveconflicts), as well as if the local government a values diversity of opinion (LGvaluesadiversityofopinions), and if partnerships have clear programmatic goals (Clearprogrammaticobjectives). The Cronbach Alpha coefficient for those variables was 0.82 . Finally, the index variable SharedVision, was created from variables that measured shared social vision (SharedSocialVision), shared economic vision (SharedEconVision) and shared decision-making power

(Sharedecisionmakingpower). Cronbach Alpha coefficient for those variables was 0.82 .

Table 16: Index Variables

\begin{tabular}{|c|c|c|}
\hline Index Variable: & Variables within Index & $\begin{array}{l}\text { Cronbach } \\
\text { Alpha } \\
\text { Coefficient: }\end{array}$ \\
\hline LG Capacity & LGTime, LGMoney, LGTech & 0.79 \\
\hline LG Stakeholder & $\begin{array}{l}\text { LGUniEconStakeholder, } \\
\text { LGUniSocialStakeholder }\end{array}$ & 0.80 \\
\hline LG Leadership & $\begin{array}{l}\text { LGStrongLeadership } \\
\text { LGLeadershipwantsColl }\end{array}$ & 0.75 \\
\hline $\begin{array}{l}\text { University } \\
\text { Capacity }\end{array}$ & $\begin{array}{l}\text { uniformalizedP, Unitech, UniMoney, } \\
\text { UniTime }\end{array}$ & 0.78 \\
\hline $\begin{array}{l}\text { LG Trusts } \\
\text { University }\end{array}$ & $\begin{array}{l}\text { UniLeadership, } \\
\text { Univaluesadiversityofopinio, } \\
\text { LGTUnitoDeliver, } \\
\text { LGTUnitoSolveIssues, Trust }\end{array}$ & 0.88 \\
\hline $\begin{array}{l}\text { University } \\
\text { Trusts LG }\end{array}$ & $\begin{array}{l}\text { UniTLGtoDeliver, } \\
\text { UniTLGtosolveconflicts, } \\
\text { LGvaluesadiversityofopinion, } \\
\text { Clearprogrammaticobjectives }\end{array}$ & 0.82 \\
\hline Shared Vision & $\begin{array}{l}\text { SharedSocialVision, SharedEconVision, } \\
\text { Sharedecisionmakingpower }\end{array}$ & 0.82 \\
\hline
\end{tabular}




\section{Control Variables}

There were various control variables used in this analysis. From IPEDS, data were collected on demographic information of the specific universities, Carnegie Classification of Institutions of Higher Education, and the IPEDs designation of the municipality, ranging from city to rural. Data were also gathered from the United States Census Bureau. For each municipality, information was gathered on demographics and economic characteristics.

\section{Marginal Effects}

For each model, the marginal effects were calculated for each statistically significant index variable. Each of the dependent variables are ordinal categorical variables, ranging from 1 to 4 (strongly disagree to strongly agree). When an index variable was found significant, the Average Adjusted Predictions (AAP) was used with the Stata command Margins to predict the odds of choosing one answer or another, per unit increase in the significant independent variable. Appendix 2 details the marginal effects discussed within the models.

\section{Stepwise Backwards Regression}

For each model, a stepwise backwards logistic regression was run with the order logistic command using all the index variables and following control variables, namely InState, StudPop, CampusCity, CampusSuburb, DoctoralUni, MastersColandUni, tfandunder, Private4yr, MedianIncome, PovertyRate, Unemployment, MedianAge, Unitown, Recession, LGBetteroff, UniAdmin, and Statelocalgrant. This method of logistic regression begins by fitting the entire model and then systematically removing 
variables one at time, each time a given variable measured is added or discounted from the model. This is done to find the model with most explanatory power. The threshold set for the regression was 95\% (alpha $=0.05)$, using the Stata command Stepwise Pr (.05). All results are explored using odds ratios.

\section{Modeling the Effect of Capacity on Engagement and Collaboration}

Model 1 tests hypothesis 1 , that an increase in local government and university capacity increases the likelihood of engagement between universities and municipalities. The variable engagement from a question within the survey. The question gave the Carnegie classification definition of engagement and asked respondents to provide their perceptions of engagement between the two parties. The local government and universities were asked to provide their perceptions of each other. The responses were then combined to create the variable Engagement. The question was asked on a fourpoint Likert scale from very engaged to not engaged. The responses were converted to numerical values, with 1 corresponding to not engaged and four corresponding to very engaged. No neutral value was offered as an option. An ordered logistic regression was conducted using the dependent variable Engagement and the independent variables contained within each individual index variables. Appendix 3 shows the results of those regression analyses.

The second model tests the hypothesis pertaining to economic engagement, namely that greater local government and university capacity increases the likelihood of economic engagement between universities and municipalities. In essence, this model tests the extent that the engagement between the local government and university are economic in nature. Respondents were asked to give their perceptions on how engaged 
their municipality and university are in addressing economic challenges. Examples given to respondents of economic engagement include grant applications, and engaging on issues concerning unemployment, housing affordability and chronic poverty. The question was asked on a four-point Likert scale from very engaged to not engaged. The responses were converted to numerical values, with 1 corresponding to not engaged and four corresponding to very engaged. No neutral value was offered as an option. This question was in the survey. The responses were used to create the variable EconEngage. Here, too, an ordered logistic regression was conducted using the dependent variable, EconEngage, and independent variables contained within each individual index. Appendix 4 describes the output of those regression analyses.

The third model concerns social policy engagement and tests the hypothesis that a higher perception of local government and university capacity is associated with a higher perception of social engagement between universities and municipalities. That is, the extent that the engagement between the local government and university concern social problems. Respondents were asked to share their perceptions on how engaged their municipality and university are in addressing social policy challenges. Examples given to respondents of economic engagement include climate change, gun violence and educational achievement gaps. The question was asked on a four-point Likert scale from very engaged to not engaged. The responses were converted to numerical values, with 1 corresponding to not engaged and four corresponding to very engaged. No neutral value was offered as an option. The responses were used to create the variable SocialEngage. An order logistic regression was conducted using the dependent variable Social Engage 
and the independent variables of each index variable. Appendix 5 shows the output of those regression analyses.

The fourth model tests the hypothesis that a higher perception of local government and university capacity is associated with a higher perception that collaboration priority for the local government. Respondents were asked if collaboration was a high priority for the local government. The question was asked on a four-point Likert scale and measured agreement to the phrase "collaboration of high priority to the local government". The responses varied from strongly agree to strongly disagree. They were converted to numerical values, with 1 corresponding to strongly disagree and four corresponding to strongly agree. No neutral value was offered as an option. These responses formed the dependent variables CollHPLG. As with the other models, an ordered logistic regressing was conducted using the dependent variable, CollHPLG, the independent variables found within the index variables. Appendix 6 shows the output of those regression analyses.

Model 5 tests the hypothesis that a higher perception of local government and university capacity is associated with a higher perception that collaboration is a priority for the university. Respondents were asked if collaboration was a high priority for the university. The question was also asked on a four-point Likert scale and measured agreement to the phrase "collaboration is of high priority to the university." Like the previous question, the responses varied from strongly agree to strongly disagree. They were converted to numerical values, with 1 corresponding to strongly disagree and four corresponding to strongly agree. No neutral value was offered as an option. These 
responses formed the dependent variables CollHPUni. Appendix 7 describes the output of those regression analyses.

The final model also concerns collaboration and tests the hypothesis that a higher perception of local government and university capacity, shared vision, and trust is associated with a higher perception of mutually beneficial collaboration between universities and municipalities. As previously discussed, the Carnegie Foundation defines engagement as the mutually beneficial collaboration. This question simply asks if collaborations between the university and municipality are mutually beneficial. This question goes to the heart of the subtle, but important distinction between engagement as university and local administrators understand the concept, and collaboration that is mutually beneficial. The placement of this question was also different from the rest. Indeed, the five previous models were in fact the first five questions of the survey. This question was placed towards the middle of the survey. The responses varied from strongly agree to strongly disagree. The responses were converted to numerical values, with 1 corresponding to strongly disagree and four corresponding to strongly agree. No neutral value was offered as an option. These responses formed the dependent variables MutuallyBenColl. As with the other models, an ordered logistic regression was used to regress the dependent variable MutuallyBenColl and the independent variables found the index. Appendix 8 presents the output of those regression analyses.

\section{Findings}

Tables 17 and 18 present estimation results of the six models. The tables report the odds ratios followed by $t$-statistics in parentheses. The analyses reveal that the most significant predictor of engagement and collaboration in most models is the variable 
capturing local government trust of universities. Consistent with Hypothesis 1, engagement variables (Models 1-3) are positively associated with local government interdependence and leadership. In the models with collaboration as the dependent variable (Models 4-6), the main determinants are university trust of the local government and shared vision. Each model is discussed in detail below. 
Table 17: Explaining Engagement and Collaboration (No Control Variables)

\begin{tabular}{|c|c|c|c|c|c|c|}
\hline & $\begin{array}{l}\text { Model 1: } \\
\text { Engagement }\end{array}$ & $\begin{array}{l}\text { Model 2: } \\
\text { Eco Engage }\end{array}$ & $\begin{array}{l}\text { Model 3: } \\
\text { Social } \\
\text { Engage }\end{array}$ & $\begin{array}{l}\text { Model 4: } \\
\text { Coll } \\
\text { HP LG }\end{array}$ & $\begin{array}{l}\text { Model 5: } \\
\text { Coll } \\
\text { HP Uni }\end{array}$ & $\begin{array}{l}\text { Model 6: } \\
\text { Coll MB }\end{array}$ \\
\hline \multirow[t]{2}{*}{ LG Capacity } & 1.012 & 1.574 & 0.856 & 1.629 & 0.6 & 0.955 \\
\hline & 0.04 & 1.63 & $(-0.56)$ & 1.63 & $(-1.74)$ & $(-0.15)$ \\
\hline \multirow[t]{2}{*}{ LG Stakeholder } & 1.309 & 1.587 & $2.095^{*}$ & $1.975^{*}$ & 1.134 & 0.818 \\
\hline & 0.89 & 1.59 & 2.44 & 2.05 & 0.4 & $(-0.59)$ \\
\hline \multirow[t]{2}{*}{ LG Leadership } & $1.946^{*}$ & 0.682 & 0.77 & $3.107 * * *$ & 1.112 & 1.854 \\
\hline & 2.11 & $(-1.27)$ & $(-0.86)$ & 3.36 & 0.32 & 1.84 \\
\hline \multicolumn{5}{|l|}{ University } & 1.154 & 0.706 \\
\hline Capacity & 0.81 & 0.18 & 0.62 & $(-0.20)$ & 0.43 & $(-0.99)$ \\
\hline \multirow[t]{2}{*}{ LG Trusts Uni } & $3.405^{* * *}$ & $4.306^{* * *}$ & $1.919^{*}$ & 1.361 & $12.49 * * *$ & $6.966 * * *$ \\
\hline & 3.75 & 4.49 & 2.09 & 0.96 & 6.3 & 4.97 \\
\hline \multirow[t]{2}{*}{ Uni Trusts LG } & 0.682 & 0.594 & 0.967 & 0.878 & 0.437 & $2.895^{*}$ \\
\hline & $(-0.95)$ & $(-1.37)$ & $(-0.09)$ & $(-0.30)$ & $(-1.96)$ & 2.37 \\
\hline \multirow[t]{2}{*}{ Shared Vision } & 0.958 & 1.354 & 1.83 & 1.087 & $2.564 * *$ & $2.419 *$ \\
\hline & $(-0.14)$ & 0.97 & 1.87 & 0.25 & 2.71 & 2.3 \\
\hline \multirow[t]{2}{*}{$\mathrm{N}$} & 159 & 159 & 160 & 159 & 159 & 155 \\
\hline & 0.1346 & 0.1264 & 0.1081 & 0.1998 & 0.2710 & 0.3427 \\
\hline
\end{tabular}

Exponentiated coefficient $\mathrm{t}$-statistic in parentheses $* \mathrm{p}<0.05, * * \mathrm{p}<0.01, * * * \mathrm{p}<0.00$

Table 18: Explaining Engagement and Collaboration (With Control Variables) 


$\begin{array}{llllll} & \text { Model 2: } & \text { Model 3: } & \text { Model 4: } & \text { Model 5: } & \text { Model 6: } \\ \text { Model 1: } & \text { Econ } & \text { Social } & \text { Coll } & \text { Coll } & \\ \text { Engagement } & \text { Engage } & \text { Engage } & \text { HP LG } & \text { HP Uni } & \text { Coll MB }\end{array}$

\begin{tabular}{|c|c|c|c|c|c|c|}
\hline LG Capacity & & $\begin{array}{l}1.795 * \\
2.25\end{array}$ & & & & \\
\hline LGStakeholder & & $\begin{array}{l}\text { 1.713* } \\
2.11\end{array}$ & $\begin{array}{l}\mathbf{2 . 3 2 3}^{* * * *} \\
3.46\end{array}$ & $\begin{array}{l}\mathbf{2 . 3 5 0}^{* * *} \\
2.93\end{array}$ & & \\
\hline LG Leadership & $\begin{array}{l}\mathbf{1 . 9 5 9 * * *} \\
2.72\end{array}$ & & & $\begin{array}{l}\mathbf{3 . 8 8 6}^{* * * * *} \\
4.49\end{array}$ & & \\
\hline University Capacity & & & & $\begin{array}{l}2.077^{*} \\
2.02\end{array}$ & & \\
\hline Shared Vision & & & & & $\begin{array}{l}\mathbf{2 . 4 6 4 * *} \\
2.68\end{array}$ & $\begin{array}{l}\text { 2.218* } \\
2.18\end{array}$ \\
\hline Uni Trusts LG & & & & & $\begin{array}{l}\text { 0.458* } \\
(-2.12)\end{array}$ & $\begin{array}{l}3.729 * * * * \\
3.36\end{array}$ \\
\hline LG Trusts Uni & $\begin{array}{l}\mathbf{5 . 0 0 2} * * * * \\
5.54\end{array}$ & $\begin{array}{l}3.619 * * * * \\
4.55\end{array}$ & $\begin{array}{l}\mathbf{2 . 2 9 8} * * \\
3.17\end{array}$ & & $\begin{array}{l}13.87^{* * * *} \\
6.46\end{array}$ & $\begin{array}{l}\mathbf{5 . 5 9 3} * * * * \\
4.74\end{array}$ \\
\hline Poverty Rate & $\begin{array}{l}\mathbf{1 . 0 4 4} \text { *** } \\
2.79\end{array}$ & & & & & \\
\hline Ed Level & $\begin{array}{l}\mathbf{0 . 9 7 8 *} \\
(-2.46)\end{array}$ & & & & & \\
\hline In-State & $\begin{array}{l}\mathbf{0 . 9 8 0}^{* * *} \\
(-2.90)\end{array}$ & & & & & \\
\hline Campus-City & & $\begin{array}{l}5.498 * * * * \\
4.97\end{array}$ & $\begin{array}{l}\mathbf{2 . 3 1 2} * * \\
2.65\end{array}$ & & $\begin{array}{l}\text { 2.711* } \\
2.11\end{array}$ & \\
\hline 24 and under & & $\begin{array}{l}\mathbf{0 . 9 5 8} * * \\
(-2.79)\end{array}$ & & & & \\
\hline CampusSuburb & & & & & $\begin{array}{l}\text { 3.157* } \\
1.99\end{array}$ & \\
\hline MedianIncome & & & & & $\begin{array}{l}.998 * * * * \\
(-3.74)\end{array}$ & \\
\hline Median Age & & & & & $\begin{array}{l}\mathbf{1 . 1 3 0}^{* * *} \\
2.95\end{array}$ & \\
\hline $\mathrm{N}$ & 154 & 155 & 154 & 154 & 151 & 156 \\
\hline Pseudo R2 & 0.1881 & 0.1953 & 0.1108 & 0.1968 & 0.3027 & 0.3249 \\
\hline
\end{tabular}




\section{Model 1: Engagement}

As Appendix 2 shows, respondents' perceptions of engagement are significantly positively associated with the technical capacity, leadership, and interdependence of the local government, as well as the leadership, technical capacity and uniformed procedures of the university. Additionally, perceptions of engagement are significantly positively associated with clear programmatic goals.

Table 17 contains the output of an ordered logistic regression on the dependent variable engagement with the independent index variables. Holding all other variables constant, for a unit change in Local Government Leadership, the odds of responding that engagement between the university and local government meets the definition of the Carnegie foundation increase by a factor of 1.95 ( $\mathrm{p}<0.05)$. However, when examining the marginal effects of the Local Government Leadership, the findings show that for every additional unit increase in the index variable, LGLeadership, decreases the probability of reporting "somewhat unengaged" by $5 \%(\mathrm{p}<0.05)$, decreases the probability of reporting "somewhat engaged" by $7 \%(\mathrm{p}<0.05)$, and increases the probability of reporting "very engaged" by $3 \%(\mathrm{p}<0.05)$. The analysis also shows that it decreases the probability of reporting "not engaged" by $2 \%$, however, yet that finding was not significant at $95 \%$.

Similarly, for a unit change in Local Government Trusts Universities, the odds of responding that engagement between the university and the local government meet the definition of the Carnegie foundation increases by a factor of $3.4(\mathrm{p}<0.00)$, holding all other variables constant. When examining the marginal effects, the impact varied by category. Every additional unit increase in the LGTrustsUni variable decreases the 
probability of reporting "not engaged" by $3 \%(\mathrm{p}<0.05)$, decreases the probability of reporting "somewhat unengaged" by $8 \%(\mathrm{p}<0.00)$, decreases the probability of reporting "somewhat engaged" by $13 \%(\mathrm{p}<0.00)$, and increases the probability of reporting "very engaged" by $24 \%(\mathrm{p}<0.00)$.

When adding controls to the models (see Table 18), the variables measuring local government leadership (LGLeadership) and the presence of trust in local government toward the university (LGTrustsUni) retain their statistical significance. Holding all other variables constant, for a unit change in LGLeadership, the odds of responding that engagement between the university and the local government meets the definition of the Carnegie foundation increases by a factor of $1.97(\mathrm{p}<0.05)$. For one unit change in LGTrustsUni, the odds of responding that engagement between the university and the local government meet the definition of the Carnegie foundation increase by a factor of $5.0(\mathrm{p}<0.00)$. The variables capturing poverty rate, percent of population with a bachelor's degree or higher, and percent of in-state students within a given university, had very small but significant effects on perceptions of engagement. For every unit increase in Poverty, the odds of responding that engagement between the university and the local government meets the definition of the Carnegie foundation increase by a factor of $1.04(\mathrm{p}<0.01)$, however, the odds decreased for every unit increase in the percent of population with a bachelor's degree or higher $(0.98, \mathrm{p}<0.05$, ) and for single unit percent increase in the population of students from within the state $(0.98, \mathrm{p}<0.01)$.

\section{Model 1 Discussion}

Model 1 has produced interesting findings. Only two of the seven index variables seem to impact the perceptions of engagement. These results do not support the 
expectation that university capacity impacts perceptions of engagement. Yet, there is a positive association between perceptions of engagement and local government leadership and local government trust in a given university. That is simultaneously surprising and not. The extant literature widely discusses the importance of organizational leadership and having leadership that wants to collaborate and engage with their local university would most likely positively impact that relationship. The surprising part is the extent to which it seemed to matter in this sample. Although the odds of having a positive perception of engagement are only 1.9 times greater than those without, it still mattered in a way that other aspects of collaborative capacity did not. A university's trust of the local government, for example, is not as relevant. It could be that at baseline, universities are more apt to collaborate, and the local government is the rate limiting step. Likewise, neither local government nor university capacity seemed to matter. Their time, money or expertise might again at baseline be primed for collaboration. In fact, leadership that actively seeks to collaborate matters way more than money, time, or technical capacity of either side.

\section{Model 2: Economic Engagement}

As displayed in Appendix 3, respondents' perceptions of economic engagement are significantly positively associated with the interdependence of the local government on economic issues, as well as local government's monetary resources and leadership. Furthermore, university leadership and uniformed procedures are positively associated with higher perceptions of economic engagement. Additionally, positive perceptions of economic engagement are associated with shared economic vision. 
When the dependent variable EconEngage was regressed on the index variables, the results show that for a unit change in Local Government Trusts Universities, the likelihood that a respondent would have a positive perception of the economic engagement between the university and the local government increases by a factor of 4.3 ( $\mathrm{p}<0.00$ ), holding all other variables constant. When examining the marginal effects, the results vary by category. Every additional unit increase in the LGTrustsUni variable decreases the probability of a respondent reporting "not engaged" by $13 \%(\mathrm{p}<0.00)$, decreases the probability of reporting "somewhat unengaged" by $14 \%$ ( $\mathrm{p}<0.00)$, and increases the probability of reporting "very engaged" by $22 \%(\mathrm{p}<0.00)$. The model also shows a decrease in the probability of reporting "somewhat engaged" by $4 \%$, but that finding was not significant $(\mathrm{P}<0.08)$.

When control variables were added to the model, three index variables became significant. Now the likelihood that a respondent would have a positive perception of the economic engagement between the university and the local government increases by a factor of 3.6 ( $\mathrm{p}<0.00)$ with unit increase in LGTrustsUni, a factor of $1.8(\mathrm{p}<0.05)$ for every unit change in LG Capacity, and a factor of 1.71 for every unit change in Local Government Stakeholders (LG Stakeholders), holding all other variables constant. Additionally, two of the control variables were significant. Campuses with town classified by IPEDS as belong to the city type increase the prospect that a respondent would have a positive perception of the economic engagement between the university and the local government increases by a factor of $5.49(\mathrm{p}<0.00)$, compared to universities with campus that have been designed by IPEDs as the rural type. The variable capturing the percent of students that were 24 and under produces a much 
smaller but still significant effect $(0.96, \mathrm{p}<0.01)$. These findings are in line with the hypothesis that a higher population of traditional students increases engagement.

\section{Model 2 Discussion}

The findings indicate that three of the seven index variables seem to impact the perceptions of economic engagement. Interestingly, it is local government capacity and stakeholders that affect perceptions of economic engagement. Within the unadjusted model, the odds of having a positive perception of economic engagement are 2.4 times greater for municipalities that perceive they have the money to collaborate with the university. It may well be that local government money is driving the index variable's significance. Overall, the odds of having a positive perception of economic engagement is 1.7 times greater, per unit increase of the index variable. Those odds are smaller, but significant, suggesting that the local government capacity also matters. Leadership likely affects the overall perception of engagement, but economic engagement, the type that local governments say they engage in mostly, is affected by the time, money and technical reallocated for a partnership.

Further, the estimations show that local government stakeholders, or interdependence, also matters. The analysis of this index variable by itself shows that that economic stakeholders seem to be driving it. That finding was to be expected, given the nature of the dependent variable, which reflects economic engagement. Again, though, this is the type of engagement that local governments say they engage in mostly, and thus it seems given this sample that it would behoove them to take the university into account as economic stakeholders when developing economic policy or campus expansion projects. 
Among the control variables, the most salient is Campus-city. Compared to rural campus, campuses that are in cities are five times more likely to have positive perceptions of economic engagement. Perhaps this is a reflection of larger issues facing higher education in rural America. Rural Americans are less likely than their urban counterparts to consider a college degree worth pursuing, and, therefore, less likely to attend college or encourage their children to go to college (Marcus and Krupnick, 2017).

\section{Model 3: Social Engagement}

Similar to economic engagement, respondents' perceptions of social engagement are positively and significantly associated with the interdependence of the local government on social issues, as well as local government's monetary resources and leadership. This supports the hypothesis that local government capacity affects positively perceptions of social engagement. Interestingly, university technical capacity and uniformed procedures were positively associated with higher perceptions of social engagement. This adds credence to the idea that for positive perceptions of engagement, both parties need to have the technical capability to do so. Unsurprisingly, positive perceptions of social engagement are associated with shared social vision. The full regression analysis can be found in Appendix 4.

The regression analysis using the index variables also yielded interesting results. For a unit change Local Government Stakeholder (LGStakeholder), the likelihood that a respondent would have a positive perception of the social engagement between the university and the local government increase by a factor of $2.09(\mathrm{p}<0.05)$. As with the other two models, Local Government Trusts Universities (LGTrustsUni) also increased the odds that a respondent's perceptions of social engagement between the university 
and the local government increased by a factor of $1.9(\mathrm{p}<0.05)$, holding all other variables constant. These findings do not support the expectation that university capacity relates positively to social engagement, and only partially supports the expectation for local government capacity. These findings suggest that interdependence on social issues and trust are more needed for positive perceptions of social engagement, than other factors such as time or money.

In terms of marginal effects, every additional unit increase in Local Government Trusts Universities (LGTrustsUni) decreases the probability of respondents choosing "not engaged" by $13 \%(\mathrm{p}<0.00)$, decreases the probability of reporting "somewhat unengaged" by $14 \%(\mathrm{p}<0.00)$, and increases the probability of reporting "very engaged" by $22 \%(\mathrm{p}<0.00)$. The results also show a decrease in the probability of reporting "somewhat engaged" by $4 \%$, but not in a significant way $(\mathrm{p}<0.08)$.

When control variables were added to the model, three index variables became significant. The likelihood that a respondent would have a positive perception of the economic engagement between the university and the local government increases by a factor of $3.6(\mathrm{p}<0.00)$ with unit increase in Local Government Trusts Universities (LGTrustsUni), a factor of $1.8(\mathrm{p}<0.05)$ for every unit change in Local Government Capacity (LG Capacity), and a factor 1.71 for every unit change in Local Government Stakeholders (LG Stakeholders), holding all other variables constant. Additionally, two of the control variables were also found to be significant. Campuses with town classified by IPEDS as belonging to a city increased the probability that a respondent would have a positive perception of the economic engagement between the university and the local government increases by a factor of 5.49 ( $\mathrm{p}<0.00)$, compared to universities with 
campus that have been designed by IPEDs as Rural. The percent of students that were 24 and under provide a much smaller but still significant variable $(0.96, \mathrm{P}<0.01)$.

\section{Model 3 Discussion}

Anchor institutions, both the university and the local government stand to gain by working together to solve the societal issues facing their community. In terms of collaborative capacity, the sample shows that much like economic engagement, the odds of having a positive perception on social engagement increase with the university being included as a local government stakeholder. Again, a stakeholder of societal challenges seems to be driving this finding. Also, like economic engagement, there appears to be an urban/rural divide. Campuses in cities are 2.3 times more likely than those in rural areas to have a positive perception of social engagement. Again, this supports the hypothesis that areas with greater populations engage more than areas with less residents.

\section{Model 4: Collaboration is a High Priority for the Local Government}

As Appendix 5 demonstrates, perceptions that collaboration is a high priority for the local government are positively associated with local government having time to collaborate. Additionally, interdependence with economic issues, trust, and uniformed procedures were also positively associated with higher perceptions that collaboration is a high priority for the local government. These findings support the extant literature that when local government engage universities it is often for economic engagement, as well as the literature that states local government are not often the integrators of the engagement. It may be an indicator that local governments simply do not have staff whose responsibilities include working with the university. Moreover, the findings 
support the qualitative research that suggest local governments value formal procedures when creating partnerships.

Similar results were found when the regression analysis used the index variables as the independent variables. For a unit change in Local Government Stakeholder (LGStakeholder), the likelihood that a respondent would have a positive perception that collaboration is a high priority for the local government increases by a factor of 1.95 ( $\mathrm{P}<0.05)$, holding all other variables constant. The marginal effects of LGStakeholder reveal that for every additional unit increase in the index variable LGStakeholder, respondents' odds of responding somewhat disagree decreases by $7 \%(\mathrm{P}<0.05)$. The same measure decreases the probability of reporting somewhat agree by $4 \%(\mathrm{P}<0.05)$, and increases the probability of reporting strongly agree by $12 \%(\mathrm{P}<0.00)$. The model also shows that it would a very small effect on the odds of responding strongly disagree, however it was not found significant at 95\% confidence. Economic stakeholders, more so that social stakeholders, seem be driving the significance, and once again provides support for the notion that local governments most often seek to collaborate for economic reasons.

Likewise, for a unit increase in the index variable LGLeadership, the probability that a respondent believes that collaboration is a high priority for the local government increases by a factor of $3.10(\mathrm{P}<0.00)$, holding all other variables constant. The marginal effects of LGStakeholder reveal that for every additional unit increase in the index variable LGStakeholder, respondents' odds of responding somewhat disagree decreases by $7 \%(\mathrm{P}<0.05)$. The same measure decreases the probability of reporting somewhat agree by $12 \%(\mathrm{P}<0.01)$, and increases the probability of reporting strongly agree by 
$20 \%(\mathrm{P}<0.00)$. Once again, the model shows that it would a very small effect on the odds of responding strongly disagree, however, it was not found significant at the $95 \%$ level.

When control variables were added to the model, three index variables become significant: LGStakeholder, LGLeadership and UniversityCapacity. The likelihood that a respondent would have a positive perception that collaboration is a high priority for the local government increases by a factor of $2.4(\mathrm{P}<0.01)$ with unit increase in perceptions of the variable Local Government Stakeholder. Similarly, with every unit increase in the perceptions of Local Government Leadership, the likelihood that a respondent would have a positive perception that collaboration is a high priority for the local government increases by a factor of $3.9(\mathrm{P}<0.00)$. Finally, the likelihood that a respondent would have a positive perception that collaboration is a high priority for the local government increases by a factor of $2.7(\mathrm{P}<0.05)$ with unit increase in perceptions in University Capacity. Interestingly, no control variables were found to be significant.

\section{Model 4 Discussion}

The fourth model skirts the line between engagement to collaboration. It examines if collaboration is a high priority to the local government. As with engagement, leadership is a driving force of having a positive perception, and in economic and social engagement stakeholders were also a driving force. In this sample, both are a significant for determining a positive perception of local government's priority for collaboration. Interestingly, university capacity is a significant variable. This is the only model where university capacity, that is their time, money, and technical ability, are a factor. This supports the hypothesis that university capacity is positively associate with higher perceptions that the local governments collaboration is a priority, 
or the local government needs to believe the university is able to collaborate for them to invest the time.

\section{Model 5: Collaboration is a High Priority for the University}

Appendix 6 displays the full regression analysis for the variable CollHPUni. Among the most interesting findings that analysis is the negative relationship the university's monetary resources has with collaboration being a high priority for the university. However, technical capacity and uniformed procedures are positively associated with dependent variable. In some ways, the hypothesis is supported, as uniformed procedures and technical skills are functions of university capacity. However, in many ways it does not support the hypothesis that higher perceptions of university capacity are linked with higher perceptions that the university believes collaboration is a priority. Indeed, even when looking at the index variables, one finds it has no impact at all on dependent variables. The negative relationship pertaining to money might indicate that the more money an institution has, the less likely they may be to seek out formalized partnerships. Rather, they may simply use engagement to their own ends, such as student-centered engagement, but not necessarily as mutually beneficial collaboration. Nor does this finding support the idea that local government capacity in the form to time, money and technical skills are associated with increased perceptions that universities want to collaborate. It does however, underscore the notion that trust in general and in the ability of a party to solve issues is vital to collaboration.

Two index variables were found to be significant in Model 5: LGTrustsUni and Shared Vision. For a unit change in Local Government Trusts the University, the likelihood that a respondent would have a positive perception that collaboration is a high 
priority for the university increases by a factor of $12.5(\mathrm{P}<0.00)$, holding all other variables constant. The marginal effects of LGTrustsUni reveal that for every additional unit increase in the index variable, a respondent's odds of replying strongly disagree decreases by $7 \%$ ( $\mathrm{p}<0.00)$; responding somewhat disagree decreases by $18 \%(\mathrm{p}<0.00)$; responding somewhat agree by $16 \%$ ( $\mathrm{p}<0.00$ ); and increases the odds of reporting strongly agree by $41 \%(\mathrm{p}<0.00)$.

The effects of perceptions of Shared Vision were not as large, yet significant. For a unit change in Shared Vision, the likelihood that a respondent would have a positive perception that collaboration is a high priority for the university increases by a factor of 2.6 ( $\mathrm{p}<0.01)$, holding all other variables constant. The marginal effects of SharedVision show that for every additional unit increase in the index variable, a respondents' odds of replying strongly disagree decreases by $3 \%$ ( $\mathrm{p}<0.05)$; responding somewhat disagree decreases by $7 \%(\mathrm{p}<0.01)$; responding somewhat agree by $6 \%(\mathrm{p}<0.01)$; and increases the probability of reporting strongly agree by $15 \%(\mathrm{p}<0.01)$.

The likelihood that a respondent would have a positive perception that collaboration is a high priority for the university increases by a factor of $13.8(\mathrm{P}<0.00)$ with unit increase in Local Government Trusts Universities (LGTrustsUni), a factor of $2.5(\mathrm{p}<0.01)$ for every unit change in Shared Vision, and decreases by a factor 0.5 $(p<0.05)$ for every unit change in perceptions reflecting the university's trust in the university (UniTrustsLG), holding all other variables constant. Additionally, four of the control variables were also found to be significant. Campuses with town classified by IPEDS as belong to a city increased the likelihood positive perception that collaboration is a high priority for the university by a factor of $3.2(\mathrm{p}<0.05)$ and increases by a factor 
of $2.7(\mathrm{P}<0.05)$ for town classified by IPEDS as suburban, as compared to universities with campus that have been designed by IPEDs as Rural. Median Age and Median Income of the municipality had a very small impact on the dependent variable, $.99(\mathrm{P}<0.00)$ and $1.13(\mathrm{P}<0.01)$, respectively.

\section{Model 5 Discussion}

Model 5 supports the hypothesis that shared vision is positively associated with that collaboration is a high priority for the university. Having positive perceptions of shared vision increased the odds having a positive perception in 2.5 times. Shared vision is important in the collaborative capacity literature, and it is interesting that it impacts universities but not the local governments. Perhaps because universities are careful to avoid mission creep, they collaborated when they buy in to the vision of the partnership or see it as vital to the mission of the university.

The most unexpected finding of Model 5 is the inverse relationship between university's trust of local government and perceptions that collaboration is a high priority for universities. This is a puzzling finding. However, when considering the findings of Table 22, it becomes clear that trusting the local government to solve conflicts and the local government valuing a diversity of opinions had a negative, if insignificant, relationship with the dependent variable. Such that the odds of perceiving that collaboration is a high priority for the university decreases the more a university trusts that a local government will value a diversity of opinions and solve conflicts. This may be an indication that the relationship is easy and thus not a high priority for the university. High priorities, after all are priority of great importance, and perhaps collaboration with a local government that can be relied on is an afterthought. However, 
a more substantial idea is the challenge of consensus (Parr, et al, 2006). When

municipalities value too many opinions it is hard to build a consensus, and get anything done. In a similar vein, Parr, et al (2006) posit that municipalities will seek consensus rather than conflict. However, that might dilute the shared vision for the university and the municipality, leading to fewer collaborations.

It is also noteworthy that the rural and urban/suburban divide continues. Urban and suburban campuses were much more likely to select that collaboration was a high priority for their university. Less impactful, but still significant was median income and median age. Both had a negative relationship with the perceptions measured in model 5, supporting the hypothesis that older, wealthier communities are less likely to seek out collaborations.

\section{Model 6: Mutually Beneficial Collaboration}

Model 6 supports the hypothesis that trust and shared vision are positively associated with collaboration with both the results displayed in Appendix 7 and in Table 16. Indeed, when considering Table 16, three index variables were significant when running an ordered logistic regression with just the seven index variables: LGTrustsUni, UniTrustsLG, and SharedVision. Holding all other variables constant, for a unit change in perceptions of Local Government trust in the local government are mutually beneficial increase by a factor of $7(\mathrm{p}<0.00)$. The marginal effects of the Local Government Trust show that for every additional unit increase in the index variable, Local Government Trusts Universities (LGTrustsUni), decreases the probability of reporting "strongly disagree" by $5 \%(\mathrm{p}<0.01)$, decreases the probability of reporting “somewhat disagree" by $10 \%(\mathrm{p}<0.00)$, decreases the probability of reporting 
"somewhat agree" by $12 \%(\mathrm{p}<0.00)$, and increases the odds of reporting "strongly agree" by $26 \%(\mathrm{p}<0.00)$.

In relation to the index variable, UniTrustsLG, holding all other variables constant, for a unit change in perceptions of university trust in the local government, the odds of responding that collaborations between the university and the local government are mutually beneficial increase by a factor of $2.9(\mathrm{P}<0.05)$. The marginal effects of UniTrusts $L G$ show that for every additional unit increase in the index variable decreases the probability of reporting "strongly disagree" by $2 \%(\mathrm{P}<0.05)$, decreases the probability of reporting "somewhat disagree" by $5 \%(\mathrm{P}<0.05)$, decreases the probability of reporting "somewhat agree" by $7 \%(\mathrm{P}<0.05)$, and increases the odds of reporting "strongly agree" by $14 \%(\mathrm{P}<0.05)$.

Concerning the index variable SharedVision, holding all other variables constant, for a unit change in perceptions of shared visions of economic and social policy, the odds of responding that collaborations between the university and the local government are mutually beneficial increase by a factor of $2.4(\mathrm{P}<0.05)$. The marginal effects of SharedVision show that for every additional unit increase in the index variable decreases the probability of reporting "somewhat disagree" by $4 \%(\mathrm{P}<0.05)$, decreases the probability of reporting "somewhat agree" by $5 \%(\mathrm{P}<0.05)$, and increases the odds of reporting "strongly agree" by $11 \%(\mathrm{P}<0.05)$. The odds of responding "strongly disagree" decrease by $2 \%(\mathrm{P}>0.05)$, however that finding was not significant at the $95 \%$ level.

The same index variables remained significant even after adding the controls. The likelihood that a respondent would have a positive perception that collaboration is mutually beneficial between the university and the local government increases by a 
factor of $5.6(\mathrm{P}<0.00)$ with unit increase in LGTrustsUni; a factor of $2.1(\mathrm{P}<0.05)$ for every unit change in SharedVision; and a factor $2.7(\mathrm{P}<0.00)$ for every unit change in perceptions reflecting the university's trust in the university (UniTrustsLG), holding all other variables constant.

\section{Model 6 Discussion}

The extant literature provides support for the notion that shared vision is necessary for mutually beneficial collaboration. It is necessary as both parties need to understand and agree on the set upon goals of the partnership. Indeed, one finds that within this sample the odds are finding collaborations mutually beneficial increase with an increase in shared vision. In a departure from Model 5, university's trust of local government is highly significant and positively associated with the perception that partnerships are mutually beneficial. Issues on consensus aside, the driving force of this index variable seems to be a diversity of opinion. That is, when the local government values the opinions of other, like the university, the collaboration is more likely to be mutually beneficial. That is more in line with the extant academic literature on collaborative capacity.

\section{Discussion}

This chapter concerns a simple question: are better perceptions of organizational capacity (university or local government) associated with higher perceptions of engagement and collaboration. Does the fact that a respondent perceives one entity or the other to have more time, money, or skills make them also more likely believe that entity is more engaged or collaborative? Does that also hold true for leadership and 
interdependence? Are those things irrelevant in the face of other factors, such as trust or shared vision?

Local government's time, money and technical capacity is only positively associated with Model 3, social engagement. Social engagement may only be something a local government partners with a university when the local government is financially able to do so. Social issues are often wicked problems that require a lot of time and attention to help mitigate. As the findings from the previous chapter suggests, wicked problems are often not as pressing as economic or policy issues the local government may be working on. As such, social issues might become backburner issue that are tended to when an opportunity, like a grant, presents itself. Likewise, university's time, money, and technical skills are only associated with model 4 , collaboration is a high priority for the local government. Undeniably, local governments are constrained by their resources, and it is most likely the case that collaborations are only a priority when the local government is sure that the university is able to undertake the task as to no squander the local government's limited resources.

Interdependence on economic and social issues are positively associated with models 2-4. Unsurprisingly, considering one another as an economic and/or social stakeholder is positively associated with economic and social engagement. It is also positively associated with model 4 . Again, it is not surprising that collaboration is a high priority for local governments that view their universities as stakeholders. Interestingly, it was not associated with engagement in general (model 1) or collaboration as mutually beneficial (model 6). From the extant literature, and interviews, it was expected that this variable be highly corrected with all 6 dependent variables. Indeed, university and local 
government interdependence on economic issues was significant in every model when analyzed on their own with the dependent variable, expect model 3 (where social interdependence was significant). It is telling how much more other variables (such as trust and shared vision) affect the models, given that the stakeholder index variable was decreased to insignificant in some models.

Local government leadership was positively associated with engagement in general and collaboration being a high priority for the local government. It was expected that having strong leadership that wants to collaborate is positively associated with engagement and collaborating being a high priority for the local government. Indeed, it is somewhat shocking that it was not associated with either economic or social engagement. It is particularly interesting when considering that the variable strong leadership was significant in both economic and social engagement and once again is more telling of the magnitude of the impact other variables have on the models.

In support of hypothesis 3, the index variable shared vision was positively associated with collaboration being mutually beneficial and collaboration being a high priority for the local government. Universities engage in a variety of ways, but for them to collaborate in a mutually beneficial way (in a two-sided way), the parties need to have a shared vision. That is in line with the extant literature and the expectations of the hypothesis. Interestingly, it was not significant for the local government to deem collaboration a high priority (model 4). Perhaps having a shared vision is a forgone conclusion on the outset of local government collaboration, given the association between university capacity, interdependence, and local government leadership that are associated with model 4. 
Similar to shared vision, university trust of local government was significant in models 5 and 6 . Universities already engage their communities. This sample is made up of universities that purport to be engaged. Therefore, it is very interesting that for collaboration to be a priority for universities, they need to have trust in the local government in general, and specifically to solve conflicts and deliver on goals. A university's lack of trust for the local government, therefore, would be make one-sided engagement more common. Understanding that dynamic also explains model 6. Keeping in line with hypothesis 3 and the extant literature, mutually beneficial collaboration is built on trust and clearly defined goals.

The index variable pertaining to local government trust appears to be of particular importance. Five of the six models analyzed had LGTrustUni as a significant variable. This variable included that the relationship was built trust, the University had strong Leadership, and can be trusted to solve issues and deliver on goals. Keeping with the hypothesis 3 , trust and university leadership, is positively associated with all forms of engagement, university's belief that collaboration is a priority, and that collaborations are mutually beneficial.

More interesting is its insignificance in model 4, where it was expected to be highly correlated. From this sample, local government collaboration as a high priority, has little to do with university leadership or their ability to solve issues and deliver on goals. The local government resources and leadership drives the priority significantly more than any external factor.

The other question underpinning this dissertation is also simple: to the extent that engagement and collaboration are different, do different factor impact perceptions of 
each. Is what is associated with engagement also, necessarily, associated with collaboration? From this sample, the answer to no. There is a clear distinction between engagement and mutually beneficial collaboration. Therefore, it is interesting to compare the term engagement in Model 1 with part of its "classic" definition in Model 6. Noteworthy are the sheer lack of similarities. With the exception of local government's trust of university there does not seem to be any overlap between the models. That harkens back to the previous chapter and its many definitions of engagement and shows yet again that engagement is not always considered the mutually beneficial collaboration between partners.

Figure 5 below shows the index variables that are associated within the engagement and collaboration models, with model 4 standing alone. It shows that by and large models 1-4 have overlapping significant variables, and models 5-6 are largely driven by other factors, such as shared vision. 


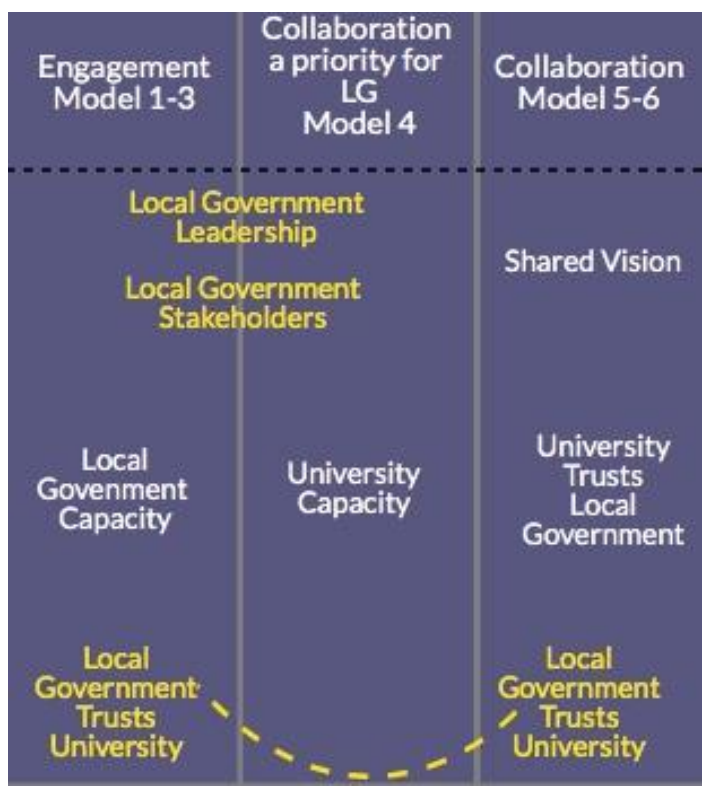

Figure 5: Findings of Models 1-6

\section{Conclusion}

There are several takeaways from the analysis performed in this chapter. Among the most interesting aspect is the way engagement, engagement on economic issues and engagement on social issues revolve around local government leaderships and stakeholders. Likewise, it was particularly interesting to see how shared vision really only impacted the dependent variables of collaboration. From the literature review, it was expected that shared vision would be of particular importance in all models. Finally, the main take away from this chapter is the extent to which university's trust of the local government seems to matter in both engagement and collaboration. 


\section{Chapter 8: A Dyadic Analysis of University Engagement Offices and Local Government Officials}

This chapter explores the relationship between local government officials and university administrators by examining a subset of the data collected in the previous chapter. Using data from 62 university pairs, the analysis measures the agreement, specifically, the intensity of agreement, between local government and university respondents as it pertains to engagement and collaboration as being seen as mutually beneficial. This chapter utilized an ordered logistic regression, where the intensity of agreement is the dependent variable. Among the independent variables are population, crime, and financial resources. Findings show a positive association between perceiving collaborations as mutually beneficial and levels of agreement in engagement.

\section{Pairing University with a Local Government}

As Tables 3-6 demonstrate, the overall sample is skewed towards doctoral universities, public universities, and universities located in urban and suburban areas. As with the prior chapter, all universities meet the Carnegie classification for community engagement. The median income of municipalities in this sample was $\$ 22,863.53$. The median poverty rate of the sample was $20.56 \%$, and the median unemployment rate was 4.10\%. In order to be considered a pair, at least one member from the city government and one member from the university had to answer the survey. In instances where more than one member of a given party answered the question, the mean score was calculated. Of this sample, $29 \%$ pairs had two answers, $37 \%$ of pairs had 3 answers, $16 \%$ of pairs had $4,10 \%$ of pairs had 5 answers, and 5 had 6 answers, and $3 \%$ of pairs had 7 answers. More city officials answered the survey than university administrators. In this sample, 
123 city officials answered the survey, compared to 93 university administrators. City officials were grouped together, but included 71 city council members, 16 city managers, and 15 mayors. Of these, 21 respondents identified as a city official but did not give their title. All the university officials came from university engagement offices. Figures 6-8 shows the breakdown of this sample based on education, size of municipality, and type of university.

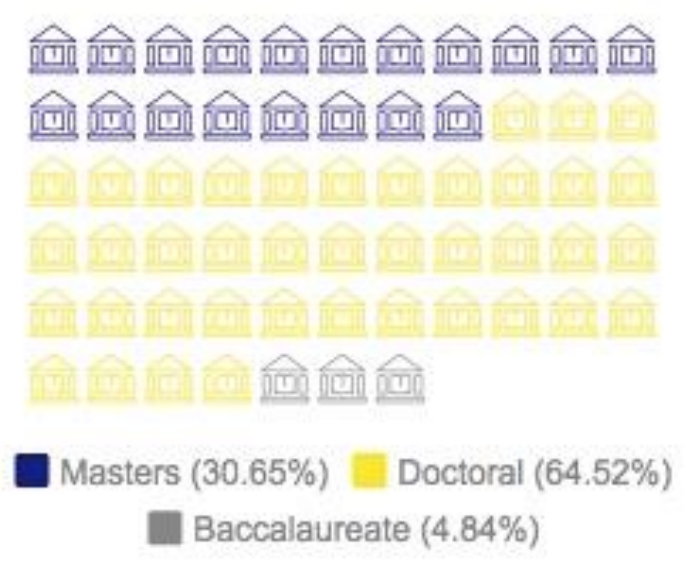

Figure

Figure 6: University Representation Models 7-8

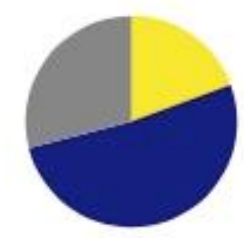

Town $(19.35 \%)$ City $(51.61 \%)$

Suburb $(29.03 \%)$

Figure 7: Local Government Representation Models 7-8 


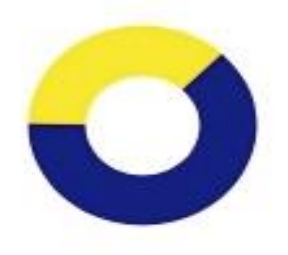

Private $(37.10 \%)$

Public (62.90\%)

Figure 8: Type of University Models 7-8

Table 19: Variable Operationalization Models 7-8

\section{Dependent Variable}

\begin{tabular}{|c|c|c|}
\hline DiffMBC & $\begin{array}{l}\text { Local Government } \\
\text { Perception of Mutually } \\
\text { Beneficial Collaboration } \\
\text { (Minus) University } \\
\text { Perception of Mutual } \\
\text { Beneficial Collaboration }\end{array}$ & $\begin{array}{l}\text { The two original variables } \\
\text { were Survey Data, Ordinal } \\
\text { Categorical variable based } \\
\text { on a Likert scale (1 } \\
\text { Strongly disagree- } 4 \\
\text { Strongly agree) } \\
\text { The new variable is a } \\
\text { continuous variable from } \\
-2 \text { to } 2 \text {. Tables } 22 \text { and } 23 \\
\text { detail the variable }\end{array}$ \\
\hline DiffEngagement & $\begin{array}{l}\text { Local Government } \\
\text { Perception of Engagement } \\
\text { (Minus) University } \\
\text { Perception of Engagement }\end{array}$ & $\begin{array}{l}\text { The two original variables } \\
\text { were Survey Data, Ordinal } \\
\text { Categorical variable based } \\
\text { on a Likert scale (1 } \\
\text { Strongly disagree- } 4 \\
\text { Strongly agree) } \\
\text { The new variable is an } \\
\text { interval variable from }-2 \text { to } \\
\text { 2. Tables } 20 \text { and } 21 \text { detail } \\
\text { the variable }\end{array}$ \\
\hline \multicolumn{3}{|l|}{ Independent Variables } \\
\hline In State & $\begin{array}{l}\text { Percent of students at a } \\
\text { given university that are } \\
\text { from the state }\end{array}$ & $\begin{array}{l}\text { Continuous variable } \\
\text { Mean: } 66.8\end{array}$ \\
\hline
\end{tabular}


Full Time Students

State and Local Funds

Median Age

Median Income

Poverty Rate

Unemployment Rate

Arrests on campus

Crimes on campus

Student Population
IPEDS data. Number of enrolled students in 20162017.

IPEDS data. Number of enrolled students in 20162017.

Census Data. Total number of persons living within the boundaries of the local government.

Census Data. Median age Continuous variable of persons living within the boundaries of the local government

Census Data. Median Income of persons living within the boundaries of the local government

Census Data. Poverty Rate of persons living within the boundaries of the local government

Census Data. Unemployment rate of persons living within the boundaries of the local government

IPEDS data. Number of arrests on campus in 20142017.

IPEDS data. Number of Continuous variable $\begin{array}{ll}\text { IPEDS data. Number of } & \text { Continuous variable } \\ \text { crimes on campus 2014- } & \text { Mean: } 162 \text { Crimes }\end{array}$ 2017.

IPEDS data. Number of Continuous variable enrolled students in 20162017.
Continuous variable (range \$14,738- \$16,577,062 state and local funds.

Continuous variable

Continuous variable

Continuous variable

Continuous variable

Continuous variable Mean: 282.2 Arrests 


\begin{tabular}{|c|c|c|}
\hline University Classification & $\begin{array}{l}\text { IPEDS classification of the } \\
\text { university }\end{array}$ & $\begin{array}{l}\text { Dummy variable Doctoral } \\
\text { (n: 40) Masters (n: 19), or } \\
\text { Bachelorette college or } \\
\text { university (n: } 3 \text { ) }\end{array}$ \\
\hline Campus Classification & $\begin{array}{l}\text { IPEDS classification of } \\
\text { where campus is located }\end{array}$ & $\begin{array}{l}\text { Dummy variable Town } \\
\text { (n:12), Suburb (n:18), and } \\
\text { City (n:32) encompass the } \\
\text { variable subcategories } \\
\text { within their name. }\end{array}$ \\
\hline Education Level & $\begin{array}{l}\text { Percent of population that } \\
\text { has a Bachelor's degree or } \\
\text { above }\end{array}$ & $\begin{array}{l}\text { Continuous variable } \\
\text { Mean: } 33 \text { Percent }\end{array}$ \\
\hline NSF Grants & $\begin{array}{l}\text { Aggregated amount of } \\
\text { NSF money received from } \\
\text { FY } 15-17\end{array}$ & $\begin{array}{l}\text { Dummy variable } 0=\text { no } \\
\text { NSF grants were received } \\
\text { in FY } 15-17 ; 1=\text { some } \\
\text { NSF grants were received } \\
\text { in FY } 15-17 \\
51(1) 11(0)\end{array}$ \\
\hline NIH Grant & $\begin{array}{l}\text { Aggregated amount of } \\
\text { NIH money received from } \\
\text { FY } 15-17\end{array}$ & $\begin{array}{l}\text { Dummy variable } 0=\text { no } \\
\text { NIH grants were received } \\
\text { in FY } 15-17 ; 1=\text { some NIH } \\
\text { grants were received in FY } \\
15-17 \\
41(1) 21(0)\end{array}$ \\
\hline
\end{tabular}

\section{Methods}

The analysis within this chapter has two dependent variables, DiffEngagment and DiffMBC (Mutually Beneficial Collaboration). The variable DiffEngagement was constructed by taking the difference between the local government's perception of engagement and the university's perception of the same. Likewise, the variable DiffMBC presents the difference between local government's perception of collaborations as mutually beneficial, and the perception of the university. Such that for all positive numbers except 0 , the local government had a better perception of engagement or that collaborations are mutually benefits than the university. For all negative integers, the local government had a worse perception of town and gown engagement or that 
collaborations are mutually beneficial than for the university. When the difference equaled zero, there was agreement between the local government and the university regarding their engagement or collaboration. It should be noted that when there was more than one response from either the university or the local government, the mean of the responses was used. For both variables, Table 25 and 27 displays agreement for the local government/university pairs.

There are twelve independent variables (See Table 19). For each dependent variable, DiffEngagement and Diffmbc, an ordered logistic regression was estimated, using either DiffEngagement or Diffmbc as the main explanatory variable. Additionally, regression analysis was subdivided by group: university administrator and city official.

Table 20: Agreement on Levels of Engagement

\section{Local Government $=$ University:} How Engaged is the Local Government with the University

\begin{tabular}{lc}
\hline Very Engaged & 6 \\
Somewhat Engaged & 9 \\
Somewhat Unengaged & 1 \\
\hline Total & 16
\end{tabular}

Table 21: Levels of Differences in Engagement

\begin{tabular}{lccc}
\hline Difference & $\begin{array}{l}\text { Local } \\
\text { University }\end{array}$ & Government & \multicolumn{1}{c}{$\begin{array}{l}\text { University }>\text { Local } \\
\text { Government }\end{array}$} \\
\hline 2 & 3 & 2 \\
or more & & 12 \\
$1-1.9$ & 4 & 12 \\
$>1$ & 13 & 26
\end{tabular}




\section{Agreement in Engagement}

As Table 20 demonstrates, $26 \%$ of universities agreed on their level of engagement. Of that, roughly $10 \%$ agreed that they were strongly engaged. Table 21 shows the variance in the answers. For example, if the local government answered 4 (very engaged) and the university answered 3 (somewhat engaged), they received a score of 1 . Therefore, the smaller the difference, the smaller the disagreement. The vast majority of pairs, $40 \%$, had a small difference from the other party, with a difference in perception of less than one. Roughly $34 \%$ of pairs show a difference of more than one, with $8 \%$ of pairs disagreeing entirely. The local government officials had a slightly less favorable perception of town-gown engagement, compared to university administrators.

Table 22: Agreement that Collaborations are Mutually Beneficial

Local Government $=$ University: Collaborations are Mutually Beneficial

\begin{tabular}{lc}
\hline Strongly Agreed & 7 \\
Somewhat Agree & 12 \\
Somewhat Disagree & 1 \\
\hline Total & 20
\end{tabular}

Table 23: Levels of Disagreement that Collaborations are Mutually Beneficial

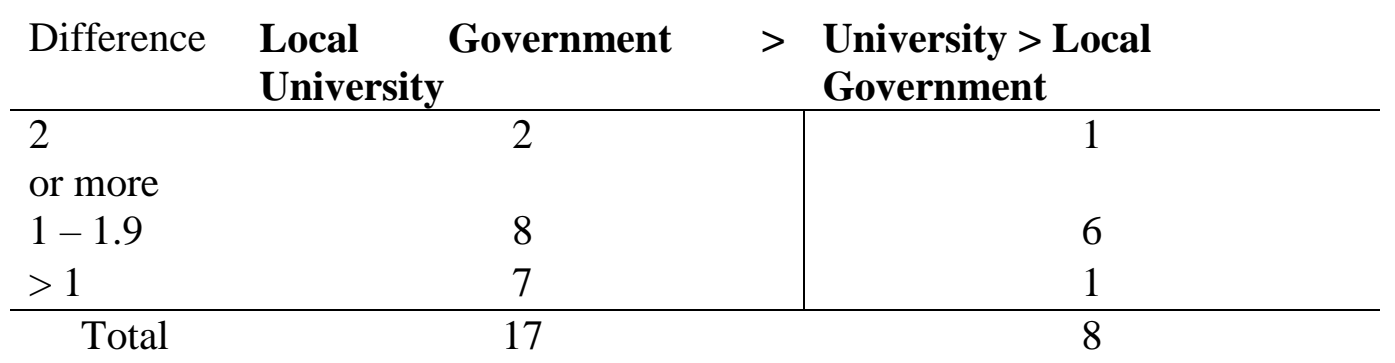

Of note, not all dyads answered the question whether collaboration is mutually beneficial—only $73 \%$, or 45 pairs, responded to that question. As table 23 displays, $44 \%$ 
of universities agreed on their perceptions that collaborations are mutually beneficial. Of that, a full $60 \%$ agreed that the collaborations were "somewhat" mutually beneficial. As with Table 22, the smaller the difference, the smaller the magnitude of disagreement. Approximately $38 \%$ of the pairs showed a difference of one or less. Roughly $18 \%$ had a considerable difference in their perception compared to the other party, with a difference between 1 and 1.9, with $6 \%$ of those respondents disagreeing entirely, with a difference in response of 2 or more. In contrast to engagement, the local government had a slightly more favorable perception of their collaborations were mutually beneficial, compared to university administrators.

\section{Rank Sum Test}

A rank sum test was done to determine if there was significant variance in responses given by city officials and university administrations. There was no statistically significant difference (see Table 24) in the way how engaged city officials and university administrators felt with the other party (Prob $>|z| 0.7282$ ). Moreover, as Table 25 shows, there was also no statistically significant difference in the answers given by city officials and university administrators on whether their collaborations were mutually beneficial (Prob $>|z|$ 0.1293). Although there is not statistical significance with regard to their answers, Models 7 and 8 provide analysis by subsamples (local government officials and university administrators, respectively) as well, for the overall sample. 
Table 24: RST-Engagement

\begin{tabular}{llll} 
Two-sample & Wilcoxon & rank-sum & (Mann-Whitney) \\
\hline & Obs & rank & sum expected \\
City Officials & 128 & 14458 & 14208 \\
University Admin & 93 & 10073 & 10323 \\
Combined & 221 & 24531 & 24531 \\
unadjusted variance & 220224.00 & & \\
adjustment for ties & -35145.20 & \\
adjusted variance & 185078.80 & \\
Ho: Diff (Office==City Official) $=$ Diff (Office==University) & \\
$Z=0.348$ & &
\end{tabular}

However, the Wilcoxon sign-rank test (see Table 27) did show a statistically significant difference in the variables diffengagement and diffMBC (Prob > $|\mathrm{z}|$ 0.0036). This test corroborates the findings in the previous chapter that there is a difference between engagement and collaboration and in how respondents perceive the two concepts.

Table 25: RST-MBC

\begin{tabular}{llll} 
Two-sample & Wilcoxon & rank-sum & $\begin{array}{l}\text { (Mann- } \\
\text { Whitney) }\end{array}$ \\
\hline & Obs & Rank & $\begin{array}{l}\text { Sum } \\
\text { Expected }\end{array}$ \\
City Officials & 94 & 7284 & 7708 \\
University Admin & 69 & 6082 & 5658 \\
Combined & 163 & 13366 & 13366 \\
unadjusted variance & 88642 & & \\
adjustment for ties & -10491.67 & & \\
adjusted variance & 78150.33 & \\
Ho: Diff (Office==City Official) = Diff (Office==University) & \\
$Z=1.517$ &
\end{tabular}

Prob > $|\mathrm{z}| \mathbf{0 . 1 2 9 3}$ 
Table 26: Engagement $=$ Collaborations are Mutually Beneficial

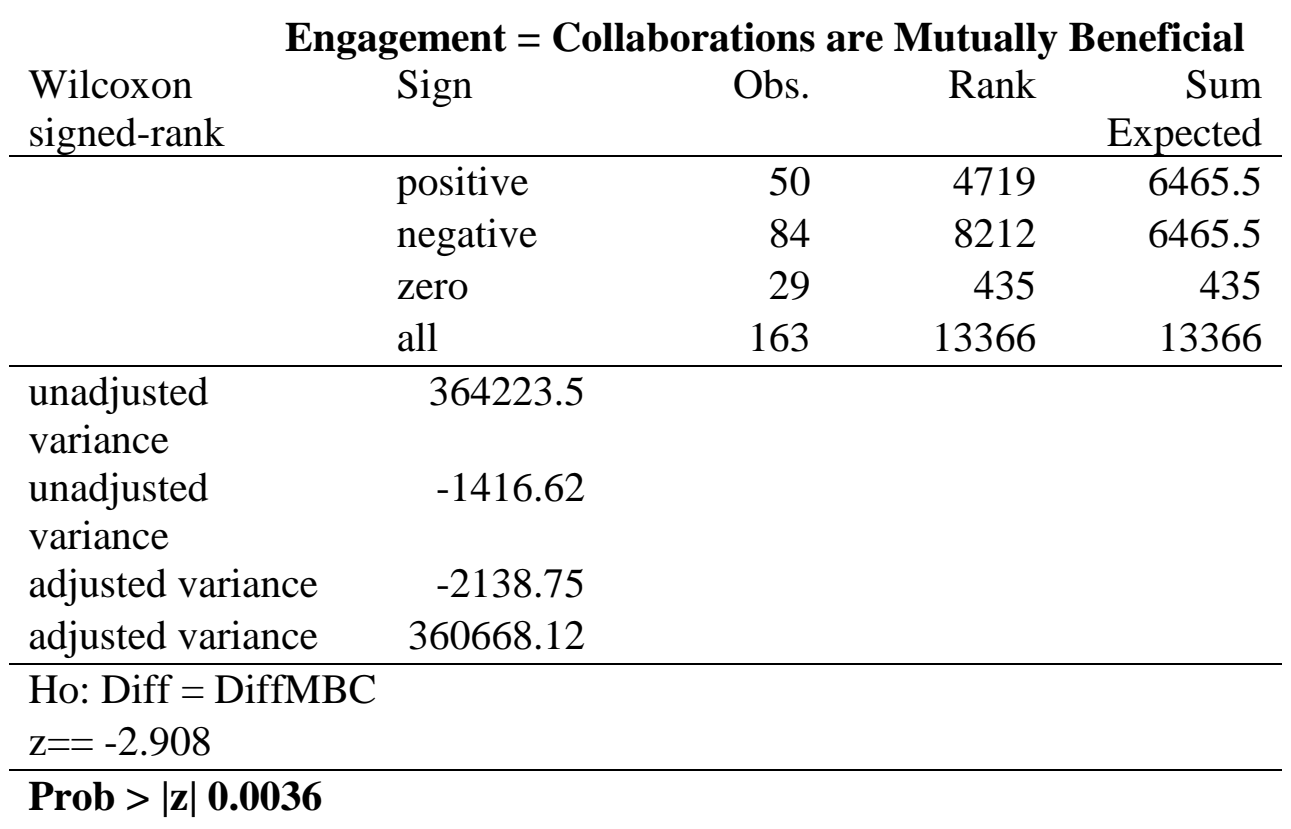

\section{Findings}

\section{Model 7}

Model 7 tests the hypothesis that agreement of mutually beneficial collaboration is positively associated with agreement in engagement. Furthermore, it tests whether agreement depends on the number of traditional students, amounts of grants, crime level, type of institution, and municipal demographics. This sample supports the hypothesis that agreement in collaboration is positively associated with agreement in engagement. In fact, the effect is statistically significant across the board. The odds of a local government officials' perceptions of engagement matching the universities' perceptions increases by a factor of five when they agree on whether their collaborations are mutually beneficial. Interestingly, for the local government officials and university officials, cities and suburbs seem to be negatively associated with engagement. Overall, it decreases the odds of agreement by a factor of 6.17 and 4.31 respectively, when compared to rural areas. It is 
surprising to note that while NIH funding is significant overall, it was insignificant for either group on their own. Nevertheless, NIH funding as positively associated with engagement, increasing the odds of agreeing on engagement by a factor of 3.094. Similarly, median age and poverty were marginally significant overall, increasing the odds of agreement by a factor of 1.066 and 1.036 , respectively.

Interestingly, for university administrators, the poverty rate was positively associated with agreement in levels of engagement. The poverty rate was not a significant factor for the local government officials. That is noteworthy because extant literature describes students as less likely to engage in improvised areas. From this sample, it is hard to discern if poverty was linked to lower engagement, or simply that is positively associated with agreement in engagement.

Of note, the difference between public and private universities seems insignificant and does not account for differences in perception. Similarly, crime seems to have no statistically significant effect on the level of agreement between the pairs on engagement. None of the other independent variables were statistically significant. The data do not support the hypothesis that university characteristics such as higher number of traditional students and more grant money relate positively with agreement in engagement. In fact, across the board those variables had no significant effect on agreement of engagement. 
Table 27: Model 7

\begin{tabular}{|c|c|c|c|}
\hline LG-Uni: Engagement (Diff) & LG Officials & Uni Admin & Overall \\
\hline \multirow[t]{2}{*}{ diffmbc } & $5.063 * * *$ & $4.255 * * *$ & $4.504 * * *$ \\
\hline & $(4.33)$ & $(3.52)$ & $(5.54)$ \\
\hline \multirow[t]{2}{*}{ NSFTotal } & 1.000 & 1.000 & 1.000 \\
\hline & $(0.72)$ & $(-0.56)$ & $(0.22)$ \\
\hline \multirow[t]{2}{*}{ NIHTotal } & 3.722 & 3.313 & 3.094* \\
\hline & $(1.92)$ & $(1.69)$ & $(2.42)$ \\
\hline \multirow[t]{2}{*}{ StatelocalFunds } & 1.000 & 1.000 & 1.000 \\
\hline & $(0.67)$ & $(0.99)$ & $(0.98)$ \\
\hline \multirow[t]{2}{*}{ PubIHE } & 0.595 & 0.357 & 0.433 \\
\hline & $(-0.71)$ & $(-1.29)$ & $(-1.62)$ \\
\hline \multirow[t]{2}{*}{ MedianAge } & 1.082 & 1.061 & $1.066 *$ \\
\hline & $(1.65)$ & $(1.26)$ & $(2.01)$ \\
\hline \multirow[t]{2}{*}{ PovertyRate } & 1.029 & $1.053 *$ & $1.036 *$ \\
\hline & $(1.47)$ & $(2.24)$ & $(2.39)$ \\
\hline \multirow[t]{2}{*}{ CampusCity } & $0.0979 * *$ & 0.261 & $0.162 * * *$ \\
\hline & $(-3.09)$ & $(-1.67)$ & $(-3.51)$ \\
\hline \multirow[t]{2}{*}{ CampusSuburb } & $0.230 *$ & 0.179* & $0.232 * *$ \\
\hline & $(-2.00)$ & $(-1.97)$ & $(-2.66)$ \\
\hline \multirow[t]{2}{*}{ DoctoralUni } & 1.797 & 0.473 & 1.053 \\
\hline & $(0.83)$ & $(-0.91)$ & $(0.10)$ \\
\hline \multirow[t]{2}{*}{ MastersColandUni } & 1.555 & 0.745 & 1.082 \\
\hline & $(0.62)$ & $(-0.42)$ & $(0.17)$ \\
\hline \multirow[t]{2}{*}{ InState } & 0.984 & 0.996 & 0.991 \\
\hline & $(-1.15)$ & $(-0.28)$ & $(-0.89)$ \\
\hline \multirow[t]{2}{*}{ FullTime } & 0.974 & 1.016 & 0.989 \\
\hline & $(-0.81)$ & $(0.40)$ & $(-0.45)$ \\
\hline \multirow[t]{2}{*}{ Arrests } & .9986238 & 1.000278 & .9993434 \\
\hline & $(0.062)$ & $(0.750)$ & $(.0818)$ \\
\hline \multirow[t]{2}{*}{ Crimesoncampus } & 1.006 & 1.001 & 1.005 \\
\hline & $(0.130)$ & $(0.818)$ & $(.0032)$ \\
\hline $\mathrm{N}$ & 94 & 69 & 163 \\
\hline$* \mathrm{p}<0.05$ & $* * \mathrm{p}<0.01$ & $* * * \mathrm{p}<0.00$ & \\
\hline
\end{tabular}


Table 28: Model 8

\begin{tabular}{llll} 
LG-Uni: MBC (DiffMBC) & LG Officials & Uni Admin & Overall \\
\hline Diff & $\mathbf{2 . 6 6 3 * *}$ & $\mathbf{2 . 4 0 9 *}$ & $\mathbf{2 . 6 7 4} * * *$ \\
NSFTotal & $(3.27)$ & $(2.54)$ & $(4.39)$ \\
& 1.000 & 1.000 & 1.000 \\
NIHTotal & $(-0.92)$ & $(1.56)$ & $(0.91)$ \\
& 2.442 & .5427 & 0.934 \\
StatelocalFunds & $(0.97)$ & $(-0.77)$ & $(-0.905)$ \\
& 1.000 & 1.000 & 1.000 \\
PubIHE & $(-0.32)$ & $(-0.02)$ & $(-0.65)$ \\
& 0.887 & $\mathbf{1 0 . 6 6} * *$ & $\mathbf{5 . 6 8 5} * *$ \\
MedianAge & $(-0.12)$ & $(2.82)$ & $(2.75)$ \\
& $\mathbf{0 . 8 0 2} * * *$ & 0.985 & $\mathbf{0 . 9 2 5}$ \\
PovertyRate & $(-3.50)$ & $(-0.32)$ & $(-2.12)$ \\
& $\mathbf{0 . 9 4 0 * *}$ & $\mathbf{0 . 9 3 0} * *$ & $\mathbf{0 . 9 3 9 * * *}$ \\
CampusCity & $(-3.20)$ & $(-2.96)$ & $(-4.28)$ \\
CampusSuburb & $\mathbf{7 8 . 4 9 * * *}$ & 5.086 & $\mathbf{1 1 . 8 3} * * *$ \\
& $(4.61)$ & $(1.95)$ & $(4.11)$ \\
DoctoralUni & $\mathbf{3 0 . 7 6 * * *}$ & 3.393 & $\mathbf{7 . 2 9 4} * *$ \\
& $(3.64)$ & $(1.32)$ & $(3.14)$ \\
MastersColandUni & 1.049 & 0.615 & 0.886 \\
& $(0.06)$ & $(-0.56)$ & $(-0.22)$ \\
InState & 0.435 & 1.922 & 1.393 \\
& $(-0.94)$ & $(0.89)$ & $(0.61)$ \\
FullTime & 1.034 & 0.987 & 1.001 \\
& $(1.77)$ & $(-0.82)$ & $(0.07)$ \\
\hline N & 1.006 & 0.997 & 1.010 \\
Standardized beta coefficients; t statistics in parentheses & & $(0.35)$ \\
& & $(-0.08)$ & 163 \\
& $(0.15)$ & &
\end{tabular}

\section{Model 8}

Model 8 tests the hypothesis that more traditional students, public institutions, larger grants, and greater town population increase the likelihood that university and local government will consider collaboration mutually beneficial. Additionally, it tests the hypothesis that higher levels of crime, poverty, and median age decrease the likelihood that university and local government will consider collaboration mutually beneficial. Finally, this model tests the hypothesis that agreement in levels of engagement will increase the likelihood of agreement that collaborations are mutually beneficial. The 
results of Model 8 do support the hypothesis that agreement in engagement is positively associated with agreement in collaboration as mutually beneficial. Among both local government and university officials, agreement in engagement increases the odds in agreement in collaboration by a factor of 2.67 and 2.4, respectively. Overall, agreement in engagement is highly significant $(\mathrm{p}<0.001)$ and increases the odds for agreement in collaboration by a factor of 2.7 .

Model 8 also supports the hypothesis that public universities agree more with their municipalities that collaborations are mutually beneficial. When compared to private institutions, agreement with regard to collaboration increases by a factor of 10.7 for university administrators, and a factor of 5.7 overall.

As with engagement, median age and poverty are negatively associated with agreement in collaborations as mutually beneficial. However, their impact is much smaller, decreasing by a factor of 1.08 and 1.06 , respectively. Although the magnitude of the effect is small, it does support the hypothesis that municipal factors, specifically median age and poverty, have negative association with agreement in collaborations as mutually beneficial.

In contrast to engagement, campuses in the city and in the suburbs, as compared to those in rural areas, are more likely to see collaborations as mutually beneficial. For local government officials, campuses in city increases the odds of agreement by a stunning factor of 78. Likewise, local government officials in the suburbs increase the odds of agreement by a factor of 30 . There is a clear distinction between local government officials in the city and suburban areas and those in rural areas. This clear distinction is not found in university administrators - there is no statistically significant 
difference between city and suburbs. Within the overall model, however, the odds of agreement in collaboration increase by a factor of 11 for respondent in the city and by a factor of 7 for respondents in suburban areas. This supports the hypothesis that the size of the local government is positively associated with agreement in collaboration.

The data do not support the hypothesis that agreement is more likely for universities with more traditional students. The variable capturing this effect, as well the variables measuring the full time and in-state students were not significant in the model. The institution's classification of doctoral, masters or baccalaureate had no impact on the agreement in collaboration either.

Surprisingly, financial incentives do not seem to have an effect on levels of agreement in collaboration as mutually beneficial. Neither research grants, nor local government and state grants were found to be significant for the agreement with regard to collaboration. This is a fairly remarkable finding given the importance of economic development and economic independence in previous chapters.

\section{Discussion}

This chapter aimed to uncover the factors predicting agreement between the local government and the universities in regard to engagement and collaboration. As Table 23 shows, agreement does not always mean that the engagement or collaboration is successful, however, agreement tended to skew towards the positive side.

Engagement and collaboration are often used interchangeably in the extant towngown literature. However, as the Wilcoxon sign-rank test shows, respondents perceive those terms differently, even if they are often conflated by the academic research. This can help explain why agreement that collaboration is mutually beneficial is positively 
associated with agreement in levels of engagement $(\mathrm{P}>0.001)$ across both university administrators and local government officials. That is not the case with agreement with regard to collaboration. While agreement in levels of engagement is significantly associated with agreement in collaboration, the effect size is considerably smaller. This may be indicative of a multi-directional association whereby a mutually beneficial collaboration increases engagement, but engagement, while important, is not be a factor for a mutually beneficial collaboration.

Models 7 and 8 also shed light on the importance of place. Agreement in levels of engagement was negatively associated with urban and suburban places, and positively associated, albeit slightly, with higher poverty level and median age. Yet, one finds the exact opposite relationship with regard to agreement in collaboration as mutually beneficial. In fact, the strongest association to the intensity of agreement that collaboration is mutually beneficial is for urban and suburban areas. This is an interesting finding, when one considers the urban-rural divide in the US with regard to politics, education, and even broadband coverage. Perhaps rural universities are engaged, but since they attract a largely external population to their campuses, the municipalities do not feel like those engagements benefit them as much as they benefit the students or university in general. This sentiment might be a symptom of the increasing rural disdain for higher education and increasingly low college enrollment by rural students, when compared to urban students (Marcus and Krupnick, 2017).

Another point of interest was the similarities in answers given by city officials and university administrators. That might be a consequence of the sample, after all these are communities that claim to be engaged. This sample provided no evidence that local 
government and university officials differed significantly when examining agreement in engagement and collaboration. That is a surprising finding given their unique points of view and different stakeholders. It could have been anticipated that their perceptions differed, particularly when probing the factors that impact their disagreement. Therefore, by and large, university administrators and local government officials are moved to agreement by roughly the same factors.

In a similar vein, this study shows that universities and local governments have a positive perception of engagement and collaboration as mutually beneficial. A total of $66 \%$ of respondents either agreed on their level of engagement or had a difference of less than one with the other party. Likewise, $62 \%$ of respondents agreed on collaboration. Again, all universities in the sample claim to be engaged. On the other hand, for a sample of universities that go out of their way to engage and be classified as engaged, one third of respondents' perceptions differed by more than one. 


\section{Chapter 9: Policy Recommendations and Conclusion}

\section{Overview of the Chapters}

Engagement can involve a number of different activities. It can be economic

development or student research. As chapter 6 shows, university and local government engagement takes a number of forms. Though it may take various forms, collaboration must be in union with the other party through a shared vision, clear goals, and within parties that are confident that the other party will follow through. Collaboration is more than the things that encompass engagement. It requires trust to build a united vision of the partnership. Understanding the two concepts as separate from one another, moved by differing factors, helps to better understand the dynamics between universities and municipalities.

The qualitative examination in Chapter 6 reveals that universities and local governments have different understandings of engagement. Such findings are particularly advantageous to the practical understanding of engagement through the lens of economic development, research, and student engagement. Finding the nuances within the practical understanding of engagement, such as workforce development, or the positive externality of sports, helps paint a wider picture of engagement, as seen through activities that are not traditionally thought of as engagement are consider such by the other party. Furthermore, while model 8 shows a strong association between urban areas and collaboration, it is perhaps the obstacles shown in Chapter 6, such as a lack of clarity on how the university and local government might work together, that is causing the urban/rural divide. 
Chapter 7 provided a cross-sectional study on perceptions of town/gown engagement and collaboration. Perceptions of engagement were significantly associated with local government leadership and interdependence, or if they considered each other stakeholders in economic and social issues facing their community. This is particularly important because no party will collaborate where they themselves are not invested. Taking care to include anchor institutions as an important stakeholder will help shore up buy-in when devising solutions to municipal problems. Likewise, the university can engender good will at the municipal level if they include the local government as a stakeholder when crafting the university's strategic plan, starting a capital campaign, or even deploying students out into the community for research.

This study helps shed light on the continuum of engagement for local government. For engagement to take place, the local government must have capacity (time, money, and skills) and their leadership must want to engage the university. The local government must view the university as a stakeholder that has something to provide, such as research expertise or economic influence. While local government or university capacity might be sufficient for engagement, they are not sufficient for collaboration. Collaboration must also include mutual trust that other party will deliver on what is considered a shared purpose.

Creating a shared purpose takes time. Time is part of capacity, and thus there is a circular relationship between engagement and collaboration. As noted in chapter 8, agreement in one is positively associated with agreement in the other. Yet, as chapter 8 demonstrates mutually beneficial collaboration has a bigger impact on engagement than engagement has on mutually beneficial collaboration. It is thus not the number of 
engagements that eventually brings mutually beneficial collaboration, but rather a mutually beneficial collaboration engenders more and more engagements. The circularity of these concepts is undoubtedly why they are often used interchangeably, but the nuance of the concepts far exceeds their similarities. Understanding and considering those nuances when engaging, not only the local government or university, but also the community, will potentially lead to better outcomes in collaborations.

\section{Policy Implications and Discussion}

As was observed earlier, town and gown engagements are largely initiated by the university. Both the qualitative and quantitative data demonstrate the need for a cohesive agenda in order to create a two-way street of engagement. However, it remains difficult to ascertain policy from organizational behaviors. For example, roughly a quarter of local government officials and university administrators stated unclear objectives as a major obstacle to collaboration. While conclusions about the causes and solutions of this problem abound, it is not feasible to establish causation from the organizational behaviors, such as shared vision and trust. That being said, there are number of policy implications and recommendations this dissertation puts forth for consideration and discussion.

The first research question seeks to understand how engagement varies, both in practice and as a concept. This study found that engagement as a concept varies profoundly. It varies in terms of who engagement is apt to serve (i.e., the community, university), and it varies in terms of its objective (i.e., economic development, student learning). This study has also found that engagement between universities and municipalities varies considerably, ranging, for example, between engagements on 
issues of public health to universities serving as a gathering place for city events. On the basis of these findings, the implication is that these two parties do not share a common definition of engagement and as a result are executing one-way engagement rather than an earnest collaboration.

This study also probes the factors that help and hinder engagement. It has become clear from most of this study that a lack of shared vision regarding engagement and collaboration between universities and local governments can account for most of the obstacles to working together. While creating a working definition of engagement is an important first step, that alone will not address the obstacles to working together. Instead, developing a clear understanding of what one party can offer the other is vital to creating clear objectives towards working together. The findings of this study suggest that university bureaucracy, poor communication, lack of interest and unclear objectives are the most common obstacles to engagement between universities and their local governments.

There are four policy implications derived from these findings. First, there may be too much red tape in what is an otherwise informal process of engagement and collaboration. That is, perhaps an undue burden which is being placed on the individuals that carry out engagement by administrators that simply collect data on engagement. Secondly, the manner in which the two parties operate and communicate may hinder collaboration, because university faculty and students often engage informally with communities, while local government officials usually operate in very formal bureaucratic system. 
The first two implications set up a seemingly paradoxical conundrum. On the one hand, there seems to be a rigid bureaucratic structure in place within universities, but on the other hand there seems to be a mismatch within the formal and informal communication preferences. This misalignment represents the third policy implication: communications between the local government and university are hampered because while engagement offices are often not the principal participants of engagement, they often create procedures to initiate engagement. This occurs in universities because while they operate within vertical organization structures, faculty and by extension their students, operate in a decentralized structure that allows for the freedom to engage in a manner that suits their own interests. If an engagement office does not take faculty into consideration, they can create burdensome rules that do not necessarily promote collaboration but rather promote one-way engagements. These procedures for collaboration can become much more burdensome than simply engaging the community on as researcher or with a group of students without developing shared goals.

The fourth policy implication is that the communication of either party is insufficient for the other party to be interested in collaboration. The data from the qualitative study show a lack of interest from either the university or the local government is obstacles to collaboration. The lack of interest may be a manifestation of a lack of clear objectives. As previously stated, roughly one third of the participants reported unclear objectives as the main obstacle to engagement. This lack of clarity can in effect create a one-way street of engagement, with one party having a clear goal and not concerning itself with the goal of the other. It also underscores the deep disconnect between the two institutions. Part of the purpose of this dissertation was to ascertain how 
municipalities and universities engage with one another. For at least a quarter of the respondents, the answer is: not very well.

\section{Policy Implications Research Questions 2 and 3:}

The implications of the second research question are derived from its major findings. Namely, that local government buy-in is the most significant factor for engagement, and Shared Vision and Trust are the most significant factors for collaboration.

The first policy implication is that engagement starts with buy-in from the leadership. Throughout the quantitative analysis, leadership is a significant variable within the engagement models. Leadership of both the university and local government was necessary for engagement to occur. There are a number of possible explanations. For universities, the internal politics of engagement offices offer a likely explanation. Largely undiscussed within this study, community engagement offices within universities are often deployed to serve the agendas of the university presidents. Accordingly, community engagement offices are highly disposed to the vision of the current administration and as such the leadership of the university would greatly influence the engagement of a given university.

Secondly, the university and the local government need to view the other as an important stakeholder in order to have mutually beneficial collaboration. The study examined the interdependence of the municipality and the university in both economic and social terms. As expected, interdependence on economic or social terms was positively associated with engagement on those issues. This implies that the parties involved need to consider that the other party will advance their respective agendas 
concerning those issues. Given the implications of the previous research question, this implies that within this sample at least a quarter of universities and local governments do not see clear interdependence on social and/or economic issues.

Lastly, the capacity (technical, financial, and time) of the local government is a determining factor for their engagement. While the engagement of local governments was dependent on their capacity, this was not found to be true for universities. The university's commitment to engaging the community, this sample in particular, renders their capacity do so a moot point. These universities have already put in time, money and technical capacity to engage. The same is not true for their respective local governments. For various aspects of engagement, different factors were significant. However, among the measures of capacity, monetary resources were the most significant variable in terms of engagement. From this sample, local governments engage if they have the money to do so or believe that the will be financially compensated for the engagement. The implication is that universities should approach local governments with collaborative projects that either save money or make money. This implication is important to keep in mind for projects that require collaboration, such as climate change resiliency, whose financial rewards manifest years later. Framing collaborations in way that saves the municipality money in terms of prevention might be the best approach when seeking to collaborate on wicked problems.

As mentioned throughout the dissertation, the factors that impact engagement are different than the factors that affect collaboration. Therefore, the policy implications are likewise different. There are three main policy implications from the findings pertaining to collaboration. First, collaboration can only be accomplished with a shared vision. This 
has been discussed previously, but bears repeating given that the measure was so significantly related to mutually beneficial collaboration. The finding is clear: engagement can be one sided, but collaboration requires a shared understanding of the metrics and goals of the partnership. The finding implies that local governments and universities that wish to collaborate must set aside their self interest in favor of a mutual goal that serves both parties in order to achieve more than either party could on their own.

The second implication of this study concerns collaboration as a priority for local governments, or more specifically Model 4 of the dissertation. From the research findings, university capacity is important for the local government to want to collaborate. Local governments need to know that their partnerships will be fruitful and that their partners have the capacity to work together. The implication, thus, is that onesided engagement for local governments is dependent on their monetary capacity, however, for collaboration occur local governments must trust that the university has the time, technical capacity and financial resources to make the collaboration successful. Short of that, collaboration is not a priority for the local government. This implication is important for universities to keep in mind when attempting to collaborate with their local government. Universities can at the onset of collaboration demonstrate the resources they plan on bringing to the partnership (i.e. full-time staff, research expertise). This would give local governments an understanding of the resources available to make a given collaboration work.

Finally, the most significant index variable for both engagement and collaboration is local government trust of the university. Trust, itself, was a leading 
significant variable in the index. The implication is that collaboration is only possible if the parties trust one another to solve conflicts, deliver on project goals, and are generally trustworthy. If university capacity is necessary for the local government to collaborate, the local government needs to trust that the resources of the university are not only accurately portrayed but also at the disposal of the partnership. Likewise, the leadership of both pairs is vital for a collaborative relationship and the respective leaders need to trust one another. All the other variables hinge upon this finding.

\section{Policy Recommendations for Local Governments}

The policy recommendations that lead from the implications of this research can be divided into recommendations for the local government and recommendations for the university. Based on the implications of this study, below are three policy recommendations for local government officials.

1: Proactive participation in university activities

2: Develop strategies for economic development that include the university

3: Appoint dedicated higher education personnel

The first policy recommendation is geared towards creating shared vision with the university. Proactively participating in university events is instrumental in creating relationships and avenues for shared objectives. It also creates opportunities for local government officials to make contacts for collaborative ventures, rather than wait for the university to initiate a partnership with the local government. Participating in events, symposiums, and lectures also allows local government officials to create contacts with the faculty, who are more often the ones with whom collaboration occurs. 
The second policy recommendation recognizes that local governments are more apt to engage if they feel they have an economic benefit for engagement. Developing shared economic strategies can help create an economic collaboration that improves the municipality and the university. Some specific examples of this include: holding meetings with university administrators and grant officials to examine if a project can garner state or federal grants, working together to attract businesses to the area, and inclusion of universities in municipal strategic planning.

The third policy recommendation is aimed at making the other two possible. A dedicated staff member charged with working to create relationships with the university will be instrumental to building trust and shared vision. Many municipalities already have a dedicated member that serves as a liaison for businesses and other nonprofit organizations. These liaison positions could include universities within the purview of their portfolio. Conversely, a separate staff position specifically dedicated to universities could be created. However, in the interest of sustainability, this should be implemented by formally adding the role of university liaison to the job description of the given position. Being part of the job description will ensure that regardless of who holds the position, the job function will be enshrined.

\section{Policy Recommendations for Universities}

Based on the implications of this study, below are three policy recommendations for university administrators:

1: Establish faculty-approved formalized procedures for engagement

2: Create an open access engagement database that encourages collaboration 
3: Develop a shared vision of engagement that accounts for the views of external stakeholders

The first recommendation is aimed at addressing the disconnect between the bureaucratic structure that might discourage collaboration. As with collaboration itself, a shared understanding of the formal procedures is required to develop useful mechanisms for collaboration. Specifically, community engagement offices could create a working group among faculty to develop best practices for engaging with the community and local government. Engagement offices could also create other materials, such as memorandums of understanding, that faculty could use in the event it is required by the local government. Such optional templates would help faculty formalize their engagement without expending additional time.

The second recommendation encourages the creation of a relationship with local partners. Universities are large, and even within universities themselves it is hard to know what research is being actively conducted. Having an open access database is an opportunity to inform both internal and external stakeholders on university research. Currently, the University of North Carolina System has a website dedicated to coalescing community engagement and economic development activities across their campuses. While each university or system can develop their own manner of disseminating this information, the database will allow anyone looking to collaborate on a given topic to find university resources. This represents a useful model that may be replicated elsewhere.

The objective of the last recommendation is to develop a shared vision between the university and the local government. The creation of a shared definition of 
engagement can happen in a variety of ways. For example, national organizations that work with local governments and universities, such as APLU or International City/County Management Association, could consider creating working groups that will develop a shared definition and disseminate it among its own constituencies. Another avenue that could create a shared definition is for local government and university officials to discuss themselves how they view engagement and how engagement can become mutually beneficial within their own specific context.

These recommendations are a first step towards creating a long lasting mutually beneficial relationship between local governments and their local university. As an anchor institution, universities have a vested interest in many of the same issues facing the local government. The difficulties of working together are eclipsed by the positive economic and social benefits to the community and surrounding areas.

\section{Limitations}

Admittedly, the present dissertation has a number of limitations. The study drew on a sample of 122 universities and municipalities, and 62 university-municipal pairs for the dyadic analysis. While it is an important first step towards understanding the dynamics of local government and university collaboration and engagement, more research needs to be done to test whether the effects derived from this analysis hold on a larger scale.

Another limitation of the study relates to the response rate. The survey was sent to every member of a particular city council, mayor, and city manager. There was a large disparity in the number of surveys sent and the number of returned surveys. Generally speaking, public emails were sent to general mail box, however it remains unclear how 
often those emails were read. In some instances, no email was publicly available. Rather to contact an elected official, it was necessary to use an online dialogue box designed to sort emails by district member. Such a mechanism is problematic because it is unclear if the elected member received the email or if it was filtered towards another inbox of unwanted or out of district emails. A similar problem was presented using traditional emails. It was unclear how many of those emails were even opened. Future studies could be more sensitive to the difficulties of reaching elected officials through email.

Another limitation to the study pertains to engagement offices themselves. The vast majority of the engagement is conducted not by engagement offices, but by faculty. Engagement offices, under the best circumstances, are there to act as clearinghouses and agenda setters. Engagement offices provided the institutional perspective that correlated with the local government perspective. That said, reaching engagement offices also proved more difficult than I expected. Email address and general contact information were sometimes not readily available on engagement office website. Additionally, some websites did not have up to date information about their directors or members of their offices.

Some engagement offices did have up to date information, but the directors did not want to take the survey. Two reasons were given for not taking the survey: engagement offices were not government relations offices, and thus did not work with local governments; and they felt their perception of engagement differed from that of the larger institution and did not want to misrepresent how the university works with the local government. One interesting manifestation of that was a phone call I received from an engagement office director. The person explained that the university maintains that 
they work very closely with the local government, but this person thought that relations were actually quite strained. The person wanted to take the survey but wanted assurances that it could not be traced back to them. While extreme, it is wholly within the realm of possibility that more than one person felt this way but did not take the time to speak with me about their concerns. Rather they ignored the request out right. This concern might have to be mitigated in some way for future research.

The other major limitation was the number of university/local government pairs. Roughly half of anticipated pairs participated. Of those, a little less than $75 \%$ answered all the questions in the survey. While this is not an insurmountable challenge, it does provide this dissertation with limitations. More pairs would have given a more accurate portrait for the external factors that drive agreement. Finally, there are limitations to studies analyzing perceptions. A person's perception is often shaped by their experience and might shift way or other in a matter that is not truly indicative of the situation. Nevertheless, the cross-sectional nature of this study attempted to mitigate that issue. However, it is a limitation that needs to be noted.

Lastly, this dissertation omits the political and power dynamics of university engagement offices. By design, the survey did not measure the university's political and organizational interests. However, in excluding those factors fails to account for important aspects of university engagement practices. The pressure places on engagement offices attain the Carnegie Classification might well explain the findings that some universities/local government pairs view themselves as not engaged. 


\section{Future Research}

This dissertation sought to understand the dynamics between local governments and their local universities. Future research should consider more objective measures than the perception-based ones used in this study. As noted, a limitation to this study was the sample size. There are thousands of universities and municipal pairs, and this study only examined a small number of them. Future studies can expand on this study by including more university/municipal pairs of all sizes. Finally, scholars could expand the scope to include other anchor institutions, such as hospital systems, school districts, and other nonprofit organizations.

Specifically, future research around this topic will be approached in four distinct ways: a similar study with all the schools on the Carnegie list; an updated study with the 62 pairs to ascertain more information and do a follow up survey; the third approach will be to branch out to Hispanic Serving Institutions, Historically Black Colleges and Universities, and other institutions whose mission it is to serve a historically underserved community; and lastly, use the information on community engagement and universities and apply it towards university led health systems. The implications of this study can be directed towards all anchor institutions. Understanding how those two entities can work together under any circumstances will prove beneficial when challenges arise that can be best met by collaborating, such as issues related to climate change or chronic poverty.

Possibly the most unexpected finding of this study is that despite the fact that the pairs were chosen on account of their perceived collaborative relationship, this dissertation found a number of discordant and divergent viewpoints. If under the best circumstances there is still room for improvement, compiling best practices in 
town/gown engagement will be invaluable to university/local government pairs that have not sought out a mutually beneficial relationship.

Finally, this study is ultimately about anchor institutions. Traditionally, Anchor Institutions have been described as "Eds and Meds." This study examined universities, but future research will explore how hospitals and academic medical centers play a key role in addressing health equity and the social determinants of health within their community. Future research on all anchor institutions will move beyond perceptions of engagement to measure metrics and outcomes, such as procurement practices and jobs created within a variety of anchor settings.

\section{Conclusion}

It is in the best interest of the community for universities and local governments to work together. As anchor institutions, universities and local governments often face different aspects of the same issues and challenges, such as workforce and economic development. This dissertation examines the factors that can aid the process of working together. More specifically, it examines the factors that may lead to one-way engagement and the factors that lead to mutually beneficial collaboration. Increasingly, institutions engage with their communities. However, it is often a one-sided approach that singularly serves the goals of the university. In that way, engagement is a self-interested activity with positive and negative externalities, rather than a collaboration whose purpose is to be mutually beneficial. The findings indicate that to participate in a mutually beneficial partnership requires a shared vision and shared goals. In order to accomplish more for their given community, each university/municipal pair must work together to create a 
shared understanding of their partnership, rather than working to accomplish different goals.

However, identifying the differences in thinking between the two parties can prove very beneficial towards developing and improving a working relationship. For example, findings show that public health and public education are areas that have been identified as potentially successful town-gown partnerships. It is also clear that there are many other areas where local government and universities can improve and work together toward the common good of both entities. Further, understanding the elements that make a project mutually beneficial will help both outcomes of the project and the relationship between the two parties. In the end, perhaps even under the best circumstances, engagement between local governments and universities was best expressed by the sentiment of a participating city council member: "it is arduous but improving". 


\section{References}

Abbas, A., Avdic, A., Xiaobao, P., Hasan, M. M., \& Ming, W. (2018). Universitygovernment collaboration for the generation and commercialization of new knowledge for use in industry. Journal of Innovation \& Knowledge

Addie, J. P. D., Keil, R., \& Olds, K. (2015). Beyond town and gown: Universities, territoriality and the mobilization of new urban structures in Canada. Territory, Politics, Governance, 3(1), 27-50.

Agranoff, R. (2006). Inside collaborative networks: Ten lessons for public managers. Public Administration Review, 66(s1), 56-65.

Agranoff, R. (2006). Inside collaborative networks: Ten lessons for public managers. Public Administration Review, 66(s1), 56-65.

Agranoff, R., \& McGuire, M. (2003). Collaborative public management: New strategies for local governments. Washington, D.C.: Georgetown Univ. Press.

American Recovery and Reinvestment Act of 2009, Pub. L. No. 111-5, 123 Stat. 115, 128.

Amin, A., \& Thrift, N. (1995). Institutional issues for the European regions: from markets and plans to socioeconomics and powers of association. Economy and society, 24(1), 41-66.

Ansell, C., \& Gash, A. (2008). Collaborative governance in theory and practice. Journal of Public Administration Research and Theory, 18(4), 543-571.

Arefi, M., \& Al-Douri, F. (2016). Exploring pedagogical opportunities between architecture and planning: the case of University of Nevada, Las Vegas. Planning Theory \& Practice, 17(1), 72-92.

Armstrong, H. (1997). Australian Collaborative Design Paradigms: Universities, Designers, Communities. Laurence and Samuels Lorenso. Emergent Paradigms in Design Education. Sydney, 10-13.

Axelroth, R., \& Dubb, S. (2010). The Road Half Traveled.

Barzun, J. (1993). The American university: How it runs, where it is going. University of Chicago Press.

Beam, P (2018) Community members describe ISU President's importance, KPVD.com 
Berry, B. J. L., \& Marble, D. F. (1968). Spatial analysis: a reader in statistical geography. Prentice-Hall.

Berube, M. R. (1978). The Urban University in America.

Bleaney, M. F., Binks, M. R., Greenaway, D., Reed, G. V., and Whynes, D. K. (1992). What does a university add to its local economy? Applied Economics, 24(3), 305-311.

Bok, D. C.,2009). Beyond the ivory tower: Social responsibilities of the modern university. Harvard University Press.

Borrero, N., \& Reed, J. (2016). A Case for Community Partnership and Professional Development: A Nine-Week Service-Learning Seminar for Faculty. Partnerships: A Journal of Service-Learning and Civic Engagement, 7(1), 27-51

Boucher, G., Conway, C., and Van der Meer, E. (2003). Tiers of engagement by universities in their region's development. Regional Studies, 37(9), 887-89

Boucher, G., Conway, C., and Van der Meer, E. (2003). Tiers of engagement by universities in their region's development. Regional Studies, 37(9), 887-89

Boyer, E. L. (1996). The scholarship of engagement. Bulletin of the American Academy of Arts and Sciences, 49(7), 18-33

Boyer, E.L. (1990). Scholarship reconsidered: priorities of the professoriate. Princeton

Bringle, R. G., \& Hatcher, J. A. (1996). Implementing service learning in higher education. The Journal of Higher Education, 67(2), 221-239.

Brown, J. R., \& Hoxby, C. M. (Eds.). (2014). How the financial crisis and great recession affected higher Education. University of Chicago Press.

Burt, R. S. (1997). A note on social capital and network content. Social networks, 19(4), 355-373.

Carter, E. H. (2017). Examining Off-Campus Students' Sense of Belonging and Behaviors in a Town-Gown Context. Michigan State University.

Cheng, Y. D. (2018). Nonprofit Spending and Government Provision of Public Services: Testing Theories of Government-Nonprofit Relationships. Journal of Public Administration Research and Theory

Christenson, S. L., Reschly, A. L., \& Wylie, C. (Eds.). (2012). Handbook of research on student engagement. Springer Science \& Business Media.

Clark, J. K., Kaiser, M. L., Hicks, R., Hoy, C., Rogers, C., \& Spees, C. K. (2015). Community-University Engagement via a Boundary Object: The Case of Food 
Mapping in Columbus, Ohio. Journal of Public Scholarship in Higher Education, 5, 126-142.

Clarke, K., \& DeGreeve, J. (2016). Town-Gown Collaborations for Enhancing Student Research Skill

Daneri, D. R., Trencher, G., \& Petersen, J. (2015). Students as change agents in a town-wide sustainability transformation: The Oberlin Project at Oberlin College. Current Opinion in Environmental Sustainability, 16, 14-21

Downs, A. (1967). Inside bureaucracy: A RAND Corporation research study. Waveland Press.

Driscoll, A. (2008). Carnegie's community-engagement classification: Intentions and insights. Change: The Magazine of Higher Learning, 40(1), 38-41.

Dubb, S., \& Howard, T. (2012). Leveraging anchor institutions for local job creation and wealth building. Big Ideas for Job Creation, 04-12.

Dubb, S., McKinley, S., \& Howard, T. (2013). The anchor dashboard: Aligning institutional practice to meet low-income community needs. Democracy Collaborative.

Ehlenz, M. M. (2017). Gown, town, and neighborhood change: An examination of urban neighborhoods with university revitalization efforts. Journal of Planning Education and Research, 0739456X17739111.

Emerson, K., \& Nabatchi, T. (2015a). Collaborative governance regimes. Washington, D.C.: Georgetown Univ. Press.

Emerson, K., \& Nabatchi, T. (2015b). Evaluating the productivity of collaborative governance regimes: A performance matrix. Public Performance and Management Review, 38(4), 717-747.

Emerson, K., Nabatchi, T., \& Balogh, S. (2012). An integrative framework for collaborative governance. Journal of Public Administration Research and Theory, 22(1), 1-29.

Etzkowitz, H. (2003). Innovation in innovation: The triple helix of university-industrygovernment relations. Social science information, 42(3), 293-337

Fattal, I (2018) What DACA's End Could Mean for Colleges. Atlantic Magagize

Feiock, R. C. (2007). Rational choice and regional governance. Journal of Urban Affairs, 29(1), 47-63. 
Feiock, R. C. (2008). Institutional collective action and local government collaboration. In L. Blomgren Bingham \& R. O'Leary (Eds.), Big ideas in collaborative public management (pp. 195-210). Armonk, NY: M.E. Sharpe.

Fenske, R. H. (1980). Setting institutional goals and objectives. In P. Jedamus \& M. W. Peterson (Eds.), Improving academic management (pp. 177-199). San Francisco: Jossey-Bass.

Florida, R. (2002). The rise of the creative class (Vol. 9). New York: Basic books.

Ford, E. (2016). Bringing Town and Gown Together: Using Local History to Engage Students and Create Collaborative Partnerships. Journal of Museum Education, 41(4), 262-274.

Foster-Fishman, P. G., Berkowitz, S. L., Lounsbury, D. W., Jacobson, S., and Allen, N. A. (2001). Building collaborative capacity in community coalitions: A review and integrative framework. American Journal of Community Psychology, 29(2), 241-261.

Fulbright-Anderson, K., Auspos, P., \& Anderson, A. (2001). Community involvement in partnerships with educational institutions, medical centers, and utility companies. Baltimore, MD: Annie E. Casey Foundation.

Funkhouser, M, (2015). The Benefits of a Better Town-and-Gown Relationship, Governing Magazine

Gabbay, S. M., and Zuckerman, E. W. (1998). Social capital and opportunity in corporate RandD: The contingent effect of contact density on mobility expectations. Social Science Research, 27(2), 189-217.

Gavazzi, S. M., \& Fox, M. (2015). A Tale of Three Cities: Piloting a Measure of Effort and Comfort Levels within Town-Gown Relationships. Innovative Higher Education, 40(3), 189-199.

Goldrick-Rab, S., Cady, C., and Coca, V. Campus Food Pantries: Insights from a National Survey. Hope Center for College, Community and Justice. (2018)

Goodman, E. P. (2013). Smart Cities Meet Anchor Institutions: The Case of Broadband and the Public Library. Fordham Urb. LJ, 41, 1665.

Goodman, R. M., Speers, M. A., McLeroy, K., Fawcett, S., Kegler, M., Parker, E and Wallerstein, N. (1998). Identifying and defining the dimensions of community capacity to provide a basis for measurement. Health Education and Behavior, 25(3), 258-278.

Grabher, G., Amin, A., and Thrift, N. (1994). The disembedded regional economy: the transformation of East German industrial complexes into Western enclaves. 
Gray, B. (1989). Collaborating: Finding common ground for multiparty problems.

Griffiths, H., \& Best, J. (2016). Social problems clusters as contexts for claimsmaking: implications for the study of off-campus housing. Sociological Spectrum, 36(2), 75-92.

Gunasekara, C. (2006). The generative and developmental roles of universities in regional innovation systems. Science and Public Policy, 33(2), 137-150.

Gupta, C., Campbell, D., Munden-Dixon, K., Sowerwine, J., Capps, S., Feenstra, G., \& Kim, J. V. S. (2018). Food policy councils and local governments: Creating effective collaboration for food systems change. Journal of Agriculture, Food Systems, and Community Development, 8(B), 11-28.

Hadfield, M., \& Ainscow, M. (2018). Inside a self-improving school system: Collaboration, competition and transition. Journal of Educational Change, 19(4), 441462.

Hagel, J., and Armstrong, A. (1997). Net gain: Expanding markets through virtual communities. Harvard Business Press.

Hechinger, G. (2003). Clark Kerr, Leading Public Educator and Former Head of California's Universities, Dies at 92. New York Times, 2, 1960-1975.

Hendriks, A. M., Jansen, M. W., Gubbels, J. S., De Vries, N. K., Molleman, G., \& Kremers, S. P. (2015). Local government officials' views on intersectoral collaboration within their organization-A qualitative exploration. Health Policy and Technology, 4(1), 47-57

Hodges, R. A., \& Dubb, S. (2012). Road half traveled: University engagement at a crossroads. East Lansing, MI: Michigan State University Press.

Hospers, G. J., Desrochers, P., \& Sautet, F. (2009). The next Silicon Valley? On the relationship between geographical clustering and public policy. International Entrepreneurship and Management Journal, 5(3), 285-299.

Iimoto, T., Nunokawa, J., Fujii, H., Takashima, R., Hashimoto, M., Fukuhara, T., ... \& Someya, S. (2015). Collaboration of local government and experts responding to increase in environmental radiation level due to the nuclear disaster: focusing on their activities and latest radiological discussion. Radiation protection dosimetry, 167(1-3), $358-364$

Keane, and Janelle Allison. (1999). The intersection of the learning region and local and regional economic development: Analyzing the role of higher education. Regional Studies 33 (9): 896-902. 
Kellogg Commission on the Future of State, Land-Grant Universities, National Association of State Universities, \& Land-Grant Colleges. (1999). Returning to our roots: The engaged institution (Vol. 3). National Association of State Universities and Land-Grant Colleges, Office of Public Affairs.

Kellogg Commission. (1999). Returning to our roots: The engaged institution [Working paper, Retrieved from http://www.aplu.

org/NetCommunity/Document.Doc?id=183

Kerr, C. (1968). The urban-grant university. A model for the future. New York: City College.

Kiron, D., Kruschwitz, N., Haanaes, K., Reeves, M., Fuisz-Kehrbach, S. K., \& Kell, G. (2015). Joining forces: Collaboration and leadership for sustainability. MIT Sloan Management Review, 56(3), 1-31.

Kuh, G. D. (2009). What student affairs professionals need to know about student engagement. Journal of College Student Development, 50(6), 683-706.

Lassick, C. E., Huber, M. T., Maeroff, G. I., and Boyer, E. L. (1997). Scholarship assessed. San Francisco: Jossey-Bass.

Levy, A. (2015). Advancing Local E-government Through Town-gown Collaboration in the Web 2.0 Environment: A Comparative Case Study of Six Small Municipalities in Pennsylvania.

Lin, N., and Dumin, M. (1986). Access to occupations through social ties. Social Networks, 8(4), 365-385.

Lindblom, C. E. (1977). Politics and Markets.

Liu, C. (2017). University Spatial Development and Urban Transformation in China. Routledge

Lynton, E. A. (1995). Making the Case for Professional Service. Forum on Faculty Roles and Rewards.

Mapes, J., Kaplan, D., Turner, V. K., \& Willer, C. (2017). Building 'College Town': Economic redevelopment and the construction of community. Local Economy, 32(7), 601-616.

Matthews, T., \& Smith, G. (2015). 'Town+ Gown'and CCNY's sustainability in the urban environment program. Current opinion in environmental sustainability, 17, 4247. 
Mayer, M., \& Kenter, R. (2015). The prevailing elements of public-sector collaboration. Advancing collaboration theory: Models, typologies, and evidence, 13, 43-64.

McCartan, J., \& Palermo, C. (2017). The role of a food policy coalition in influencing a local food environment: an Australian case study. Public health nutrition, 20(5), 917926.

McGirr, D., Kull, R., \& Enns, K. S. (2003). Town and gown. Economic Development Journal, 2(2), 16-23.

Moos, M., Revington, N., Wilkin, T., \& Andrey, J. (2018). The knowledge economy city: Gentrification, studentification and youthification, and their connections to universities. Urban Studies, 0042098017745235

Mosher, R., \& MacGowan (1985). Assessing Student Engagement in Secondary Schools: Alternative Conceptions. Strategies of Assessing, and Instruments.

Mosier, S. (2015). Does the Gown Help the Town? Examining Town-Gown Relationship Influence on Local Environmental Sustainability in the United States. International Journal of Public Administration, 38(11), 769-781.

Mowery, D. C., Nelson, R. R., Sampat, B., and Ziedonis, A. A. (1999). The effects of the Bayh-Dole Act on US university research and technology transfer: An analysis of data from Columbia University, the University of California, and Stanford University. Research Policy, 29, 729-40.

Nahapiet, J., and Ghoshal, S. (1998). Social capital, intellectual capital, and the organizational advantage. Academy of Management Review, 23(2), 242-266.

Niewolny, K. L., Grossman, J. M., Byker, C. J., Helms, J. L., Clark, S. F., Cotton, J. A., \& Jacobsen, K. L. (2016). Sustainable agriculture education and civic engagement: The significance of community-university partnerships in the new agricultural paradigm. Journal of Agriculture, Food Systems, and Community Development, 2(3), $27-42$.

O'Mara, M. P. (2015). Cities of knowledge: Cold War science and the search for the next Silicon Valley. Princeton University Press.

O'Mara, M. P. (2005). Cities of knowledge: Cold war science and the search for the Next Silicon Valley. New York: Princeton University Press.

O’Mara, M. P. (2007). Landscapes of knowledge: History and the evolving geography of high technology. Places, 19, 1. 
O'Mara, M. P. (2012). Beyond town and gown: university economic engagement and the legacy of the urban crisis. The Journal of Technology Transfer, 37(2), 234-250.

O’Meara, K. (2007). Striving for what? Exploring the pursuit of prestige. In Higher Education: Handbook of Theory and Research (pp. 121-179). Springer Netherlands.

Pérez-López, G., Prior, D., \& Zafra-Gómez, J. L. (2015). Rethinking new public management delivery forms and efficiency: Long-term effects in Spanish local government. Journal of Public Administration Research and Theory, 25(4), 1157-1183.

Perry, D. C. (2010), The University and Urban Revival: Out of the Ivory Tower and Into the Streets by Judith Rodin. Journal of Urban Affairs, 32: 134-137.

Perry, D. C., \& Wiewel, W. (2015). The University as Urban Developer: Case Studies and Analysis: Case Studies and Analysis. Routledge.

Perry, D. C., and Wiewel, W. (Eds.). (2005). The university as urban developer: Case studies and analysis. ME Sharpe.

Perry, D. C., Wiewel, W., \& Menendez, C. (2009). The university's role in urban development: From enclave to anchor institution. Land Lines, 21(2), 2-7.

Podolny, J. M., and Baron, J. N. (1997). Resources and relationships: Social networks and mobility in the workplace. American Sociological Review, 673-693.

Porter, M. E. (1998). Clusters and the new economics of competition (Vol. 76, No. 6, pp. 77-90). Boston: Harvard Business Review.

Porter, M. E. (2000). Location, competition, and economic development: Local clusters in a global economy. Economic development quarterly, 14(1), 15-34.

Portes, A. (2000, March). The two meanings of social capital. In Sociological forum (Vol. 15, No. 1, pp. 1-12). Kluwer Academic Publishers-Plenum Publishers.

Powell, K. H. (2016). A New Neighborhood Every Fall: Aging in Place in a College Town. Journal of gerontological social work, 59(7-8), 537-553.

Putnam, R. D. (1995). Bowling alone: America's declining social capital. Journal of Democracy, 6(1), 65-78.

Rodrigues, C., \& Melo, A. I. (2013). The Triple Helix Model as Inspiration for Local Development Policies: An Experience-Based Perspective. International Journal of Urban and Regional Research, 37(5), 1675-1687 
Roper, C. D., \& Hirth, M. A. (2005). A history of change in the third mission of higher education: The evolution of one-way service to interactive engagement. Journal of Higher Education Outreach and Engagement, 10(3), 3-21

Roussos, S. T., and Fawcett, S. B. (2000). A review of collaborative partnerships as a strategy for improving community health. Annual Review of Public Health, 21, 369402.

Sandmann, L. R., and Weerts, D. J. (2006). Engagement in higher education: Building a federation for action. A Wingspread Report.

Schildt, C., \& Rubin, V. (2015). Leveraging anchor institutions for economic inclusion. Oakland: PolicyLink.

Shelton, A. J. (2016). Implementing community engagement projects in classrooms. Journal of Higher Education Theory \& Practice, 16(1).

Shen, R., Feiock, R. C., \& Yi, H. (2017). China's local government innovations in inter-local collaboration. In Public service innovations in China (pp. 25-41). Palgrave, Singapore.

Sitas, N., Reyers, B., Cundill, G., Prozesky, H. E., Nel, J. L., \& Esler, K. J. (2016). Fostering collaboration for knowledge and action in disaster management in South Africa. Current Opinion in Environmental Sustainability, 19, 94-102.

Srouri, D. (2005, June). Colleges of Cambridge: The Spatial Interaction between the Town and the Gown. In Proceedings of Fifth International Space Syntax Symposium (pp. 13-17

Starr, K. (2015). Small rural school leadership: Creating opportunity through collaboration. In School leadership in diverse contexts (pp. 49-62). Routledge

Strong, J. (1907). The challenge of the city. Young people's missionary movement.

Swann, W. L. (2017). Examining the Impact of Local Collaborative Tools on Urban Sustainability Efforts: Does the Managerial Environment Matter?. The American Review of Public Administration, 47(4), 455-468.

Taylor, H. L., \& Luter, G. (2013). Anchor institutions: An interpretive review essay. Anchor Institutions Task Force, 14.

Thanki, R. 1999. How do we know the value of higher education to regional development? Regional Studies 33: 84-89. 
Tolsma, J., Van der Meer, T., and Gesthuizen, M. (2009). The impact of neighbourhood and municipality characteristics on social cohesion in the Netherlands. Acta Politica, 44(3), 286-313.

Tomkinson, R. (2017). Shared services in local government: improving service delivery. Routledge.

Toutkoushian, R. K., and Shafiq, M. N. (2010). A conceptual analysis of state support for higher education: Appropriations versus need-based financial aid. Research in Higher Education, 51(1), 40-64.

Troost, S. (2016). The Optimal Town-Gown Marriage: Taking Campus-Community Outreach and Engagement to the Next Level. Planning for Higher Education, 44(4), 108

Tsipouri L., Lalayanni E. and Papadakou M. (2000a) UNIREG Regional Case Study Report: Athens. Centre of Financial Studies, University of Athens, Athens.

Tsipouri, L. (2000, November). Regional innovation indicators: merits and problems. In Conference Innovation and Enterprise Creation: Statistics and Indicators France, 2324 (Vol. 11).

Uveges, J. A., \& Carter, L. F. (1983). The university as a bureau: Public administration and higher education. Public Administration Quarterly, 102-114.

Valdivia, W. D. (2013). University start-ups: Critical for improving technology transfer. Center for Technology Innovation at Brookings. Washington, DC: Brookings Institution.

Van der Meer, J. (2003). Rain or fog? An empirical examination of social capital's rainmaker effects. In Generating Social Capital (pp. 133-151). Palgrave Macmillan US.

Vernon, K. (2017). Engagement, estrangement or divorce? The new universities and their communities in the 1960s. Contemporary British History, 31(4), 501-523

Vogt, C., Jordan, E., Grewe, N., \& Kruger, L. (2016). Collaborative tourism planning and subjective well-being in a small island destination. Journal of Destination Marketing \& Management, 5(1), 36-43

Wallis, J., and Dollery, B. (2002). Social capital and local government capacity. Australian Journal of Public Administration, 61(3), 76-85.

Wandersman, A., Goodman, R. M., and Butterfoss, F. D. (1997). Understanding coalitions and how they operate: An open systems framework. In M. Minkler (Ed.), Community organizing and community building for health (pp. 261-277). New Brunswick, N.J.: Rutgers University Press. 
Weber, E. U., \& Johnson, E. J. (2009). Mindful judgment and decision making. Annual review of psychology, 60, 53-85.

Weerts, D., and Hudson, E. (2009). Engagement and institutional advancement. New Directions for Higher Education, 147, 65-74.

Wiewel, W., \& Perry, D. C. (2015). Global Universities and Urban Development: Case Studies and Analysis: Case Studies and Analysis. Routledge.

Wiewel, W., \& Perry, D. C. (2015). Varsity Real Estate in Scotland: New Visions for Town and Gown?. In Global Universities and Urban Development: Case Studies and Analysis (pp. 77-104). Routledge.

Wise, N. (2017). Local community and local economy: Place, policies and power at the micro-scale.

Wynn, J. (2017). An arson spree in college town: community enhancement through media convergence. Media, Culture \& Society, 39(3), 357-373

Yusuf, S., \& Evenett, S. J. (2003). Lifelong learning in the global knowledge economy: Challenges for developing countries. The World Bank 


\section{Appendices}

Factor Analysis:

\section{Local Government Capacity}

$\begin{array}{lccccc}\text { Variable } & \text { Obs } & \text { Mean } & \text { Std. Dev. } & \text { Min } & \text { Max } \\ \text { LGTime } & 198 & 3.106061 & .8021947 & 1 & 4 \\ \text { LGMoney } & 197 & 2.639594 & .873099 & 1 & 4 \\ \text { LGTech } & 303 & 3.188119 & .7853738 & 1 & 4 \\ \text { LGLawsUni } & 295 & 3.389831 & .6602656 & 1 & 4 \\ \text { LGUniEcoStakeholder } & 196 & 3.107143 & .8125616 & 1 & 4 \\ \text { LGUniSocialStakeholder } & 197 & 2.918782 & .8351357 & 1 & 4 \\ \text { LGStrongLeadershp } & 198 & 3.055556 & .8197712 & 1 & 4 \\ \text { LGLeadershipwColl } & 198 & 3.247475 & .7502072 & 1 & 4\end{array}$

Kaiser-Meyer-Olkin Measure of Sampling Adequacy

KMO $=0.822$

Determinant of the correlation matrix Det $=0.05$

Bartlett test of sphericity

Chi-square $\quad=\quad 551.144$

Degrees of freedom $=\quad 28$

p-value $\quad=\quad 0.000$

H0: variables are not intercorrelated

Factor analysis/correlation

Method: principal factors

Rotation: (unrotated)

Factor | Eigenvalue Difference Proportion Cumulative

\begin{tabular}{l|llll} 
Factor1 & 3.18432 & 2.58627 & 0.9369 & 0.9369 \\
Factor2 & 0.59804 & 0.43578 & 0.1760 & 1.1128 \\
Factor3 & 0.16226 & 0.07870 & 0.0477 & 1.1606 \\
Factor4 & 0.08356 & 0.15611 & 0.0246 & 1.1852 \\
Factor5 & -0.07255 & 0.08866 & -0.0213 & 1.1638 \\
Factor6 & -0.16121 & 0.01624 & -0.0474 & 1.1164 \\
Factor7 & -0.17744 & 0.04068 & -0.0522 & 1.0642 \\
Factor8 & -0.21813 &. & -0.0642 & 1.0000
\end{tabular}

Number of obs $=195$

Retained factors $=4$

Number of params $=26$

LR test: independent vs. saturated: $\operatorname{chi} 2(28)=554.04$ Prob $>\operatorname{chi} 2=0.0000$ 
Factor loadings (pattern matrix) and unique variances

\begin{tabular}{lcccc|c} 
Variable & Factor1 & Factor2 & Factor3 & Factor4 & Uniqueness \\
& & & & & \\
LGTime & 0.6576 & 0.3570 & -0.0540 & $-0.0734 \mid$ & 0.4319 \\
LGMoney & 0.6164 & 0.3378 & 0.0818 & $-0.1333 \mid$ & 0.4815 \\
LGTech & 0.6064 & 0.2759 & 0.0876 & $0.1271 \mid$ & 0.5324 \\
LGLawsUni & 0.4001 & 0.0738 & 0.1022 & $0.1855 \mid$ & 0.7896 \\
LGUniEcoStakeholder & 0.6298 & -0.3019 & 0.1706 & $-0.0686 \mid$ & 0.4783 \\
LGUniSocialstakeholder & 0.5912 & -0.3665 & 0.1406 & $-0.0289 \mid$ & 0.4955 \\
LGStrongLeadershp & 0.7736 & -0.1701 & -0.1689 & $0.0640 \mid$ & 0.3400 \\
LGLeadershipwColl & 0.7067 & -0.1434 & -0.2390 & $-0.0143 \mid$ & 0.4226
\end{tabular}

Factor analysis/correlation $\quad$ Number of obs $=195$

Method: principal factors $\quad$ Retained factors $=\quad 4$

Rotation: orthogonal varimax (Kaiser off) Number of params $=26$

Factor | Variance Difference Proportion Cumulative

\begin{tabular}{l|llll} 
Factor1 & 1.54415 & 0.20049 & 0.4543 & 0.4543
\end{tabular}

\begin{tabular}{l|llll} 
Factor2 & 1.34366 & 0.34233 & 0.3953 & 0.8496
\end{tabular}

\begin{tabular}{l|lrrr} 
Factor3 & 1.00133 & 0.86229 & 0.2946 & 1.1442
\end{tabular}

$\begin{array}{lllll}\text { Factor4 | } & 0.13904 & \text {. } & 0.0409 & 1.1852\end{array}$

LR test: independent vs. saturated: $\operatorname{chi} 2(28)=554.04$ Prob $>\operatorname{chi} 2=0.0000$

Rotated factor loadings (pattern matrix) and unique variances

\begin{tabular}{lcccc|c} 
Variable | & Factor1 & Factor2 & Factor3 & Factor4 | & Uniqueness \\
LGTime | & 0.6772 & 0.3167 & 0.0929 & $0.0248 \mid$ & 0.4319 \\
LGMoney | & 0.6693 & 0.1932 & 0.1821 & $-0.0040 \mid$ & 0.4815 \\
LGTech | & 0.5701 & 0.2389 & 0.1670 & $0.2402 \mid$ & 0.5324 \\
LGLawsUni | & 0.2830 & 0.1750 & 0.1811 & $0.2586 \mid$ & 0.7896 \\
LGUniEcoSt $\sim \mathrm{r} \mid$ & 0.1979 & 0.3534 & 0.5971 & $0.0327 \mid$ & 0.4783 \\
LGUniSocia $\sim \mathrm{r} \mid$ & 0.1138 & 0.3772 & 0.5886 & $0.0531 \mid$ & 0.4955 \\
LGStrongLe p | & 0.3089 & 0.6578 & 0.3493 & $0.0998 \mid$ & 0.3400 \\
LGLeadersh 1 | & 0.2914 & 0.6470 & 0.2718 & $0.0007 \mid$ & 0.4226
\end{tabular}

Factor rotation matrix

Factor1 Factor2 Factor3 Factor4

\begin{tabular}{|c|c|c|c|}
\hline Factor1 & $0.6135 \quad 0.6136$ & 0.4815 & 0.1233 \\
\hline Factor2 & $0.7528-0.3218$ & -0.5690 & 0.0777 \\
\hline & $0.1541-0.7078$ & 0.6394 & 0.25 \\
\hline ac & 21 & -0.1884 & \\
\hline
\end{tabular}


Rotated factor loadings (pattern matrix) and unique variances sorted

\begin{tabular}{lcccc|c} 
Variable | & Factor1 & Factor2 & Factor3 & Factor4 | Uniquenes \\
& & & & & \\
LGTime | & 0.6772 & 0.3167 & 0.0929 & $0.0248 \mid$ & 0.4319 \\
LGMoney | & 0.6693 & 0.1932 & 0.1821 & $-0.0040 \mid$ & 0.4815 \\
LGTech | & 0.5701 & 0.2389 & 0.1670 & $0.2402 \mid$ & 0.5324 \\
LGLawsUni | & 0.2830 & 0.1750 & 0.1811 & $0.2586 \mid$ & 0.7896 \\
LGStrongLeadership | & 0.3089 & 0.6578 & 0.3493 & $0.0998 \mid$ & 0.3400 \\
LGLeadershipwColl & 0.2914 & 0.6470 & 0.2718 & $0.0007 \mid$ & 0.4226 \\
LGUniEcoStakeholder | & 0.1979 & 0.3534 & 0.5971 & $0.0327 \mid$ & 0.4783 \\
LGUniSocialStakeholder & 0.1138 & 0.3772 & 0.5886 & $0.0531 \mid$ & 0.4955
\end{tabular}

\section{Cronbach Alpha Coefficient}

Test scale $=$ mean (unstandardized items $)$

Average interitem covariance: $\quad .3678069$

Number of items in the scale: 3

Scale reliability coefficient: $\mathbf{0 . 7 8 7 6}$

Test scale $=$ mean (unstandardized items $)$

Average interitem covariance: $\quad .4125776$

Number of items in the scale: 2

Scale reliability coefficient: $\quad \mathbf{0 . 8 0 1 1}$

Test scale $=$ mean $($ unstandardized items $)$

Average interitem covariance: $\quad .403663$

Number of items in the scale: 2

Scale reliability coefficient: $\mathbf{0 . 7 4 5 8}$ 


\section{University Capacity}

$\begin{array}{lrrrrr}\text { Variable } & \text { Obs } & \text { Mean } & \text { Std. Dev. } & \text { Min } & \text { Max } \\ \text { unitech } & & & & & \\ \text { UniMoney } & 273 & 3.479853 & .7228904 & 1 & 4 \\ \text { UniTime } & 273 & 3.120879 & .8291806 & 1 & 4 \\ \text { uniformalizeProcedures } & 263 & 3.304183 & .7034956 & 1 & 4 \\ & 271 & 2.767528 & .8742282 & 1 & 4\end{array}$

\section{Kaiser-Meyer-Olkin Measure of Sampling Adequacy \\ KMO $=0.768$}

Bartlett test of sphericity

$\begin{array}{lc}\text { Chi-square }= & 223.935 \\ \text { Degrees of freedom }= & 10 \\ \text { p-value } \quad= & \mathbf{0 . 0 0 0} \\ \text { H0: variables are not intercorrelated }\end{array}$

Factor analysis/correlation $\quad$ Number of obs $=258$

Method: principal-component factors $\quad$ Retained factors $=\quad 1$

Rotation: (unrotated) Number of params $=\quad 4$

Factor | Eigenvalue Difference Proportion Cumulative

\begin{tabular}{l|cccc} 
Factor1 & 2.29497 & 1.52405 & 0.5737 & 0.5737 \\
Factor2 & 0.77092 & 0.23713 & 0.1927 & 0.7665 \\
Factor3 & 0.53379 & 0.13348 & 0.1334 & 0.8999 \\
Factor4 & 0.40032 &. & 0.1001 & 1.0000
\end{tabular}

LR test: independent vs. saturated: $\operatorname{chi} 2(6)=248.85$ Prob $>\operatorname{chi} 2=0.0000$

Factor loadings (pattern matrix) and unique variances

Variable

unitech

UniMoney

UniTime

uniformalizeProcedures
Factor1 | Uniqueness

$$
\begin{array}{r|r}
0.7828 \mid & 0.3872 \\
0.8159 \mid & 0.3343 \\
& 0.6374 \mid \quad 0.5937
\end{array}
$$


Factor analysis/correlation

Number of obs $=258$

Method: principal-component factors

Retained factors $=\quad 1$

Rotation: orthogonal varimax (Kaiser off) $\quad$ Number of params $=\quad 4$

Factor Variance Difference Proportion Cumulative

Factor1

2.29497

0.5737

0.5737

LR test: independent vs. saturated: $\operatorname{chi} 2(6)=248.85$ Prob $>\operatorname{chi} 2=0.0000$

Rotated factor loadings (pattern matrix) and unique variances

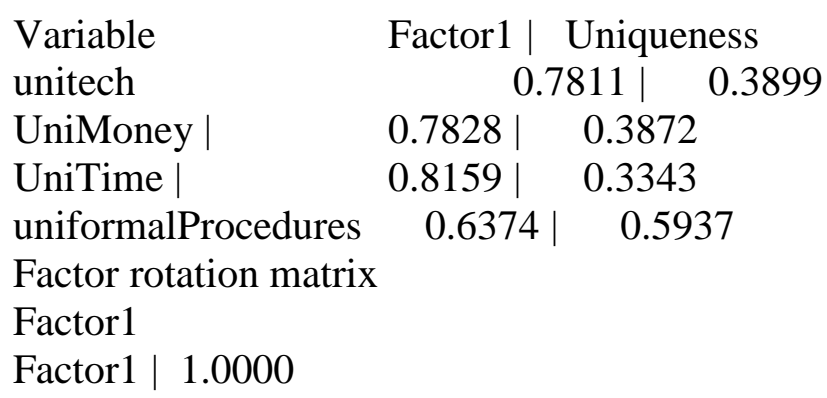

Rotated factor loadings (pattern matrix) and unique variances sorted

Variable |

UniTime

Factor1 | Uniqueness

UniMoney

$0.8159 \mid 0.3343$

unitech

0.7828 | 0.3872

uniformalProcedures $0.6374 \mid 0.5937$

Test scale $=$ mean $($ unstandardized items $)$

Average interitem covariance: $\quad .2543179$

Number of items in the scale: $\quad 4$

Scale reliability coefficient: $\quad \mathbf{0 . 7 3 6 5}$ 


\section{Trust and Shared Vision}

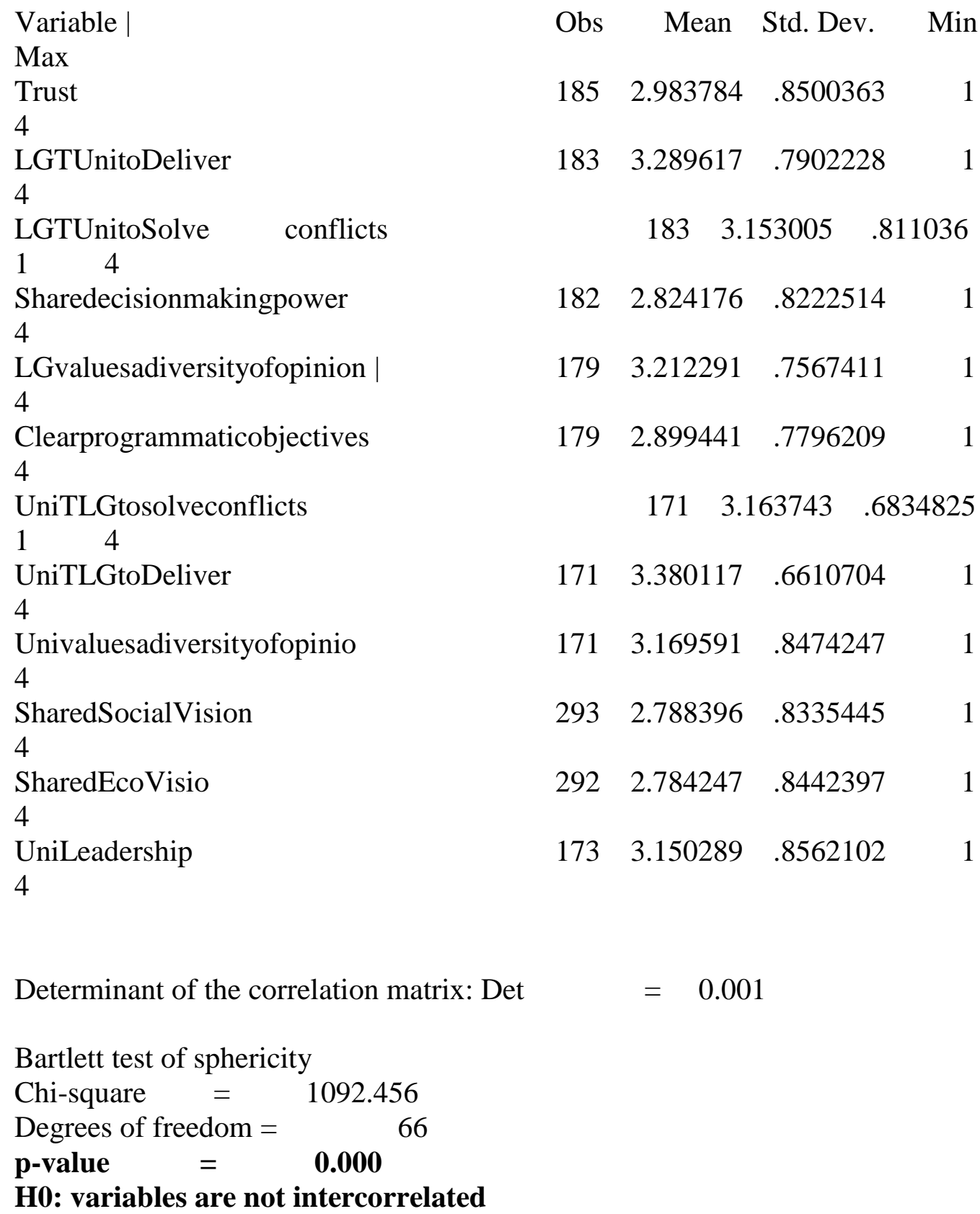

Kaiser-Meyer-Olkin Measure of Sampling Adequacy

$$
\text { KMO }=0.873
$$

Factor analysis/correlation Method: principal-component factors Rotation: (unrotated)
Number of obs $=167$

Retained factors $=\quad 3$

Number of params $=33$ 


\begin{tabular}{l|cccc} 
Factor | & \multicolumn{2}{c}{ Eigenvalue } & Difference & \multicolumn{2}{c}{ Proportion Cumulative } \\
Factor1 | & 5.84411 & 4.38290 & 0.4870 & 0.4870 \\
Factor2 & 1.46121 & 0.33370 & 0.1218 & 0.6088 \\
Factor3 & 1.12752 & 0.42229 & 0.0940 & 0.7027 \\
Factor4 & 0.70523 & 0.13261 & 0.0588 & 0.7615 \\
Factor5 & 0.57263 & 0.07034 & 0.0477 & 0.8092 \\
Factor6 | & 0.50229 & 0.08399 & 0.0419 & 0.8511 \\
Factor7 & 0.41830 & 0.08061 & 0.0349 & 0.8859 \\
Factor8 | & 0.33770 & 0.03123 & 0.0281 & 0.9141 \\
Factor9 | & 0.30646 & 0.02472 & 0.0255 & 0.9396 \\
Factor10 | & 0.28175 & 0.02509 & 0.0235 & 0.9631 \\
Factor11 & 0.25665 & 0.07051 & 0.0214 & 0.9845 \\
Factor12 | & 0.18614 &. & 0.0155 & 1.0000 \\
LR test: independent vs. saturated: chi2(66) $=1099.23$ Prob $>$ chi2 $=0.0000$
\end{tabular}

Factor loadings (pattern matrix) and unique variances

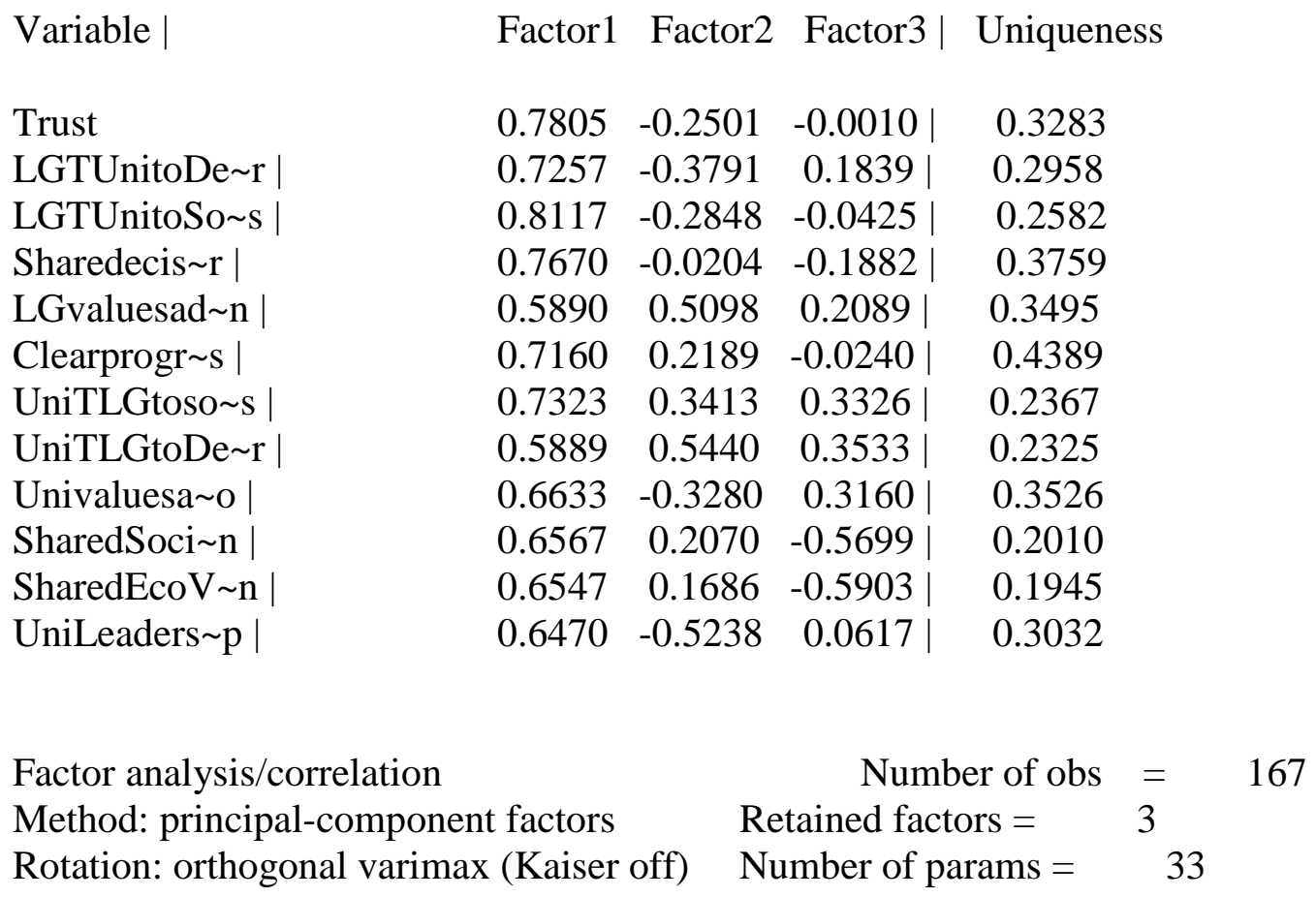

Factor | Variance Difference Proportion Cumulative

\begin{tabular}{l|llll} 
Factor1 | & 3.44108 & 0.87990 & 0.2868 & 0.2868
\end{tabular} 
\begin{tabular}{l|llll} 
Factor2 & 2.56117 & 0.13058 & 0.2134 & 0.5002 \\
Factor3 & 2.43059 &. & 0.2025 & 0.7027
\end{tabular}

LR test: independent vs. saturated: $\operatorname{chi} 2(66)=1099.23$ Prob $>$ chi $2=0.0000$

Rotated factor loadings (pattern matrix) and unique variances

\begin{tabular}{lccc|c} 
Variable | & Factor1 & Factor2 & Factor3 | & Uniqueness \\
Trust | & 0.7008 & 0.2340 & $0.3547 \mid$ & 0.3283 \\
LGTUnitoDe $\sim \mathrm{r} \mid$ & 0.7990 & 0.2111 & $0.1458 \mid$ & 0.2958 \\
LGTUnitoSo $\sim \mathrm{s} \mid$ & 0.7358 & 0.2053 & $0.3978 \mid$ & 0.2582 \\
Sharedecis $\sim \mathrm{r} \mid$ & 0.4859 & 0.2893 & $0.5516 \mid$ & 0.3759 \\
LGvaluesad n | & 0.0950 & 0.7624 & $0.2453 \mid$ & 0.3495 \\
Clearprogr $\sim \mathrm{s} \mid$ & 0.3257 & 0.5104 & $0.4410 \mid$ & 0.4389 \\
UniTLGtoso $\sim \mathrm{s} \mid$ & 0.3394 & 0.7843 & $0.1818 \mid$ & 0.2367 \\
UniTLGtoDe $\sim \mathrm{r} \mid$ & 0.1067 & 0.8592 & $0.1335 \mid$ & 0.2325 \\
Univaluesa $\sim \mathrm{o} \mid$ & 0.7538 & 0.2808 & $0.0152 \mid$ & 0.3526 \\
SharedSoci $\sim \mathrm{n} \mid$ & 0.1595 & 0.1937 & $0.8579 \mid$ & 0.2010 \\
SharedEcoV $\sim \mathrm{n} \mid$ & 0.1798 & 0.1560 & $0.8654 \mid$ & 0.1945 \\
UniLeaders $\sim \mathrm{p} \mid$ & 0.8163 & 0.0087 & $0.1742 \mid$ & 0.3032
\end{tabular}

Factor rotation matrix

\begin{tabular}{l|cll}
$\mid$ & Factor1 & Factor2 & Factor3 \\
Factor1 & 0.6755 & 0.5203 & 0.5225 \\
Factor2 & -0.6950 & 0.6860 & 0.2155 \\
Factor3 & 0.2463 & 0.5087 & -0.8250
\end{tabular}

Average interitem covariance: $\quad .4040263$

Number of items in the scale: 5

Scale reliability coefficient: $\mathbf{0 . 8 7 5 8}$

Average interitem covariance: $\quad .279952$

Number of items in the scale: 4

Scale reliability coefficient: $\mathbf{0 . 8 2 1 8}$

Average interitem covariance: $\quad .4194052$

Number of items in the scale: $\quad 3$ 
Scale reliability coefficient: $\quad 0.8192$ 
Appendix 2: Marginal Effects

Marginal Effects Model 1

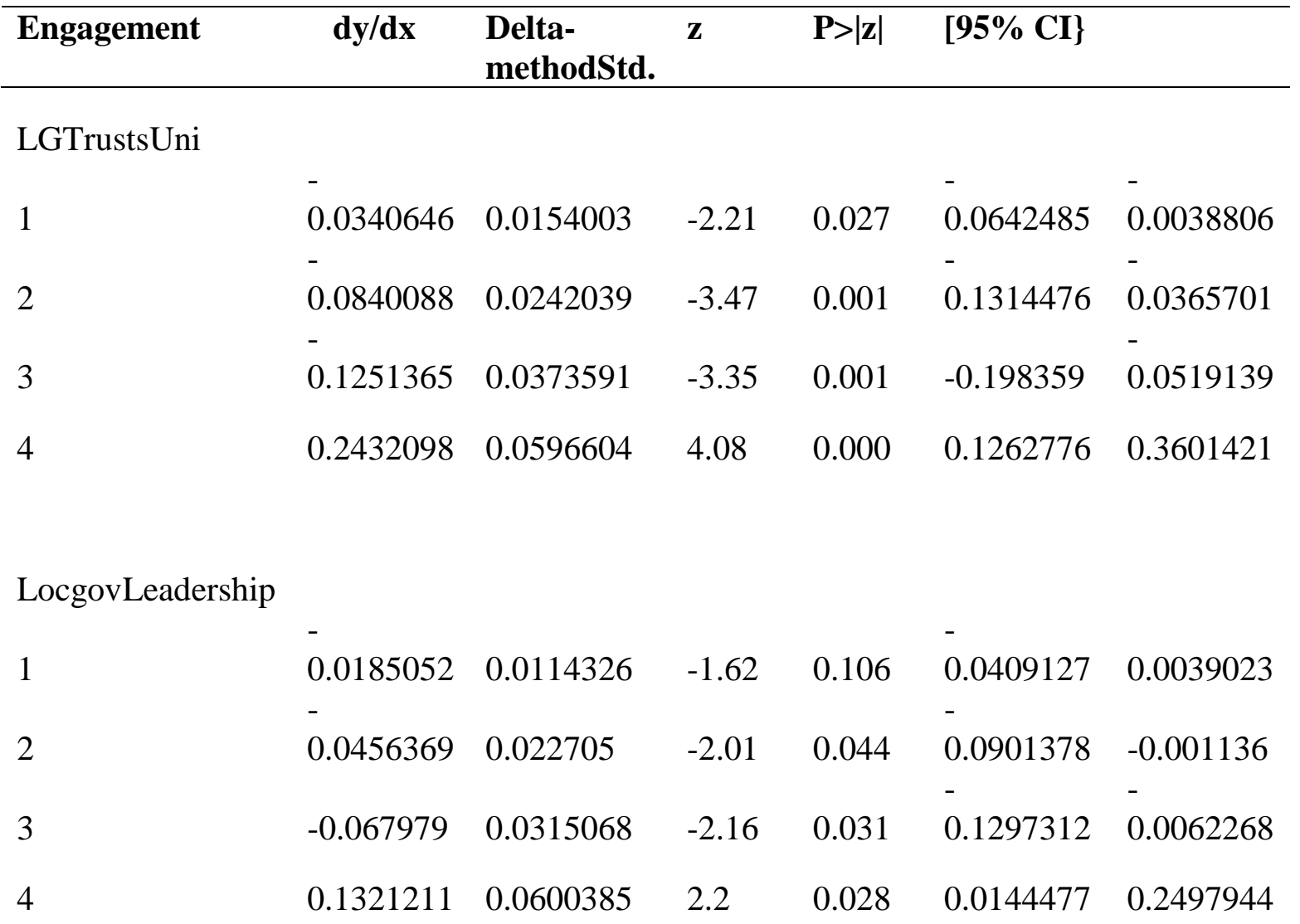




\section{Marginal Effects Model 2}

\begin{tabular}{lllllll}
\hline $\begin{array}{l}\text { Eco } \\
\text { Engage }\end{array}$ & $\mathbf{d y} / \mathbf{d x}$ & $\begin{array}{l}\text { Delta- } \\
\text { methodStd. }\end{array}$ & $\mathbf{z}$ & $\mathbf{P}>|\mathbf{z}|$ & {$[\mathbf{9 5 \%} \mathbf{C I}\}$} & \\
\hline LGTrustsUni & & & & & & \\
1 & - & 0.0283588 & -4.46 & 0.000 & -0.1821012 & -0.0709367 \\
& 0.1265189 & & & & & \\
2 & - & 0.0334369 & -4.1 & 0.000 & -0.2027467 & -0.0716764 \\
& 0.1372116 & & & & & \\
3 & 0.0424789 & 0.0243353 & 1.75 & 0.081 & -0.0052175 & 0.0901753 \\
4 & 0.2212516 & 0.0499858 & 4.43 & 0.000 & 0.1232813 & 0.3192219
\end{tabular}

Marginal Effects Model 3

\begin{tabular}{lllllll}
\hline $\begin{array}{l}\text { Social } \\
\text { Engage }\end{array}$ & \multicolumn{1}{c}{$\mathbf{d y} / \mathbf{d x}$} & $\begin{array}{l}\text { Delta- } \\
\text { methodStd. }\end{array}$ & $\mathbf{z}$ & $\mathbf{P}>|\mathbf{z}|$ & {$[\mathbf{9 5 \%} \mathbf{C I}\}$} & \\
\hline $\begin{array}{l}\text { LocCap } \\
\text { Stakeholder }\end{array}$ & & & & & & \\
1 & -0.055387 & 0.0243136 & -2.28 & 0.023 & -0.1030407 & -0.0077332 \\
2 & -0.058529 & 0.0248514 & -2.36 & 0.019 & -0.1072369 & -0.0098211 \\
3 & - & 0.0147747 & -1.28 & 0.202 & -0.0478148 & 0.010101 \\
& 0.0188569 & & & & & \\
4 & 0.1327729 & 0.0530029 & 2.51 & 0.012 & 0.028889 & 0.2366567 \\
LG & & & & & & \\
TrustsUni & & & & & & \\
1 & - & 0.0245287 & -1.99 & 0.047 & -0.0968978 & -0.0007471 \\
2 & 0.0488225 & & & & & \\
& - & 0.0243883 & -2.12 & 0.034 & -0.0993922 & -0.0037919 \\
3 & 0.0515921 & & & & & \\
& -0.016622 & 0.0146428 & -1.14 & 0.256 & -0.0453213 & 0.0120773
\end{tabular}


Marginal Effects Model 4:

\begin{tabular}{lllllll}
\hline $\begin{array}{l}\text { CollHPL } \\
\text { G }\end{array}$ & $\mathbf{d y} / \mathbf{d x}$ & $\begin{array}{l}\text { Delta- } \\
\text { method } \\
\text { Std. }\end{array}$ & $\mathbf{z}$ & $\mathbf{P}>|\mathbf{z}|$ & {$[\mathbf{9 5 \%} \mathbf{C I}]$} & \\
\hline $\begin{array}{l}\text { LocCap } \\
\begin{array}{l}\text { Stakehol } \\
\text { der }\end{array}\end{array}$ & & & & & & \\
1 & -0.008213 & 0.006553 & -1.25 & 0.210 & -0.0210574 & 0.0046315 \\
2 & -0.0408604 & $\begin{array}{l}0.020732 \\
1\end{array}$ & -1.97 & 0.049 & -0.0814946 & -0.0002262 \\
3 & -0.0722302 & $\begin{array}{l}0.035618 \\
9\end{array}$ & -2.03 & 0.043 & -0.1420421 & -0.0024184 \\
4 & 0.1213036 & 0.057834 & 2.1 & 0.036 & 0.0079504 & 0.2346568 \\
& & 3 & & & &
\end{tabular}

Locgov

Leadershi

$\mathrm{p}$

$\begin{array}{lllllll}1 & -0.0136795 & 0.009557 & -1.43 & 0.152 & -0.0324116 & 0.0050526\end{array}$

$\begin{array}{lllllll}2 & -0.0680568 & 0.022545 & -3.02 & 0.003 & -0.1122445 & -0.0238691\end{array}$

$\begin{array}{llllllll}3 & -0.1203062 & 0.035954 & -3.35 & 0.001 & -0.1907764 & -0.0498361\end{array}$

$\begin{array}{lllllll}4 & 0.2020425 & 0.055657 & 3.63 & 0.000 & 0.0929567 & 0.3111283\end{array}$

\section{Marginal Effects Model 5:}

\begin{tabular}{lllllll}
\hline $\begin{array}{l}\text { CollHP } \\
\text { Uni }\end{array}$ & $\mathbf{d y / d x}$ & $\begin{array}{l}\text { Delta- } \\
\text { methodSt } \\
\mathbf{d} .\end{array}$ & $\mathbf{z}$ & $\mathbf{P}>|\mathbf{z}|$ & {$[\mathbf{9 5 \%} \mathbf{C I}]$} & \\
\hline $\begin{array}{l}\text { LGTrus } \\
\text { ts }\end{array}$ & & & & & & \\
Uni & & & & & & \\
1 & -0.0701241 & 0.0152135 & -4.61 & 0.000 & -0.099942 & -0.0403062 \\
2 & -0.1751971 & 0.0320522 & -5.47 & 0.000 & -0.2380182 & -0.112376 \\
3 & -0.1620555 & 0.0372704 & -4.35 & 0.000 & -0.2351041 & -0.0890068 \\
4 & 0.4073766 & 0.0519275 & 7.85 & 0.000 & 0.3056006 & 0.5091527 \\
Shared & & & & & & \\
Vision & & & & & & \\
1 & -0.0261529 & 0.0109118 & -2.4 & 0.017 & -0.0475396 & -0.0047663 \\
2 & -0.0653401 & 0.0251448 & -2.6 & 0.009 & -0.1146229 & -0.0160573 \\
3 & -0.0604389 & 0.0231157 & -2.61 & 0.009 & -0.1057449 & -0.015133
\end{tabular}


$\begin{array}{llllll}0.151932 & 0.0536204 & 2.83 & 0.005 & 0.046838 & 0.257026\end{array}$ 


\section{Marginal Effects Model 6}

\begin{tabular}{|c|c|c|c|c|c|c|}
\hline CollMB & & $d y / d x$ & $\begin{array}{l}\text { Delta- } \\
\text { methodStd. }\end{array}$ & $\mathbf{z}$ & $\mathbf{P}>|\mathbf{z}|$ & {$[95 \% \mathrm{CI}\}$} \\
\hline \multirow{2}{*}{\multicolumn{7}{|c|}{$\begin{array}{l}\text { LGTrusts } \\
\text { Uni }\end{array}$}} \\
\hline & & & & & & \\
\hline 1 & $-\overline{0}-0423775$ & 0.0138808 & -3.05 & 0.002 & 0.0695834 & -0.0151716 \\
\hline 2 & $\begin{array}{l}0.0945797 \\
-\end{array}$ & 0.0227994 & -4.15 & 0 & $\begin{array}{l}0.1392658 \\
-\end{array}$ & -0.0498936 \\
\hline 3 & 0.1211519 & 0.0314748 & -3.85 & 0 & 0.1828414 & -0.0594623 \\
\hline 4 & 0.2581091 & 0.0457238 & 5.64 & 0 & 0.168492 & 0.3477261 \\
\hline \multicolumn{7}{|c|}{$\begin{array}{l}\text { UniTrusts } \\
\text { LG }\end{array}$} \\
\hline 1 & $\begin{array}{l}- \\
0.0232078 \\
-\end{array}$ & 0.0111272 & -2.09 & 0.037 & $\overline{0} .0450168$ & -0.0013988 \\
\hline 2 & $\begin{array}{l}0.0517961 \\
-\end{array}$ & 0.024133 & -2.15 & 0.032 & $\begin{array}{l}-0.099096 \\
-\end{array}$ & -0.0044963 \\
\hline 3 & 0.0663483 & 0.0279292 & -2.38 & 0.018 & 0.1210885 & -0.0116081 \\
\hline \multirow{2}{*}{$\begin{array}{l}4 \\
\text { Shared } \\
\text { vision }\end{array}$} & 0.1413523 & 0.0567623 & 2.49 & 0.013 & 0.0301001 & 0.2526044 \\
\hline & - & & & & - & \\
\hline 1 & 0.0192858 & 0.0102751 & -1.88 & 0.061 & 0.0394246 & 0.0008531 \\
\hline 2 & 0.0430427 & 0.0203309 & -2.12 & 0.034 & 0.0828906 & -0.0031949 \\
\hline 3 & 0.0551356 & 0.0225222 & -2.45 & 0.014 & 0.0992784 & -0.0109928 \\
\hline 4 & 0.1174641 & 0.0480705 & 2.44 & 0.015 & 0.0232477 & 0.2116805 \\
\hline
\end{tabular}




\begin{tabular}{|c|c|c|c|c|c|c|}
\hline $\begin{array}{l}\text { Appendix } 3 \\
\text { Dependent } \\
\text { Engagemen }\end{array}$ & $\begin{array}{l}\text { Regression } \\
\text { ariable: }\end{array}$ & Outpu & Enga & ment & & \\
\hline LGTime & 1.164 & & & & & \\
\hline & -0.67 & & & & & \\
\hline LGMoney & 1.075 & & & & & \\
\hline & -0.35 & & & & & \\
\hline LGTech & 1.634* & & & & & \\
\hline & 2.43 & & & & & \\
\hline LGStrong & 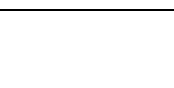 & 1.996 $_{*}^{*}$ & & & & \\
\hline & & 2.93 & & & & \\
\hline LGLeadersh & owantsC & & & & & \\
\hline oll & & $\begin{array}{l}1.256 \\
0.89\end{array}$ & & & & \\
\hline $\begin{array}{l}\text { LGUniEcoS } \\
\mathrm{r}\end{array}$ & keholde & & 1.652 & & & \\
\hline & & & 2.3 & & & \\
\hline $\begin{array}{l}\text { LGUniSocia } \\
\text { der }\end{array}$ & Stakehol & & 1.585 & & & \\
\hline & & & 2.18 & & & \\
\hline uniformalize & & & & * $1.812^{* * *}$ & & \\
\hline & & & & 3.62 & & \\
\hline unitech & & & & $1.547^{*}$ & & \\
\hline & & & & 2.1 & & \\
\hline UniMoney & & & & 1.313 & & \\
\hline & & & & 1.47 & & \\
\hline UniTime & & & & $\begin{array}{l}0.729 \\
(-1.36)\end{array}$ & & \\
\hline SharedSocia & Vision & & & & $\begin{array}{l}0.984 \\
(-0.06)\end{array}$ & \\
\hline SharedEcoV & sion & & & & 1.364 & \\
\hline & & & & & $\begin{array}{l}1.23 \\
\mathbf{2 . 0 6 1}\end{array}$ & \\
\hline Sharedecisic & Imakingpo & wer & & & $\begin{array}{l}* \\
3.14\end{array}$ & \\
\hline UniTLGtoD & liver & & & & & $\begin{array}{l}0.568 \\
(-1.66)\end{array}$ \\
\hline $\begin{array}{l}\text { UniTLGtoso } \\
\text { cts }\end{array}$ & veconfli & & & & & $2.252^{*}$ \\
\hline
\end{tabular}


LGvaluesadiversityofopinion

Clearprogrammaticobjectives

UniLeadership

UniLeadership

4.58

Univaluesadiversityofopinio

1.177

LGTUnitoDeliver

0.68

LGTUnitoDetiver

0.712

$(-1.14)$

LGTUnitoSolveIssues

1.182

0.55

Trust

1.344

1.14

Exponentiated coefficients; $z$ statistics in parentheses

${ }^{*} p<0.05,{ }^{* * *} p<0.01,{ }^{* * * *} p<$ 0.001

Brant Test Chi $>\mathrm{P}$

0.405 


\section{Appendix 4 Regression Output: EconEngage}

Dependent Variable:

Economic Engagement

\begin{tabular}{ll}
\hline LGTime & 0.859 \\
& $(-0.67)$ \\
LGMoney & $\mathbf{1 . 6 7 0}^{*}$ \\
& -2.46 \\
LGTech & 1.311 \\
& -1.4 \\
\hline
\end{tabular}

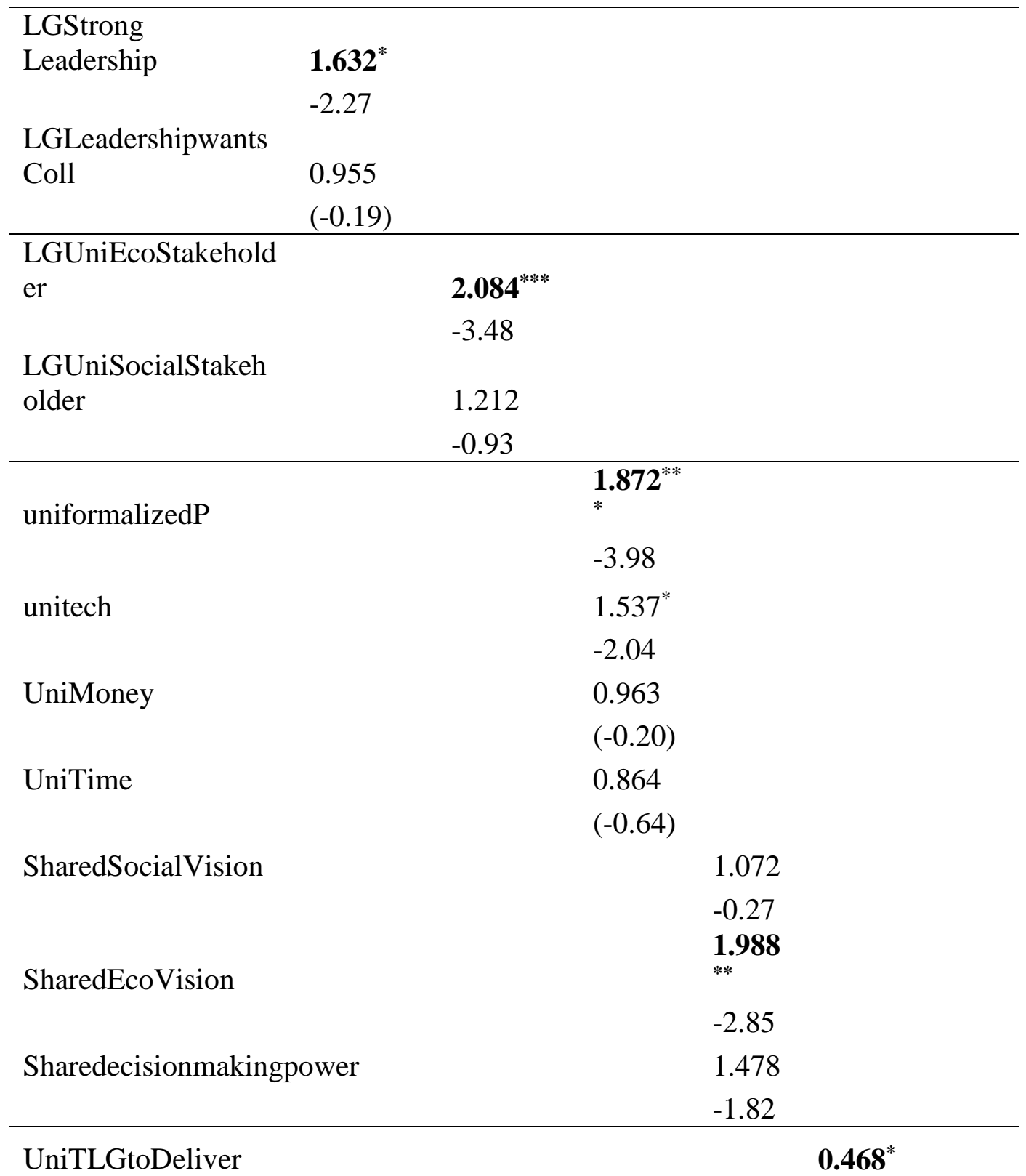


UniTLGtosolveconfl

$(-2.33)$

icts

2.060*

$-2.23$

LGvaluesadiversityofopinion

1.479

$-1.55$

Clearprogrammaticobjectives

1.459

$-1.63$

UniLeadership

1.502

1.81

Univaluesadiversityofopinio

1.408

1.54

LGTUnitoDeliver

1.226

0.78

LGTUnitoSolveIssu

1.536

es

1.48

Trust

1.21

0.76

Exponentiated coefficients; $z$ statistics in parentheses

${ }^{*} p<0.05,{ }^{* *} p<0.01,{ }^{* * *} p<$

0.001

Brant Test Chi $>\mathrm{P}$

0.737 


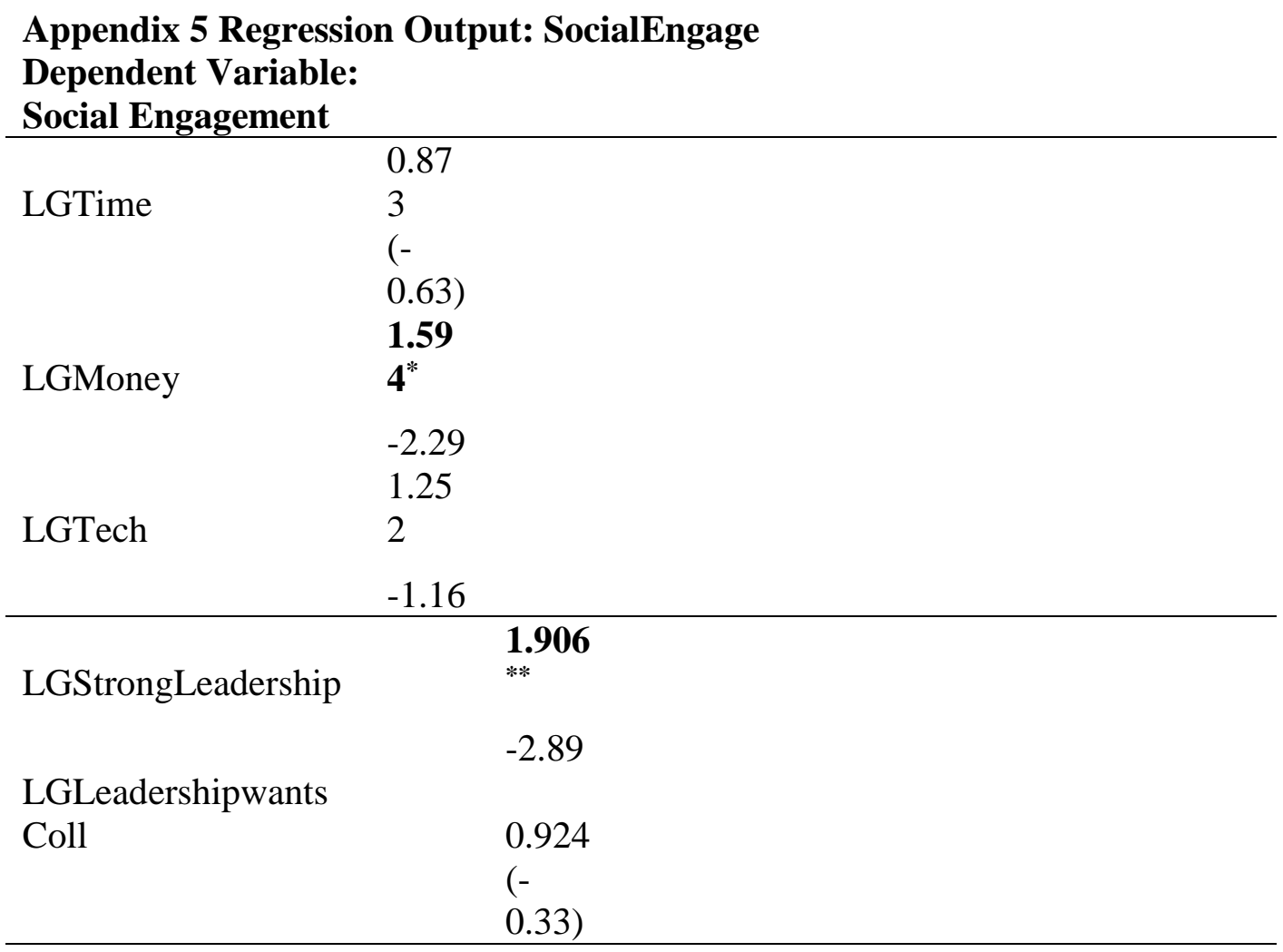

LGUniEcoStakehold

er

1.373

$-1.43$

LGUniSocialStakeho

2.639*

lder

$-4.32$

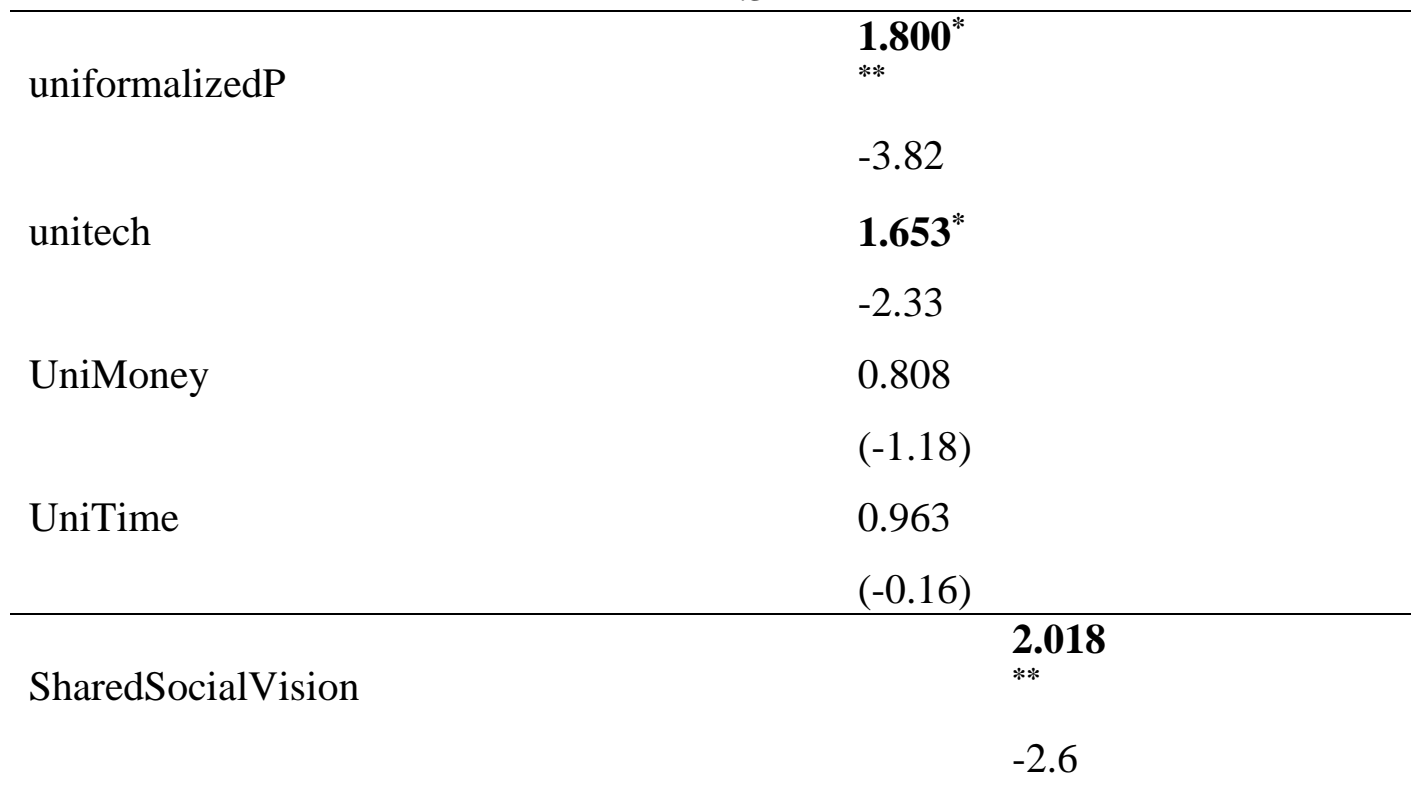


SharedEcoVision

1.103

$-0.41$

1.801

Sharedecisionmakingpower

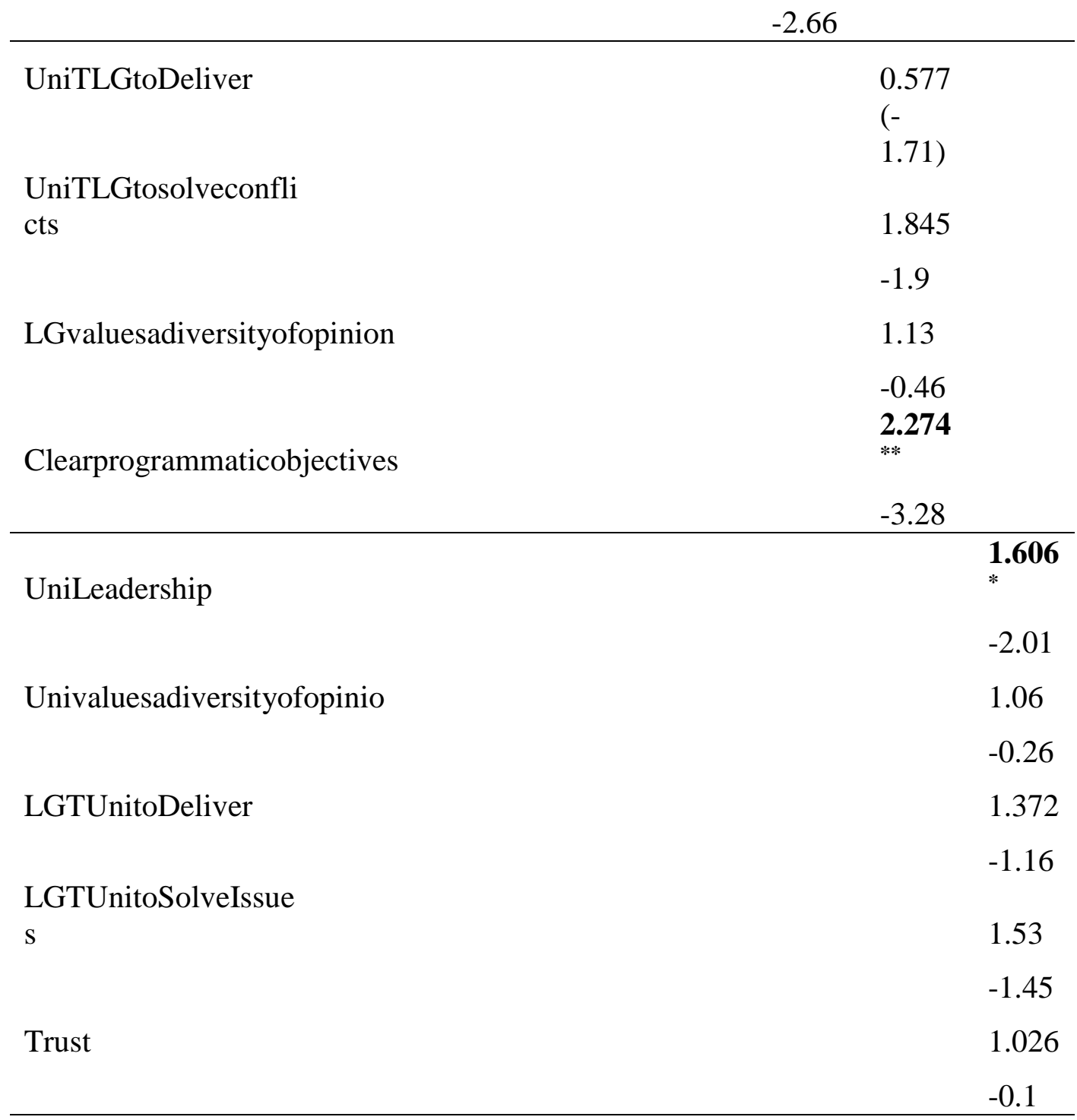

Exponentiated coefficients; $z$ statistics in parentheses

${ }^{*} p<0.05,{ }^{* *} p<0.01,{ }^{* * *} p<0.001$

Brant Test Chi $>\mathrm{P}$

0.83
**

$-2.66$

$(-$

1.13

$-0.46$

2.274

$-3.28$
$-2.01$

1.06

372

1.16

.026

$-0.1$ 
Appendix 6 Regression Output: CollHPLG

Dependent Variable:

Collaboration a High Priority to Local Government

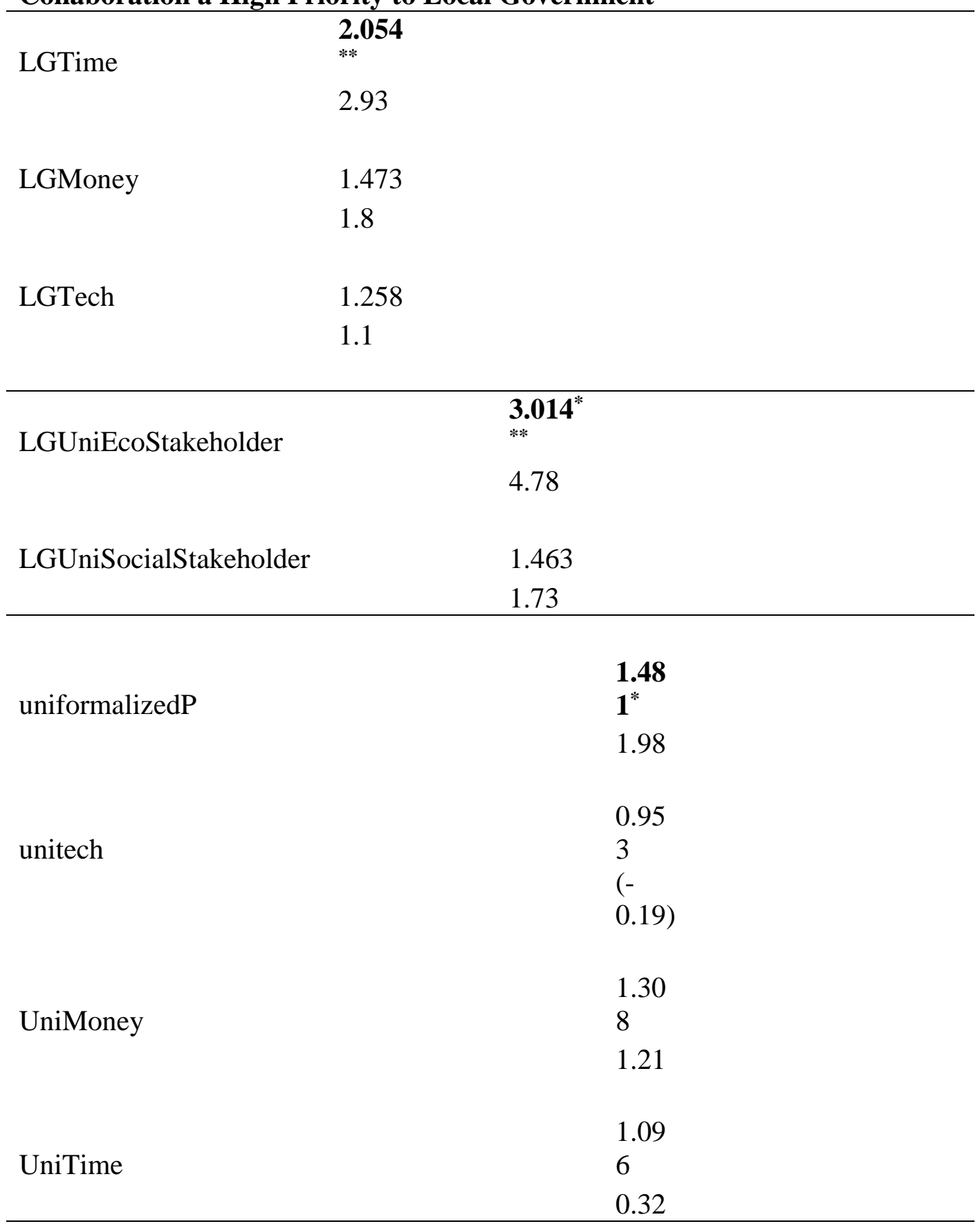


SharedSocialVision 1.601

1.75

SharedEcoVision

1.18

0.67

Sharedecisionmakingpo

wer

1.545

1.95

\begin{tabular}{ll}
\hline & 1.65 \\
UniTLGtoDeliver & 5 \\
& 1.45 \\
& 1.13 \\
UniTLGtosolveconflicts & 3 \\
& 0.37 \\
LGvaluesadiversityofopi & $\mathbf{1 . 8 2}$ \\
nion & $\mathbf{1}^{*}$ \\
& 2.17 \\
Clearprogrammaticobjec & \\
tives & 1.26 \\
& 4 \\
& 0.98
\end{tabular}

UniLeadership

1.144

0.53

Univaluesadiversityofopi

nio

0.736

(-

1.24)

LGTUnitoDeliver

1.021

0.07

LGTUnitoSolveIssues

1.126

0.4 
Trust

Exponentiated coefficients; $z$ statistics in parentheses

${ }^{*} p<0.05,{ }^{* *} p<0.01,{ }^{* * *} p<$

0.001

Brant Test Chi>P 0.385 
Appendix 7 Regression Output: CollHPUni

Dependent Variable:

Collaboration a High Priority to University

\begin{tabular}{ll}
\hline LGTime & $\begin{array}{l}0.803 \\
(-1.00)\end{array}$ \\
& \\
LGMoney & 1.415 \\
& 1.7 \\
& 1.192 \\
LGTech & 0.89
\end{tabular}

\begin{tabular}{|c|c|c|}
\hline LGStrongLeadership & $\begin{array}{l}\mathbf{2 . 1 7 3}^{\text {** }} \\
3.28\end{array}$ & \\
\hline LGLeadershipwantsColl & $\begin{array}{l}0.715 \\
(-1.34)\end{array}$ & \\
\hline LGUniEcoStakeholder & & $\begin{array}{l}\mathbf{2 . 0 0 8}{ }^{\text {** }} \\
3.19\end{array}$ \\
\hline LGUniSocialStakeholder & & $\begin{array}{l}1.187 \\
0.8\end{array}$ \\
\hline
\end{tabular}

uniformalizedP

$\mathbf{2 . 1 0 8}^{* * * *}$

4.34

unitech

$2.202^{* * * *}$

3.6

UniMoney

$0.641^{*}$

$(-2.17)$

UniTime

0.915

$(-0.35)$

SharedSocialVision

1.424

1.27

SharedEcoVision

1.139 
Sharedecisionmakingpow $\quad \mathbf{3 . 0 0 8}^{\text {*****}}$

er

4.71

\begin{tabular}{|c|c|}
\hline UniTLGtoDeliver & $\begin{array}{l}0.769 \\
(-0.77)\end{array}$ \\
\hline UniTLGtosolveconflicts & $\begin{array}{l}1.533 \\
1.19\end{array}$ \\
\hline LGvaluesadiversityofopinion & $\begin{array}{l}0.654 \\
(-1.58)\end{array}$ \\
\hline Clearprogrammaticobjectives & $\begin{array}{l}\mathbf{3 . 1 6 2}^{* * * *} \\
4.53\end{array}$ \\
\hline UniLeadership & $\begin{array}{l}\mathbf{2 . 5 1 4} \\
3 * * \\
3.63\end{array}$ \\
\hline Univaluesadiversityofopinio & $\begin{array}{l}1.061 \\
0.24\end{array}$ \\
\hline LGTUnitoDeliver & $\begin{array}{l}1.563 \\
1.55\end{array}$ \\
\hline LGTUnitoSolveIssues & $\begin{array}{l}1.927 \\
* \\
2.04\end{array}$ \\
\hline Trust & $\begin{array}{l}\mathbf{1 . 7 5 4} \\
2.08\end{array}$ \\
\hline
\end{tabular}

Exponentiated coefficients; $z$ statistics in parentheses

${ }^{*} p<0.05,{ }^{* *} p<0.01,{ }^{* * *} p<0.001$

Brant Test Chi $>$ P 0.385 
Appendix 8 Regression Output: Mutually Beneficial Collaborations

Dependent Variable:

Mutually Beneficial Collaborations

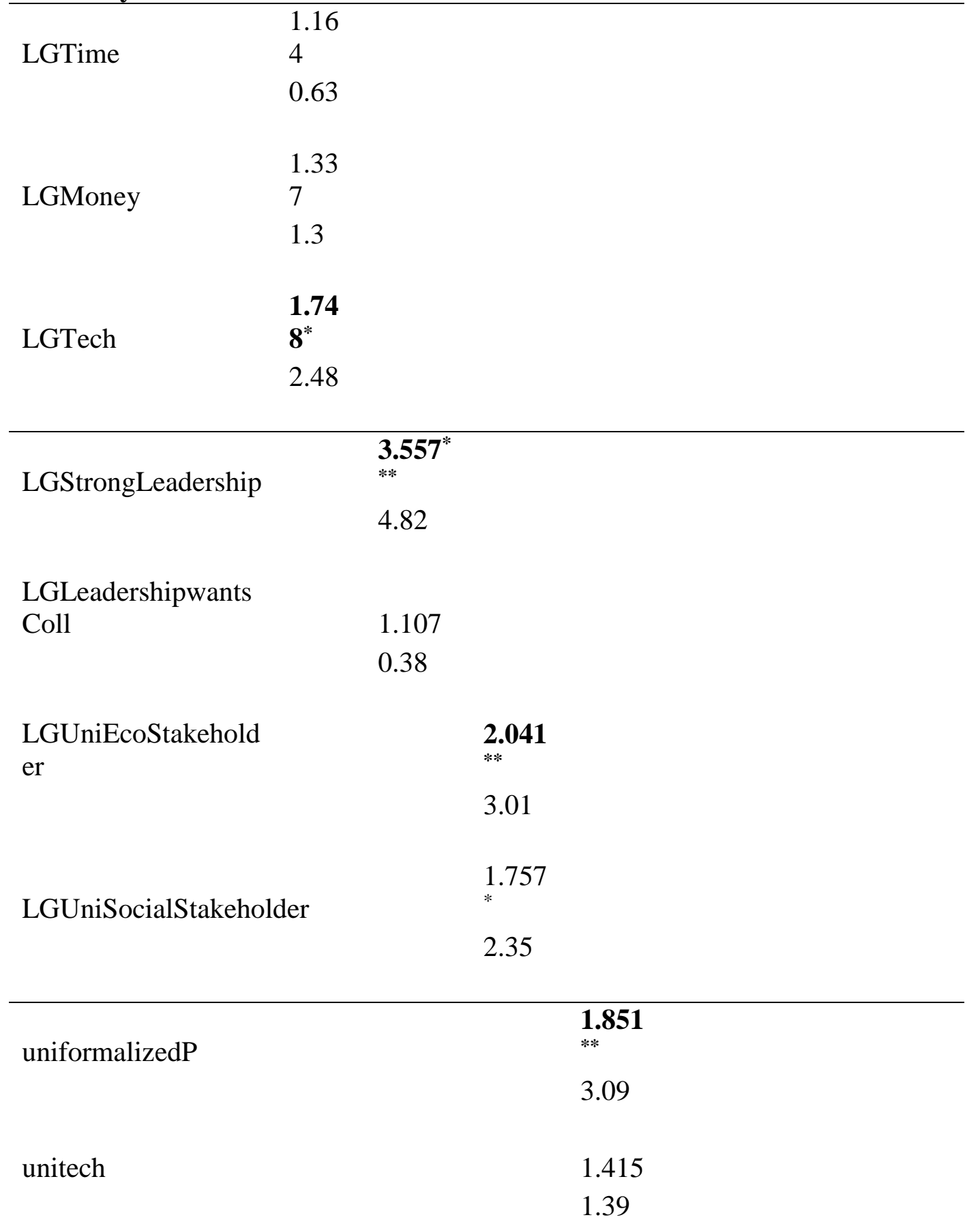




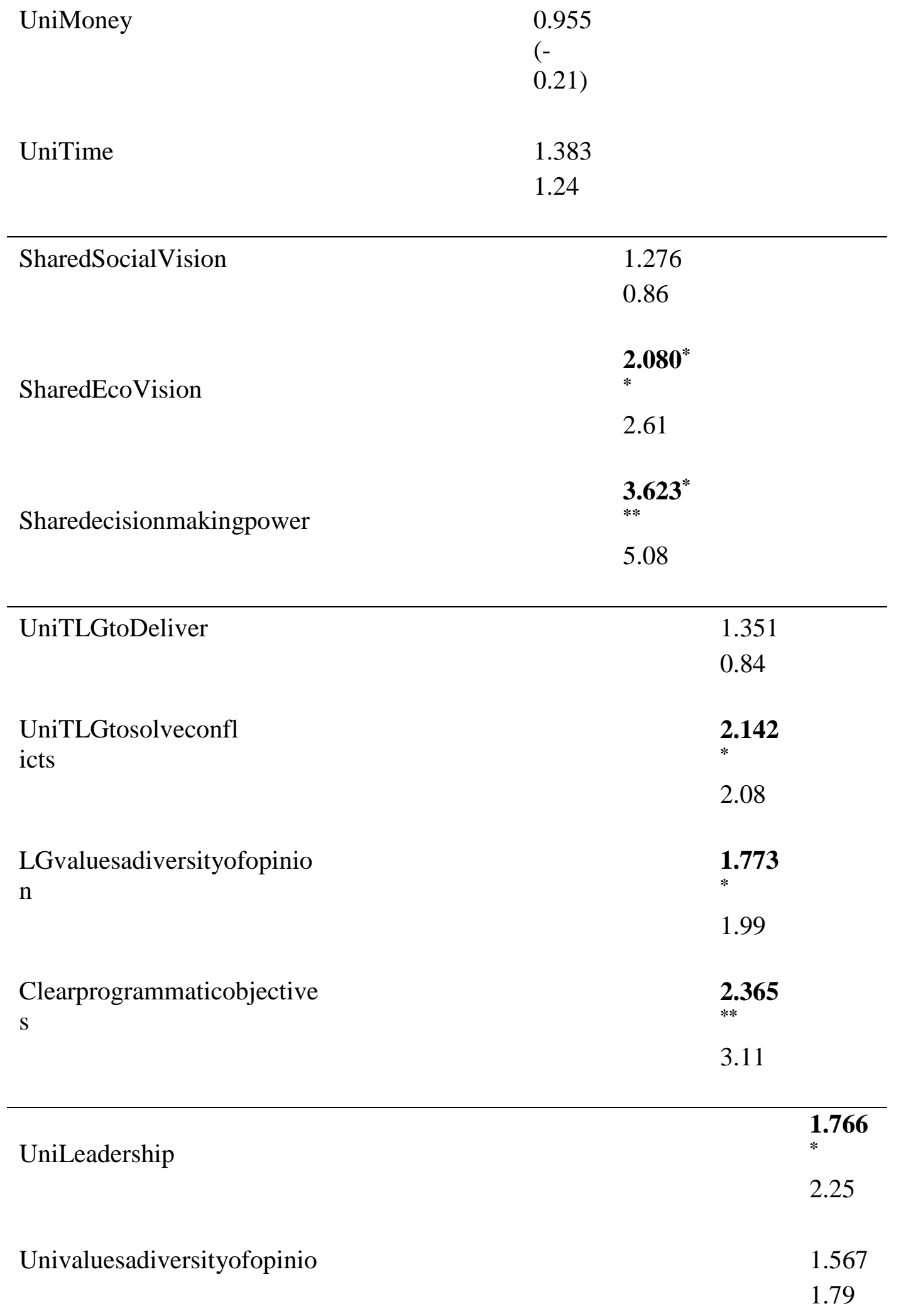


LGTUnitoSolveIssu

es

1.591

1.48

2.059

Trust

**

2.63

Exponentiated coefficients; $z$ statistics in parentheses

${ }^{*} p<0.05,{ }^{* *} p<0.01,{ }^{* * *} p<0.001$

Brant Test Chi $>\mathrm{P}$

0.472 
Survey

\section{Start of Block: Default Question Block}

Q1 Hello: My name is Vivian Cueto and I am a PhD candidate at the Steven J. Green School of International and Public Affairs at Florida International University. As part of my dissertation, I am examining how local governments engage universities. I am asking you to participate in this survey because the you are in a unique position to speak to the community engagement relationship between the University and the city. This study examines approximately 600 cities and universities. As a researcher, I believe that the voice of every city and University should be heard. My study will help your perspective reach policy makers and administrators at the local and state levels, as well as University administration. Please take the survey and share your experience. When the study is completed, I will send you the results. This information will better assist you in forming meaningful and mutually beneficial partnerships. The survey is completely anonymous and any publication will only address aggregated data. Please use the link below to answer the survey questions. It will not take more than 10-15 minutes:

Q2 (City Officials Only) According to the Carnegie Foundation: "Community engagement describes collaboration between institutions of higher education and their larger communities (local, regional/state, national, global) for the mutually beneficial exchange of knowledge and resources in a context of partnership and reciprocity." Based on that definition, how engaged is [ Name of University]

Strongly engaged (1)

Somewhat engaged (2)

Somewhat unengaged (3)

Not engaged (4)

Q53 (University Officials Only) According to the Carnegie Foundation:

"Community engagement describes collaboration between institutions of higher education and their larger communities (local, regional/state, national, global) for the mutually beneficial exchange of knowledge and resources in a context of partnership and reciprocity."

Based on that definition, how engaged is the [Local Government]?

Strongly engaged (1)

Somewhat engaged (2) 
Somewhat unengaged (3)

Not engaged (4)

Q76 How engaged are the [local government/university] in addressing economic challenges (e.g., unemployment, housing affordability, chronic poverty)

Strongly engaged (1)

Somewhat engaged (2)

Somewhat unengaged (3)

Not engaged (4)

Q74 How engaged are [local government/university] addressing the social challenges of your community? (e.g., climate change, gun violence, educational achievement gaps)

Strongly engaged (1)

Somewhat engaged (2)

Somewhat unengaged (3)

Not engaged (4)

Q6 Overall, Local Government/University Collaboration is a high priority for the local government

Strongly agree (12)

Somewhat agree (13)

Somewhat disagree (15)

Strongly disagree (16)

Q78 Overall, Local Government/University Collaboration is a high priority for the university 
Strongly agree (29)

Somewhat agree (30)

Somewhat disagree (32)

Strongly disagree (33)

\section{End of Block: Default Question Block}

\section{Start of Block: Local Government Capacity}

Q55 The local government has the time resources to form mutually beneficial partnerships with the university

Strongly agree (11)

Somewhat agree (12)

Somewhat disagree (14)

Strongly disagree (15)

Q56 The local government has the monetary resources to form mutually beneficial partnerships with the university

Strongly agree (11)

Somewhat agree (12)

Somewhat disagree (14)

Strongly disagree (15)

Q10 The local government has the technical expertise to form mutually beneficial partnerships with the University

Strongly agree (1)

Somewhat agree (2)

Somewhat disagree (3) 
Q7 The local government sets policies and laws that can positively impact the University

Strongly agree (1)

Somewhat agree (2)

Somewhat disagree (3)

Strongly disagree (4)

Q8 The local government includes the university as a vital stakeholder when creating and implementing policies to achieve broad economic goals

Strongly agree (1)

Somewhat agree (2)

Somewhat disagree (3)

Strongly disagree (4)

Q9 The local government includes the university as a vital stakeholder when creating and implementing policies that address social challenges (e.g., noise ordinances, gun violence, climate change)

Strongly agree (1)

Somewhat agree (2)

Somewhat disagree (3)

Strongly disagree (4)

Q67 The local government has effective leadership in regard to municipal/university collaborations

Strongly agree (1) 
Somewhat agree (2)

Somewhat disagree (3)

Strongly disagree (4)

Q68 The local government leadership actively seeks to collaborate

Strongly agree (1)

Somewhat agree (2)

Somewhat disagree (3)

Strongly disagree (4)

Q13 (City Officials Only) Do you regularly interact with the University's Office of Community Engagement?

A few times a week (1)

Weekly (2)

Monthly (3)

Once a semester (4)

Once an academic year (5)

Never (6)

Q51 (University officials Only) Do you regularly interact with municipal leaders (e.g., Mayor's office, City Council members' office)

A few times a week (1)

Weekly (2)

Monthly (3) 
Once a semester (4)

Once an academic year (5)

Never (6)

Q51 (City Officials Only) Does the University have a dedicated office for community engagement?

Yes (1)

No (2)

Q52 (University Administrators Only) Does the municipality have a dedicated office that works with Higher Education Institutions?

Yes (1)

No (2)

\section{End of Block: Local Government Capacity}

\section{Start of Block: Social Capital}

Q15

The local government has a dedicated staff member that serves as a liaison with the University

Strongly agree (1)

Somewhat agree (2)

Somewhat disagree (3)

Strongly disagree (4)

Q57 The local government has formalized procedures to engage the university Strongly agree (1)

Somewhat agree (2)

Somewhat disagree (3) 
Q59 In terms of social policy, the local government and the university have a shared vision of what is in the community's best interest

Strongly agree (1)

Somewhat agree (2)

Somewhat disagree (3)

Strongly disagree (4)

Q60 In terms of economic policy, the local government and the university have a shared vision of what is in the community's best interest

Strongly agree (1)

Somewhat agree (2)

Somewhat disagree (3)

Strongly disagree (4)

Q75 Local government leaders attend activities at the university (e.g., public meetings, university events)

Strongly agree (1)

Somewhat agree (2)

Somewhat disagree (3)

Strongly disagree (4)

End of Block: Social Capital

\section{Start of Block: Trust and Decision}

Q61 The local government and the university have a relationship built on trust

Strongly agree (12) 
Somewhat agree (13)

Somewhat disagree (15)

Strongly disagree (16)

Q62 The local government can trust the university to deliver on previously agreed upon terms

Strongly agree (12)

Somewhat agree (13)

Somewhat disagree (15)

Strongly disagree (16)

Q63 The local government can trust the university leaders to solve any conflicts that might arise as part of a collaboration

Strongly agree (12)

Somewhat agree (13)

Somewhat disagree (15)

Strongly disagree (16)

Q64 During collaborations, the local government and university share decisionmaking power

Strongly agree (12)

Somewhat agree (13)

Somewhat disagree (15)

Strongly disagree (16) 
Q65 During collaborations, the local government values a diversity of opinions

Strongly agree (12)

Somewhat agree (13)

Somewhat disagree (15)

Strongly disagree (16)

Q66 During collaborations between the local government and university there are clear programmatic objectives

Strongly agree (12)

Somewhat agree (13)

Somewhat disagree (15)

Strongly disagree (16)

Q81 Collaborations between the local government and university are generally mutually beneficial

Strongly agree (12)

Somewhat agree (13)

Somewhat disagree (15)

Strongly disagree (16)

\section{End of Block: Trust and Decision}

\section{Start of Block: University Capacity}

Q19

University leaders

attend local government activities (e.g., attend public meetings, community events)

Strongly agree (1)

Somewhat agree (2)

Somewhat disagree (3)

Strongly disagree (4)

Q17

The university has

dedicated staff members that serve as liaisons with local government 
Strongly agree (1)

Somewhat agree (2)

Somewhat disagree (3)

Strongly disagree (4)

Q24 The University has formalized procedures to engage the local government

Strongly agree (1)

Somewhat agree (2)

Somewhat disagree (3)

Strongly disagree (4)

Q25 The University has the technical expertise to form

mutually beneficial partnerships with the local government

Strongly agree (1)

Somewhat agree (2)

Somewhat disagree (3)

Strongly disagree (4)

Q26 The University has the monetary resources to form mutually beneficial partnerships with the local government

Strongly agree (1)

Somewhat agree (2)

Somewhat disagree (3)

Strongly disagree (4)

Q27 The University has the time resources to

form mutually beneficial partnerships with the local government

Strongly agree (1)

Somewhat agree (2)

Somewhat disagree (3) 
Q69 The University has effective leadership in regard to municipal/university collaborations

Strongly agree (1)

Somewhat agree (2)

Somewhat disagree (3)

Strongly disagree (4)

Q70 During collaborations, the university can trust the local government to resolve any conflicts that might arise

Strongly agree (1)

Somewhat agree (2)

Somewhat disagree (3)

Strongly disagree (4)

Q80 During collaborations, the university can trust the local government to deliver on previously agreed terms

Strongly agree (1)

Somewhat agree (2)

Somewhat disagree (3)

Strongly disagree (4)

Q82 During collaborations, the university values a diversity of opinions

Strongly agree (1)

Somewhat agree (2)

Somewhat disagree (3)

Strongly disagree (4)

Q30 During times of economic hardship (e.g., Great Recession of 2008), local government increases its collaboration with the University

Strongly agree (1) 
Somewhat agree (2)

Stayed the same (3)

Somewhat disagree (4)

Strongly disagree (5)

Q72 During times of economic hardship (e.g., Great Recession of 2008), the local government is better off economically than surrounding municipalities on account of municipal/university collaborations

Strongly agree (1)

Somewhat agree (2)

Stayed the same (3)

Somewhat disagree (4)

Strongly disagree (5)

\section{End of Block: University Capacity}

\section{Start of Block: Proactive local government engagement}

Q31 What type of collaboration is the University MOST likely to initiate?

(1)

$\square$ Student Learning (e.g., internships, class projects, experiential learning)

$\square$ Research (e.g., climate change, impact studies,) (2)

$\square$ Economic Development (e.g., grant applications, housing developments, workforce development) (3)

Other (please specify) (4)

Q33 What type of collaboration is the University LEAST likely to initiate?

$\square$ Student Learning (e.g., internships, class projects, experiential learning)

(1)

$\square$ Research (e.g., climate change, impact studies,) (2)

$\square$ Economic Development (e.g., grant applications, housing developments, workforce development) (3) 
Other (please specify) (4)

Q32 What type of collaboration is the local government MOST likely to initiate?

$\square$ Student Learning (e.g., internships, class projects, experiential learning) (1)

$\square$ Research (e.g., climate change, impact studies,) (2)

$\square$ Economic Development (e.g., grant applications, housing developments, workforce development) (3)

Other (please specify) (4)

Q34 What type of collaboration is the local government LEAST likely to initiate? $\square$ Student Learning (e.g., internships, class projects, experiential learning) (1)

$\square$ Research (e.g., climate change, impact studies,) (2)

$\square$ Economic Development (e.g., grant applications, housing developments, workforce development) (3)

Other (please specify) (4)

Q53 What type of partnerships is the local government MOST likely to initiate?

K-12 Education (1)

Public Health (2)

Continuing education for city employees (3)

Climate Change (4)

$\square$ Income Inequality (5)

Gathering place for city events (6)

Other (please specify) (7)

Q35 In relation to the University, how do you define community engagement? 
Q36 What is the main obstacle to initiating a partnership with the University

$\square$ University bureaucracy (1)

Unclear who is the contact person at local government (3)

Poor Communication (4)

Lack of interest by local government (6)

Unclear objectives on collaborations (7)

Poor experience in past collaborations (5)

Other (please specify) (8)

Q79 What is the main obstacle to initiating a partnership with the Local Government

$\square$ University bureaucracy (1)

Unclear who is the contact person at University (3)

Poor Communication (4)

Lack of interest by University (5)

Unclear on how local government would partner with University (7)

Poor experience in past collaborations (6)

Other (please specify) (8)

Q52 Students are treated as constituents by the local government

Strongly agree (1)

Somewhat agree (2)

Somewhat disagree (3)

Strongly disagree (4)

End of Block: Proactive local government engagement

Start of Block: Descriptive Questions: 
Q54 Which best describes the College/University you are referring to in this survey?
$\square$ Public 2-year institution (1)
$\square$ Public 4-year institution (2)
$\square$ Private 4-year institution (3)
$\square$ Religiously Affiliated institution (4)
4 year Liberal Arts University (6)
Other (please specify) (5)

Q55 Which option best describes your city?

$\square$ University Town (1)

$\square$ Suburban (2)

$\square$ Metropolitan (3)

$\square$ Rural (4)

Other (please specify) (5)

Q56 Please select the option that best describes you

Female (1)

Male (2)

Q57 What geographic region best describes your location

\section{South (1)}

Mid-Atlantic (2)

Southwest (3)

West (4)

Northeast (5)

Northwest (7) 
MidWest (8)

Other (please specify) (6)

Q58 Which option best describes your office?

Mayor (1)

City Manager or Assistant City Manager (2)

City Council Member (3)

University Administrator (4)

Provost Office (6)

Community Engagement Office (7)

Other (please specify) (5)

End of Block: Descriptive Questions: 
VITA

\title{
VIVIAN GONZÁLEZ CUETO
}

\author{
Born, Miami, Florida
}

2006

Bachelor of Arts in Political Science

Florida International University

Miami, FL

2008

Master of Public Administration

University of Pennsylvania

Philadelphia, PA

2008

Graduate Certificate in Public Finance

University of Pennsylvania

Philadelphia, PA

2008

Graduate Certificate in Politics

University of Pennsylvania

Philadelphia, PA

2015

Scholar

Academy of Graduates for Integrative Learning Experiences

Florida International University

Equity and Inclusion Fellowship Association for Public Policy Analysis and Management

International Young Scholar Public Policy and Administration Research American Society for Public Administration

2018 Dissertation Year Fellowship Florida International University

2019

Ph.D. in Public Affairs

Florida International University

Miami, FL 
Cueto, V.G. (2018, March). How Town Engages Gown: The Role of Collaborative Capacity in Municipal Engagement with Universities. American Society for Public Administration Conference, Denver, CO

Cueto, V.G. (2017, July). How Town Engages Gown. American Society for Public Administration's International Young Scholars Conference, Chennai, India

Cueto, V.G., Gresham, E., (2017, April). The Broader Impacts of University Based Economic Development: The Case of StartUP FIU. Broader Impacts Summit, Stevenson, WA

Cueto, V.G. (2017, April). Safe Spaces Make Good Neighbors? Community and University Engagement in a Time Social Unrest. Urban Affairs Association Annual Conference, Minneapolis, MN

Cueto, V.G. (2017, March). Community Participation in University Engagement: A Token Process or a Partnership? American Society for Public Administration Conference, Atlanta, GA

Cueto, V.G. (2016, March). School Choice and the Budget Deficit: Lessons from the Chester Upland School District. American Society for Public Administrators Conference, Seattle, WA

Cueto, V.G. (2016, March). Panelist, 'Tested' - A film about educational equity, Film Screening at the Urban Affairs Association Annual Conference, San Diego, CA, March 2016

Cueto, V.G. and Garcia, J., (Oct. 2015) "Public Admin in 140 Characters or Less: SNS and the Administrative Procedures Act" International Journal of Art \& Humanity Science, Volume 2, Issue 5, pp. 26-42. 